\title{
WestVirginiaUniversity
}

THE RESEARCH REPOSITORY @ WVU

Graduate Theses, Dissertations, and Problem Reports

2012

\section{Macroeconomic Recovery after a Currency Crisis}

\author{
Sheida Teimouri \\ West Virginia University
}

Follow this and additional works at: https://researchrepository.wvu.edu/etd

\section{Recommended Citation}

Teimouri, Sheida, "Macroeconomic Recovery after a Currency Crisis" (2012). Graduate Theses,

Dissertations, and Problem Reports. 4928.

https://researchrepository.wvu.edu/etd/4928

This Dissertation is protected by copyright and/or related rights. It has been brought to you by the The Research Repository @ WVU with permission from the rights-holder(s). You are free to use this Dissertation in any way that is permitted by the copyright and related rights legislation that applies to your use. For other uses you must obtain permission from the rights-holder(s) directly, unless additional rights are indicated by a Creative Commons license in the record and/ or on the work itself. This Dissertation has been accepted for inclusion in WVU Graduate Theses, Dissertations, and Problem Reports collection by an authorized administrator of The Research Repository @ WVU.

For more information, please contact researchrepository@mail.wvu.edu. 


\title{
Macroeconomic Recovery after a Currency Crisis \\ Sheida Teimouri
}

\author{
Dissertation submitted to the \\ College of Business and Economics \\ at West Virginia University \\ in partial fulfillment of the requirements \\ for degree of \\ Doctor of Philosophy \\ in \\ Economics
Arabinda Basistha, Ph.D, Chair
Ronald Balvers, Ph.D.
Stratfor Douglas, Ph.D.
Andrew Young, Ph.D.
Alexander Kurov, Ph.D.
Department of Economics

Morgantown, West Virginia

2012

Keywords: Currency Crisis, Banking Crisis, Devaluation, Recovery, Labor Market, Real Wage, Labor Productivity, Output Growth. 


\section{Abstract \\ Three Empirical Essays on the Aftermath of a Currency Crisis}

Sheida Teimouri

This dissertation explores the dynamics adjustment of output, output components, labor market variables and output growth after currency crises. In the first essay, I examine the dynamic response of output and its components to large devaluations in 159 countries over the 1970-2005 period. Recent empirical literature on measuring the effects of currency crises shows permanent drops in output following these events. However, theoretical models of contractionary devaluations predict only temporary drops in output due to nominal wage rigidities. I examine whether one can reconcile early theoretical predictions of full long-run recovery of output with the data after isolating the twin crisis episodes. Our estimates show that the output fully recovers to its pre-crisis level in about four years when a currency crisis is not associated with a banking crisis. The analyses of the components show that the initial contractionary effects are due to drops in consumption and investment with slow recovery. The net exports do increase though not sufficient to offset the drops in the other components. In the second essay, I use a panel of 66 countries over the 1990-2010 period to examine the short and long-term impact of currency crises on key labor market variables including real wages. Previous studies are either short-term, case study analysis of the issue or focus mainly on employment. The results, suggest that the adjustment in labor market following a currency crisis is mainly through real wages. While employment and labor productivity initially decline, these decreases are far less than the decrease in real wages and the recovery is also swifter. The recovery in real wages is sluggish and usually takes at least three and at most eight years. The results are robust to different definitions of currency crises and estimation methods. The third essay concerns the shape of GDP growth recovery following currency crises. While theoretically the shape of output growth recovery is ambiguous, the empirical literature employs univariate approach and reports mixed results. Therefore, I re-examine the issue further with a multivariate approach. I estimate "U-shape", "Vshape" and "L-shape" models of growth recovery first proposed by Kim et al. (2005) in the context of post-recession recovery. Thereafter, based on the information criteria I allow the data to select the appropriate model. The methodology enables us to test for the significance of higher than average growth rate or 'bounce-back' term in the recovery phase. I consider currency crashes and reserve crises, as the two forms of currency crises, separately. The results suggest that there is a significant and positive bounce-back in growth rates after currency crashes. Moreover, the shape of the recovery is "U-shaped" across the entire panel. Alternatively, after reserve losses, the recovery resembles a long "U-shaped" model and there is no bounce-back in growth rates. Moreover, I found that a large pre-crisis short term debt relative to total foreign debt and pre-crisis share of export sector in an economy are the best predictors of post-crisis recovery. 


\section{Dedication}

I want to dedicate this dissertation to my beloved mom, dad and sister who supported me each step of the way. Thank you for always being there and thank you for always encouraging me and loving me. I am who I am because of you. 


\section{Acknowledgements}

I would like to express my gratitude to my advisor, Dr.Arabinda Basistha for his guidance, patience and support throughout my dissertation process and graduate studies. He showed me the path to become a scholar and I learned a great deal from him. I could not be where I am without him.

Also, I would like to specially thank my dissertation committee members, Dr. Balvers, Dr.Young, Dr. Douglas, and Dr.Kurov for their comments and suggestions which greatly improved the dissertation. I would like to thank Dr.Hawley, for always taking my teaching preferences into account and provided me with a great deal of teaching experience. Also, I want to genuinely thank Dr.Cushing for always being available for me. Thank you for spending so many hours to run this program the great way you do.

I want to specially express my deepest thanks to my dear dear friends, Maryam Naghshnejad and Derek Stemple, for their unbelievable support and love throughout the entire graduate school. Thanks guys for being there for me, for all the good times we spent together and for all the times you fed me! You are awesome!

I am also grateful to my precious friend Yasaman Khazaeni who was always there for me, who saved me countless times from difficult situations. Without her I could never become an adult. Thank you, Yassi. Also, I want to thank my dear and old friend Hossein Radmard who was with me throughout all my educational and personal growth and who has always been there for me when I needed him. Thanks to Vida Gholami for seeing me in the first international students orientation day at WVU and for being my friend ever since. Thank Mohamad Meysami for helping me a great deal during this time.

I also want to express thanks to my lovely friend Jorida Papakroni who is the best and the most patient listener in the world, who shared with me so many beautiful, happy, stressful, and sad moments, and who has always been there to help me get through the graduate school and life! Thank you Jori!

And at last but not least, I want to thank Alessandro Quartiroli for his amazing support and for his belief in my abilities. Ale, thanks for being there for me and for helping me to become a better person and scholar. You are special!

Any errors are the sole responsibility of the author. 


\section{Table of Contents}

CHAPTER1. GENERAL OVERVIEW OF THE DISSERTATION .......................................... 1

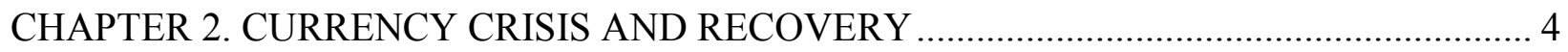

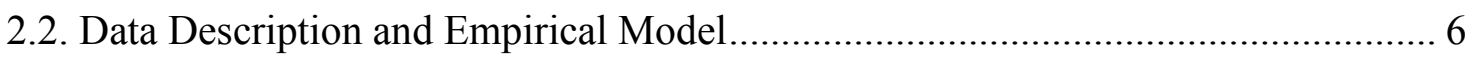

2.3. Estimates of Output Loss from Currency Crisis ................................................... 10

2.4 Components of output loss from currency crisis................................................. 12

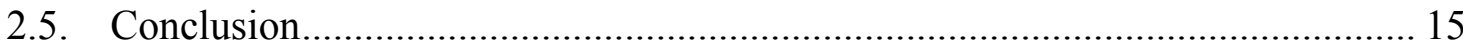

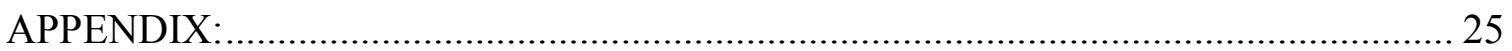

CHAPTER 3. CURRENCY CRISIS AND DYNAMICS OF REAL WAGES .............................. 26

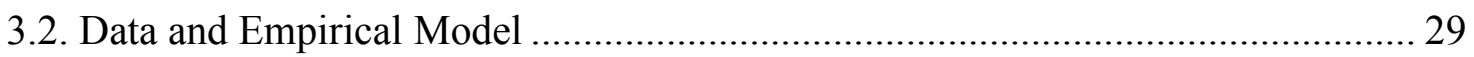

3.3. Real Wage Dynamics following a Currency Crisis .............................................. 33

3.4. Real Wage per Hour Dynamics..................................................................... 37

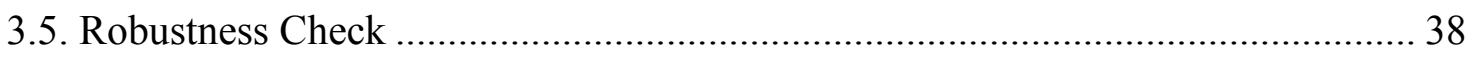

3.6. Dynamics of Employment and Labor Productivity following Currency Crises .... 40

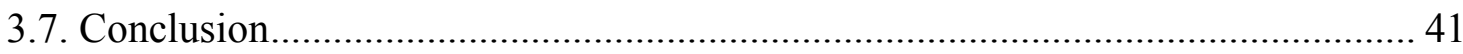

Figure 3.1- Response of Real Wages to a Currency Crisis (Fixed effect) .................... 49

Figure 3.2- Response of Real Wages to a Currency Crisis (Arellano \& Bond)............ 50

Figure 3.3- Real Wage per Hour Response to a Currency Crisis................................... 51

Figure 3.4- Employment Response to a Currency Crisis ............................................ 52

3.5- Labor Productivity Response to a Currency Crisis .............................................. 53 
CHPATER 4. SHAPE OF GROWTH RECOVERY FOLLOWING CURRENCY CRISES ..... 54

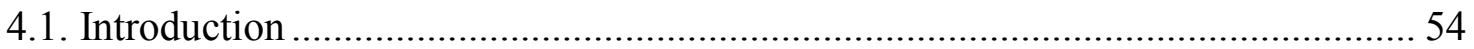

4.2. Data Description and Empirical Model............................................................... 58

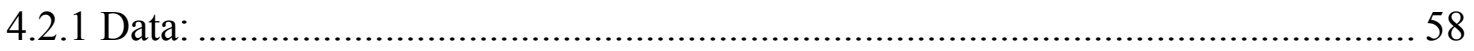

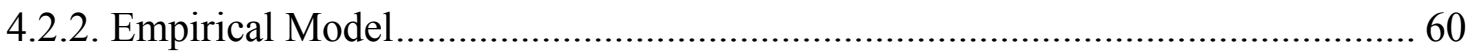

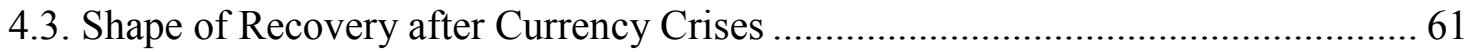

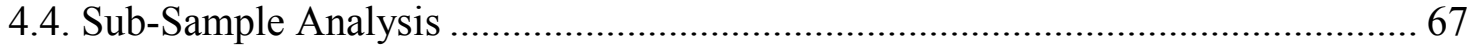

4.5. Determinant of Growth after Currency Crises ................................................... 69

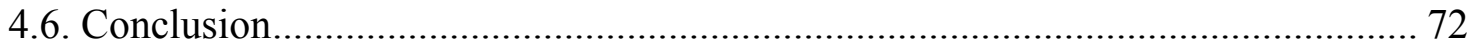

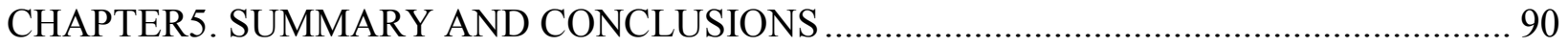

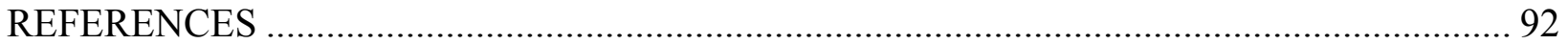




\section{List of Tables}

Table 2.1: Description of Currency Crises Indicators ............................................................... 16

Table 2.2: Panel Unit Root Tests for GDP and its Components................................................. 17

Table 2.3: Estimates of Output Loss from Currency Crises ....................................................... 18

Table 3.1- Data Description and List of Countries ....................................................................... 43

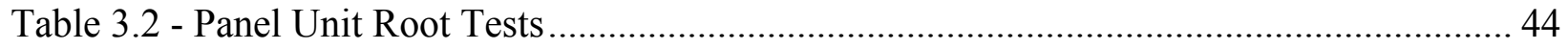

Table 3.3- Real Consumption Wages after Currency Crises ....................................................... 45

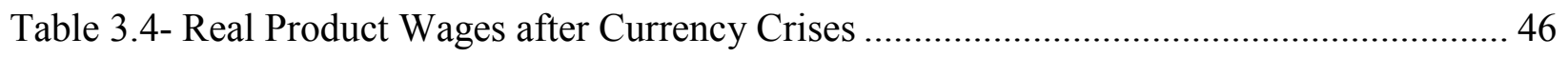

Table 3.5- Real Consumption Wages after Currency Crises .................................................... 47

Table 3.6- Real Product Wages after Currency Crises ................................................................. 48

Table 4.1- Data Description and List of Countries ...................................................................... 74

Table 4.2- Shape of Recovery Using Laeven and Valencia (2008) Dummy................................. 75

Table 4.3- Models Estimates Using EVENT Dummy .................................................................. 76

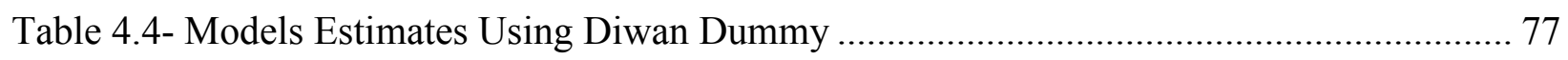

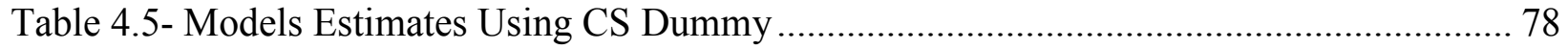

Table 4.6- Model Estimates Using CRISIS Dummy ………..................................................... 79

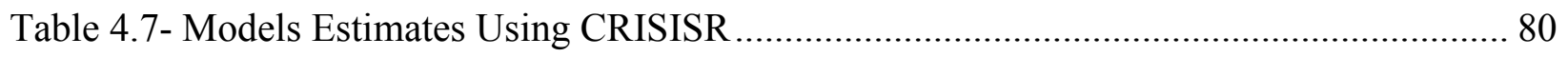

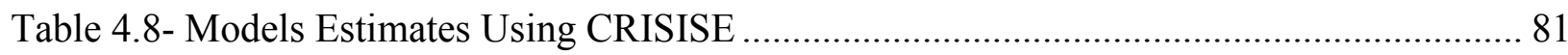

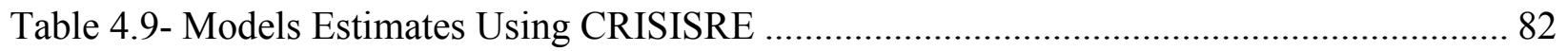

Table 4.10- Model Estimates Using EVENT for Industrial Countries ........................................ 83 
Table 4.11- Model estimates Using EVENT for Latin American Countries.

Table 4.12- Model Estimates Using Event for Transition Countries....................................... 85

Table 4.13- Model Estimates Using EVENT for Asian Countries ............................................ 86

Table 4.14- Shape of Growth Recovery for High Income Group......................................... 87

Table 4. 15- Shape of Growth Recovery for Upper Middle Income Group ............................ 87

Table 4.16- Shape of Growth Recovery for Middle Lower Income Group.............................. 88

Table 4.17- Shape of Growth Recovery for Lower Income Group ...................................... 88

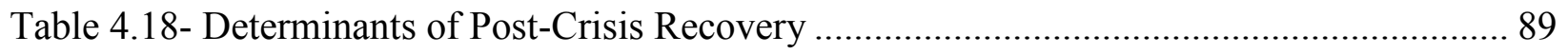




\section{List of Figures}

Figure 2.1: GDP Response to Currency Crisis ................................................................ 19

Figure 2.2: Private GDP Response to Currency Crisis .................................................... 20

Figure 2.3: Consumption Response to a Currency Crisis .................................................. 21

Figure 2.4: Investment Response to Currency Crisis............................................................... 22

Figure 2.5: Government Expenditure Response to a Currency Crisis .................................... 23

Figure 2.6: Net Exports Response to Currency Crisis ................................................... 24

Figure 3.1- Response of Real Wages to a Currency Crisis (Fixed effect) ............................... 49

Figure 3.2- Response of Real Wages to a Currency Crisis (Arellano \& Bond) ........................ 50

Figure 3.3- Real Wage per Hour Response to a Currency Crisis .......................................... 51

Figure 3.4- Employment Response to a Currency Crisis................................................... 52

Figure 3.5- Labor Productivity Response to a Currency Crisis ........................................... 53 


\section{CHAPTER1. GENERAL OVERVIEW OF THE DISSERTATION}

Currency crises are when speculators sell the domestic currency short en mass in anticipation of near devaluation. This imposes a great deal of pressure on foreign exchange market that can be eliminated through depreciation, increasing interest rate, or losing foreign reserves. The crises in Latin America in the late 1970s and early 1980s, England crisis of 1994 and Asian financial crises of 1997-1998 are examples of such crises. While the causes of currency crises have been well-studied, only a few studies have addressed what happens in the wake of a currency crisis to a number of macroeconomic variables, particularly GDP and its components.

Recent literature on measuring the effects of currency crises shows permanent drops in output following crises (Bussiere et al. (2010), Cerra and Saxena (2008), Hong and Tornell (2005)). Theoretical models of contractionary devaluations on the other hand, predict only a temporary drop in output due to nominal wage rigidities (Krugman and Taylor (1978)). Therefore, in Chapter 2, we examine whether one can reconcile early theoretical predictions of full long-run recovery of output with the data after isolating the twin crisis episodes. Our estimated impulse responses show full long-run recovery of the two measures of output, GDP and private GDP, following a currency crisis not associated with a banking crisis. This is consistent with the theoretical predictions of rigid nominal wage models of currency devaluations. However, this recovery is sluggish and starts often after three years. The analysis of the components (as a share of GDP) shows an initial drop in consumption and investment followed by slow recovery. Net exports do jump initially but the jump is not enough to fully compensate the drop in consumption and investment. Overall, the sluggishness of the recovery stresses the need to analyze the role of additional rigidities like costly intersectoral reallocation of resources in the currency crisis models. 
In the third chapter of this dissertation I explore the impact of large devaluations on the labor market variables, real wages in particular. There are only few studies assessing the impacts of financial crises on labor market. These studies are mainly divided into two categories of panel and country case studies. While the panel studies mainly focused on employment to assess the impact of crises on labor market, case-studies explored a wider set of labor market variables such as real wages, labor participation rate, etc. Nevertheless, these country case studies only consider the short-term impact of crises on labor market variables. Therefore, I expand the literature by examining labor market variables other than employment, real wage in particular, in a panel of 66 countries over the 1990-2010 period. Moreover, unlike country case studies, I explore the short-, medium-, and long-term adjustment of real wages, employment, and productivity following currency crises.

The results broadly support the case studies' results; while the decline in employment is trivial, real wages drop substantially. In particular, 30 percent depreciation depending on the estimation method leads to a drop of 11-19 percent in the level of real wages just one year after a crisis. A full recovery takes at least three and at most eight years. Labor productivity initially drops by 3-4 percent, but returns to pre-crisis trend within three to five years. The initial decline can be due to reallocation of labor across sectors after a crisis that may lead to a loss in labor productivity. Employment declines by about one percentage point and recovers swiftly within one to three years. These results remain robust to different definition of currency crises and estimation methods.

In chapter 4, I look at the shape of output growth recovery from currency crises. The theoretical literature on currency crises does not predict a particular pattern of growth recovery following these events. However, the empirical literature, relying on a univariate or 'event-study' approach, estimates a V- or U-shaped recovery in growth rates. This chapter investigates the 
issue further by using a multivariate approach and in a panel of 159 countries over the 1970-2005 period. I estimate "U-shape", "V-shape" and "L-shape" models of growth recovery first proposed by Kim et al. (2005) in the context of post-recession recovery. Thereafter, based on the information criteria I allow the data to select the appropriate model. The methodology allows us to test the hypothesis that growth rate in the post-crisis recovery phase is greater than average growth rate in non-crisis years. In other words, I test to see if there is a significant 'bounce-back' in output growth in the recovery phase. Currency crashes and reserve crises, as the two forms of currency crises, are considered separately. The results suggest that there is a significant and positive bounce-back in growth rates after currency crashes. Moreover, in contrast with the previous literature, the shape of the recovery is U-shaped across the entire panel. Alternatively, after reserve losses, the recovery resembles a long U-shaped model and there is no bounce-back in growth rates. The sub-sample analysis confirms the results. Moreover, I found that a large precrisis short term debt relative to total foreign debt and pre-crisis share of export sector in an economy are the best predictors of post-crisis recovery. 


\section{CHAPTER 2. CURRENCY CRISIS AND RECOVERY}

\subsection{Introduction}

Early theoretical research on currency crises does not necessarily entail a large output cost of these episodes. The first generation model introduced by Krugman (1979) stresses the fiscal sources of crises but does not imply serious contraction of output. The second generation models (Obstfeld (1994)) highlighting the self-fulfilling outcomes in currency crises are least likely to be costly output wise. There is no apriori reason for output to decline in a frictionless economy, temporarily or permanently, unless we introduce additional rigidities in these models. The key assumption that allows for contractionary devaluations, as explained by Krugman and Taylor (1978), is the excess rigidity of nominal wages relative to prices. The nominal nature of the rigidity also implies that there should be a full recovery in the long-run.

Empirical research on measuring the currency crisis costs show fairly large output loss, mostly in the short-run. Early studies like Cooper (1971), Edwards (1989), Morley (1992), Hutchison and Noy (2002) all show short-run output losses associated with devaluations. Recent estimates by Hutchison and Noy (2005) find output growth decline of five to eight percent in the emerging economies over a two to four year horizon. Gupta et al. (2006) point out that while some currency crises are expansionary; the majority of them are contractionary. Hong and Tornell (2005) examine the recovery dynamics stressing that the output registers a permanent fall below the pre-crisis trend. Cerra and Saxena (2008) estimate the losses to be around four percent and permanent. Bussiere et al. (2010) also estimate the effect of a currency collapse to be a permanent loss of output between two to six percent. These results stress that output losses from 
a typical currency crash do not recover in the long run and do not match the theoretical predictions of early currency crisis models with nominal stickiness ${ }^{1}$.

Balance of payments crisis models with banking sector vulnerabilities were introduced by Diaz-Alejandro (1985) and Velasco (1987). McKinnon and Pill (1995) examine the role of moral hazard in the banking sector and overlending of funds leading to crisis. The recent third generation models explicitly analyze the interaction of financial instabilities and imperfect information in the context of currency crisis (Aghion, Bacchetta and Banerjee (2001), Chang and Velasco (2001)) $)^{2}$. These are models of large, domestic vulnerabilities associated with currency crises and are most likely to be economically costly. The output losses from currency crisis are estimated to be very large when associated with a banking or financial crisis as pointed out in the Kaminsky and Reinhart (1999) study on 'twin' crisis. Bordo et al. (2001) report output loss of 16 percent in their recent sample. Hutchison and Noy (2005) estimate the costs of these twin crises to be 13 to 18 percent of output for emerging economies. Cerra and Saxena (2008) show a 10 percent permanent loss.

In this study, we examine whether one can reconcile early theoretical predictions of full long-run recovery of output with the data after isolating the twin crisis episodes. We estimate the short-run and the long-run dynamics of output and its components following a currency crisis under two conditions: a. the currency crisis is defined on the basis of large devaluation of exchange rates that can boost net exports and $b$. the crisis is not associated with a banking crisis that by itself is a domestic shock. Additionally, we allow for time effects to address the issue of

\footnotetext{
${ }^{1}$ A related study by Radelet and Sachs (1998) distinguishes between U shaped and V shaped recoveries. Lee and Park (2002) argue that real GDP growth in South Korea following the Asian crisis represents a V shaped recovery. However, as stressed by Hong and Tornell (2005), the recovery in just the growth rates will still result in a permanent output loss.

${ }^{2}$ Kaminsky (2008) provides an overview of the types of currency crises and intuition behind the models. Hutchison and Glick (2001) show that the banking crisis often leads currency crisis in financially liberalized emerging economies.
} 
simultaneous occurrences of some currency crises that can affect the net exports through global demand (e.g. the Exchange Rate Mechanism (ERM) crisis). Eichengreen, Rose and Wyplosz (1997) show that trade links are one of the major sources of such contagious currency crisis. A new database on currency and banking crises by Laeven and Valencia $(2008,2010)$ allows us to estimate the dynamic responses from a large panel of 160 countries based on our above two conditions ${ }^{3}$.

Our estimated impulse responses show full long-run recovery of the two measures of output, GDP and private GDP, following a currency crisis when not associated with a banking crisis. This is consistent with the theoretical predictions of rigid nominal wage models of currency devaluations. However, this recovery is sluggish and starts often after three years. The analysis of the components (as a share of GDP) shows an initial drop in consumption and investment followed by slow recovery. Net exports do jump initially but the jump is not enough to fully compensate the drop in consumption and investment. Overall, the sluggishness of the recovery stresses the need to analyze the role of additional rigidities like costly intersectoral reallocation of resources in the currency crisis models.

The paper is organized as follows: in Section II we describe the data and the empirical model. In Section III we report the estimates of output loss from a currency crisis. In Section IV we present the estimation results of the loss in GDP components. We conclude in Section V.

\subsection{Data Description and Empirical Model}

We obtain macroeconomic data for 160 countries between 1970-2005 from World Bank`s World Development Indicators (WDI). The variables are real GDP, households' final consumption expenditure, gross fixed capital formation, and general government final consumption

\footnotetext{
${ }^{3}$ Out of the 160 countries, 41 countries never experienced any currency crisis thereby forming our 'control group'.
} 
Expenditure, exports of goods and services and imports of goods and services; all in constant 2000 US dollars. We compute "private GDP" to isolate the role of government output as the difference between real GDP and general government final consumption expenditure following King, Plosser, Stock and Watson (1991). We also compute net exports as the difference between exports and imports.

The currency and banking crises dates are obtained from Laeven and Valencia (2008, 2010). Laeven and Valencia (2008) identify currency crises based on Frankel and Rose (1996) approach and define currency crises as: "a nominal depreciation of at least 30 percent that is also at least a 10 percent increase in the rate of depreciation compared to the year before". The definition yields 210 currency crises during the period 1970-2005 as shown in Table $1^{4}$. Laeven and Valencia (2008) construct the systematic banking crisis based on Caprio and Klingebiel (1996) database and restrict their analysis to the first year of banking crises. We also use Laeven and Valencia (2010) which documents the ending dates of the systematic banking crises as well as their starting dates over the period 1970-2005. To isolate the currency crises episodes from that are not associated with a banking crisis, we construct three dummy variables based on Laeven and Valencia $(2008,2010)$ database; "Pure Currency Crisis" (PCC), "One Year Window Pure Currency Crisis” (PCC1) and “One Year Window Start Pure Currency Crisis” (PCCS).

The first two dummies are based on banking and currency crisis dates of Laeven and Valencia (2010) which includes both the start and end dates of banking crises. The pure currency crisis (PCC) dummy is constructed to capture only the currency crises episodes that were not accompanied by a simultaneous banking crisis. Therefore, anytime we have a currency crisis for a country in year $t$, we also check the banking crisis dummy in the same year. If the banking

\footnotetext{
${ }^{4}$ Some studies like Hong and Tornell (2005), Cerra and Saxena (2008) also incorporate reserve losses in their definition of currency crisis. That definition includes no devaluation episodes thereby not affecting the net exports through the expenditure switching channel.
} 
crisis dummy is one, meaning that if there was a banking crisis in year $t$, the year is not a "pure" currency crisis year and PCC is set to zero. Otherwise, the year is a pure currency crisis year and the dummy is equal to one.

The one year window pure currency crisis dummy ( $\mathrm{PCC} 1)$ is constructed the same way as the PCC dummy except that the banking crisis dates one year before and one year after a currency crisis are also checked. If a year is identified as a currency crisis year and is preceding, following or in the same year as a banking crisis, the dummy is set to zero. Otherwise it is equal to one. As reported in Table 1, we have 167 episodes of PCC and 157 episodes of PCC1. For our third currency crisis indicator, we use the banking crises dates from Laeven and Valencia (2008) which include only the banking crises start dates to construct "One Year Window Start Pure Currency Crisis" (PCCS). This dummy is formed exactly the same as 1-year PCC but when only banking crises start dates are considered. We have 171 episodes of PCCS in our dataset.

Following the Cerra and Saxena (2008) approach that builds on the Romer and Romer (1989) study of monetary policy; we estimate the following autoregressive model allowing for both country effects and time effects:

1. $\boldsymbol{g}_{i t}=\boldsymbol{\alpha}_{i}+\gamma_{t}+\sum_{j=1}^{m} \boldsymbol{\beta}_{j} \boldsymbol{g}_{i, t-j}+\sum_{k=0}^{n} \delta_{k} \boldsymbol{D}_{i, t-k}+\boldsymbol{E}_{i t}$

Where $g_{i}$ is the dependent variable for country $i, \mathrm{D}_{i}$ is a currency crisis dummy for country $i, \alpha_{i}$ is the country fixed effects and $\gamma_{t}$ capture the time effects. The model allows us to analyze the short-run and long-run dynamic effects of currency crises through impulse response functions. It avoids the need to select the number of post crisis years to estimate the short-run effects. Using the estimated parameters we calculate impulse response of each GDP component to one unit shock to the currency crisis dummy.

One important issue arising when estimating equation (1) is the potential endogeneity of currency crisis. If low output growth causes currency crises then ignoring this feedback leads to a 
bias in our estimations. One way to deal with this problem is to test if probability of a crisis is a function of current and past output growth as well as previous currency crises. The other way is to assume that a currency crisis has only lagged effect on output growth and re-estimate the results. However, in this case if crises are serially correlated, we will face omitted variable bias. Also, some studies use GMM to control for endogeneity issue in the growth models.

Cerra and Saxena (2008) performed several exogeneity tests and found some evidence that currency crises are contemporaneously exogenous with respect to growth rates. Moreover, they argue that even if this is not the case, lagged impact of a currency crisis on output is still contractionary. Since we use almost an identical dataset to Cerra and Saxena (2008), we assume currency crises are exogenous.

Moreover, our panel unit root tests are reported in Table 2. In panel A, we report the Levin, Lin and Chu (2002) t-tests and Im, Pesaran and Shin (2003) W statistics for GDP and private GDP. For GDP, we can reject the null hypothesis of a unit root against the alternative of not a common unit root, though not at one percent level of significance. However, once we relax the assumption of the common unit root in the Im, Pesaran and Shin W-stats, none the tests can reject the null hypothesis of unit root for both GDP and Private GDP. Based on the above results, we use growth rates of GDP and Private GDP when estimating our equation (1) and use cumulative impulse responses to examine dynamic level effects. The unit root tests for the components are in panel B of Table 2. The four individual GDP components are measured as share of GDP following the 'great ratios' of King, Plosser, Stock and Watson (1991). Not surprisingly, we can reject the null hypotheses of unit root in all the variables. These variables will be used as shares of GDP in our equation (1) and we will use impulse response functions (not cumulative) to analyze their dynamic effects following a currency crisis. 
Following Cerra and Saxena (2008), we select a lag length of four to capture the autoregressive dynamics. However, the selection of lags of the dummy variables proved to be more difficult. Formal model selection criteria like SIC generally favored no lags of dummies. A closer examination of the coefficient estimates revealed that most of the immediate lags have often low and insignificant coefficients. But, the coefficients of the fourth lag were large and significant. For private GDP, the coefficients of the sixth lag were also important. These two lags formed crucial elements of the recovery dynamics, but the SIC penalty function suggested against inclusion of these long lags due to the presence of insignificant intermediate lags. In the results reported in this paper, we use four lags of currency crisis dummies for GDP, six lags for private GDP. For the GDP components, we use four lags since they are expressed as shares of GDP.

\subsection{Estimates of Output Loss from Currency Crisis}

In this section we estimate equation (1) and compute the cumulative impulse responses for GDP and private GDP. The ten year cumulative GDP losses are reported in panel A of Table 3. The impulse responses are shown in Figure 1. We have four sets of currency crisis indicators. For each set we report the results without and with time effects to understand the influence of global movements in the data.

In top panel of Figure 1 we show the impulse responses of GDP to currency crises (CC) that do not separate out banking crisis dates. The estimates show a short-run drop to 4.25 percent and then a slow partial recovery in the left column. There is about 2.5 percent loss in the level of GDP ten years after a crisis as shown in panel A of Table 3. In the top-right panel of Figure 1, we report the impulse responses with time effects. The short-run drops reach 3.5 percent and then show partial but steeper recovery. The ten year loss is 1.1 percent, less than 2.5 percent with 
just country effects. This suggests that the contractions and the recovery process are adversely affected in case of multi-country crises. Overall, these results are very similar to Hong and Tornell (2005), Cerra and Saxena (2008) results of permanent output loss associated with currency crises.

Next we re-estimate the loss in GDP using the pure currency crisis dummy (PCC) that isolates the simultaneous banking crisis episodes. The impulse responses in the second row left panel of Figure 1 show a short run decline in output to about 3.5 percentage points. After ten years the loss in the level of output shrinks to about 1.45 percent showing some recovery. When we allow for time effects the GDP recovers fully in ten years. This is our primary difference in results with the literature showing permanent loss of output following a currency crisis. This implies that even though the short-run effect of currency crisis is contractionary, the country in crisis will have a good chance of full recovery if the crisis is not associated with a banking crisis and the global conditions are stable.

We follow this up in the third row and the bottom panels of Figure 1. In the third row we show the effects of one year pure currency crisis episodes (PCC1). In the bottom panel we show the effects of one year pure currency crisis episodes with start dates (PCCS). All the impulse responses show full recovery of output to its pre-crisis level in ten years. The estimated impulse responses with time effects are somewhat expansionary with net gain of 1.28 and 1.31 percent for PCC1 and PCCS respectively. However, the standard error bands for these are wide and include the zero lines.

The long-term results for private GDP are in panel B of Table 3 and the impulse responses are in Figure 2. The presentation of the results follows the same format for GDP. There are strong similarities with the GDP results although with important differences. All the impulse responses show short-run contractionary effects, though in general bigger than the GDP. The 
short-run loss following CC in the top left panel of Figure 1 reaches 4.9 percent. The loss in output after 10 years is 2.2 percent. In further contrast to the GDP results the PCC estimates with time effects still show a small, long-term loss of 0.8 percent. However, we do see full recovery in the PCC1 and PCCS cases with time effects as in the GDP cases.

Overall, we see two features of the data coming out of the above analysis. One, large devaluations are less costly in the short-run with no banking crisis and inclusion of time effects. Two, the empirical evidence supporting long-run full recovery depends on three features: a. isolating the banking crisis episodes, b. allowing for time effects and c. allowing for long lags. Once we allow for these features, the discrepancy between theoretical prediction of full recovery in case of excess wage rigidity (Krugman and Taylor (1978)) and empirical results of permanent loss in Hong and Tornell (2005), Cerra and Saxena (2008), Bussiere et al. (2010) can be reconciled.

\subsection{Components of output loss from currency crisis}

In this section, we estimate and present the impulse responses of GDP components following a currency crisis. The four GDP components used are consumption, investment, government spending and net exports; all as shares of GDP. They are presented in Figures 3, 4, 5 and 6 respectively. The left columns in each figure report the impulse responses with country fixed effects only. The right columns report the impulse responses with country and time effects. The top rows of each figure report the results for CC, the second rows report the results for PCC, the third rows report the results for PCC1 and bottom rows report the results for PCCS.

We start out by analyzing consumption as a share of GDP. The impulse responses in Figure 3 show a fall in consumption on impact. The range of this decline is between 1.5 to 1.9 
percent. After that the dynamics show a slow gradual recovery reaching close to, but not equal to, zero after 10 years. This immediate drop in consumption and a slow recovery is consistent with the Krugman and Taylor (1978) model emphasizing fall in real wage following currency devaluation due to excess nominal wage rigidity. As Kamin and Rogers (2000) explain this is because workers are low savers and their incomes depend mostly on wages. However, the slow process of incomplete readjustment does suggest a role for real rigidities as well.

The results for investment are reported in Figure 4. The impact effects of investment shares range from declines of 1.4 percent to two percent; the lower values typically associated with PCC and PCC1 with time effects. These numbers are very similar to the values reported by Joyce and Nabar (2009) using just fixed effects and using GMM. However, we do see a further decline in investment for another year before the recovery starts. This can happen due to multiple reasons including readjustment following a rise in the price of intermediate inputs (Lizondo and Montiel (1989), Agenor (1991)), a persistent decline in real money supply (Krugman and Taylor (1978), Kamin and Rogers (2000)) or worsening of corporate balance sheets. The long term 10 year losses in investment are similar to consumption and small, ranging from 0.5 percent to 0.2 percent.

One feature of investment dynamics is worth discussing at this point though not explicitly reported in the paper for space considerations. The maximum drop in investment share impulses for $\mathrm{CC}$ is 3.23 percent. When we compare this drop to the maximum drop of 2.3 percent in the impulses for PCC1 with time effects; this difference is quite large for an average investment share of 22 percent. For $\mathrm{CC}$, this will translate to a 4.7 percent drop in its levels after 10 years based on its GDP dynamics. For PCC1 with time effects, this implies a full recovery to its precrisis levels in 10 years. This difference highlights the crucial role banking crisis plays in investment dynamics and long-term output loss. 
An additional observation is that unlike GDP and consumption, the recovery in investment starts with a lag. Investment declines because on one hand, in the presence of large foreign denominated debt, a large devaluation exacerbates firms' balance sheets and therefore, their ability to borrow. On the other hand, bank's balance sheet deterioration affects their ability to lend. Moreover, the uncertainty tangled with a currency crisis makes it difficult for banks to distinguish low risk from high risk borrowers. As supply and demand for loans both decrease, investment drops. The delayed recovery can be due to prolonged binding credit constraints and sudden stop of capital inflows which occasionally accompanies currency crises.

The impulse responses for government spending are in Figure 5. The effects are generally numerically small and the standard error bands almost always include the zero line. There are two interesting common features in the estimated responses. The first is the initial small but positive effects. The second is the sharp drop in its share around the fourth year when the GDP start to recover. Although the initial theory of currency crisis by Krugman (1979) uses fiscal sources as the reason for the currency collapse, there is no reason for any significant drop in government spending to happen after the devaluation. The empirical results also reflect mostly the short-run dynamics in the GDP rather than the government spending.

The impulse responses for net exports are in Figure 6. The nominal devaluation can lead to a real devaluation due to sticky prices. Burstein, Eichenbaum and Rebelo (2005) show that the sticky adjustment is mostly in the non-traded goods and services prices. The impact effects of the devaluation are positive and between 2 to 3 percent. The dynamics show a further rise for a year before the decline and the 10 year effects range from 0.3 to 0.5 percent, quite close to zero. This is consistent with the theoretical predictions that the real exchange rate will adjust to its equilibrium in the long-run. However, the short-run dynamics, associated with our output results 
in Section III, show that the rise in net exports is not sufficient to close the fall in GDP due to declines in consumption and investment.

Overall, the components analysis analyzes and estimates the nature of reallocation in the GDP components following large currency devaluations. It shows a short-run reallocation in favor of net exports from both consumption and investment, though not large enough to stop the drop in GDP. It also shows very slow process of adjustment towards the equilibrium suggests roles for both real and nominal rigidities.

\subsection{Conclusion}

Recent literature on measuring the effects of currency crises shows permanent drops in output following crises. Theoretical models of contractionary devaluations (Krugman and Taylor (1978)) predict temporary drops in output due to nominal wage rigidities. Our output results show that the countries do recover fully in the long run following large devaluations. The empirical evidence supporting long-run full recovery depends on three features: a. isolating the banking crisis episodes, b. allowing for time effects and c. allowing for long lags. Once we allow for these features, the discrepancy between theoretical prediction of full recovery in case of nominal wage rigidity and empirical results of permanent loss can be reconciled. The estimates from GDP components analysis show a short-run reallocation in favor of net exports from both consumption and investment, though not large enough compensate for the decline in GDP. The process of adjustment towards the equilibrium is very slow and incomplete even after 10 years suggesting a role for real rigidities beyond sticky nominal wage. 


\begin{tabular}{|c|c|c|}
\hline Data & Definition & Count \\
\hline $\begin{array}{l}\text { Banking Crisis } \\
\text { Dummy (BC) }\end{array}$ & $\begin{array}{l}\text { Two versions. Starting dates of banking crises based on } \\
\text { Laeven and Valencia (2008). } \\
\text { Starting and ending dates of banking crises are reported in } \\
\text { Laeven and Valencia (2010) }\end{array}$ & - \\
\hline $\begin{array}{l}\text { Currency Crisis } \\
\text { Dummy (CC) }\end{array}$ & $\begin{array}{l}30 \% \text { depreciation of exchange rate which is also } 10 \% \\
\text { higher than the depreciation rate in the previous period. } \\
\text { Laeven and Valencia (2008) }\end{array}$ & 210 \\
\hline $\begin{array}{l}\text { Pure Currency } \\
\text { Crisis Dummy } \\
\text { (PCC) }\end{array}$ & $\begin{array}{l}\text { This dummy captures all years in which currency crisis and } \\
\text { banking crisis did not happen simultaneously. } \\
\text { If } C C(t)=1 \text { and } B C(t)=0 \text {, then } \operatorname{PCC}(t)=1 \text {, Otherwise } \\
P C C=0 \text {. }\end{array}$ & 167 \\
\hline $\begin{array}{l}1-\text { Year Pure } \\
\text { Currency Crisis } \\
\text { Dummy (PCC1) }\end{array}$ & $\begin{array}{l}\text { This dummy eliminates all the episodes in which banking } \\
\text { crisis happened within a one-year window of a currency } \\
\text { crisis. } \\
\text { If } C C(t)=1 \text { and } B C(t)=B C(t-1)=B C(t+1)=0 \text {, then } \\
\operatorname{PCC} 1(t)=1 \text {, Otherwise } \operatorname{PCC} 1=0 \text {. }\end{array}$ & 157 \\
\hline $\begin{array}{l}\text { 1-Year Start Pure } \\
\text { Currency Crisis } \\
\text { Dummy (PCCS) }\end{array}$ & $\begin{array}{l}\text { Same as PCC1 with BC dummy that includes only the start } \\
\text { dates of banking crises. }\end{array}$ & 171 \\
\hline
\end{tabular}


Table 2.2: Panel Unit Root Tests for GDP and its Components

\begin{tabular}{|c|c|c|c|c|}
\hline \multicolumn{5}{|l|}{ Panel A: GDP } \\
\hline Tests & \multicolumn{2}{|c|}{ GDP } & \multicolumn{2}{|c|}{ Private GDP } \\
\hline Levin, Lin, Chu t & \multicolumn{2}{|c|}{$-2.08(0.02)$} & \multicolumn{2}{|c|}{$-0.78(0.22)$} \\
\hline Im, Pesaran, Shin W & \multicolumn{2}{|c|}{$9.13(1.00)$} & \multicolumn{2}{|c|}{$10.80(1.00)$} \\
\hline \multicolumn{5}{|l|}{ Panel B: GDP Components } \\
\hline Tests & $\mathrm{C}$ & I & G & $\mathrm{NX}$ \\
\hline Levin, Lin, Chu t & $-46.69(0.00)$ & $-3.49(0.00)$ & $-3.63(0.00)$ & $-3.92(0.00)$ \\
\hline Im, Pesaran, Shin W & $-11.65(0.00)$ & $-4.41(0.00)$ & $-3.49(0.00)$ & $-5.09(0.00)$ \\
\hline
\end{tabular}

Note: The sample range is 1970-2005. The data for the real GDP and its components are obtained from World Development Indicators database. The real GDP and Private GDP data are in natural logarithms. The rest are as a share of GDP. The tests allow for individual intercepts. The lags are selected based on SIC. The GDP test used 158 countries and the Private GDP test used 129 countries. Consumption (C) used 127 countries, Investment (I) used 130 countries, Government Spending (G) used 129 countries and Net Exports (NX) used 134 countries. P-values are indicated in the parentheses. 
Table 2.3: Estimates of Output Loss from Currency Crises

\begin{tabular}{lcc}
\hline \multicolumn{1}{|c}{ Panel A: GDP Loss } & Country Effects & $\begin{array}{c}\text { Country and Time } \\
\text { Effects }\end{array}$ \\
Laeven/Valencia Currency Crisis (CC) & -2.52 & -1.08 \\
Pure Currency Crisis (PCC) & -1.45 & 0.11 \\
1-Year Pure Currency Crisis ( PCC1) & 0.21 & 1.28 \\
1-Year Start Pure Currency Crisis ( PCCS) & 0.43 & 1.31
\end{tabular}

Panel B: Private GDP Loss

Laeven/Valencia Currency Crisis (CC) $\quad-2.20 \quad-1.29$

$\begin{array}{lll}\text { Pure Currency Crisis (PCC) } & -1.76 & -0.81\end{array}$

$\begin{array}{lll}\text { 1-Year Pure Currency Crisis ( PCC1) } & -0.23 & 0.42\end{array}$

$\begin{array}{lll}\text { 1-Year Start Pure Currency Crisis ( PCCS) } & 0.06\end{array}$

Note: The estimates are 10 year cumulative losses and in percentages. The sample range is 1970-2005 with 160 countries for GDP and 129 countries for Private GDP. 


\section{Figure 2.1: GDP Response to Currency Crisis}
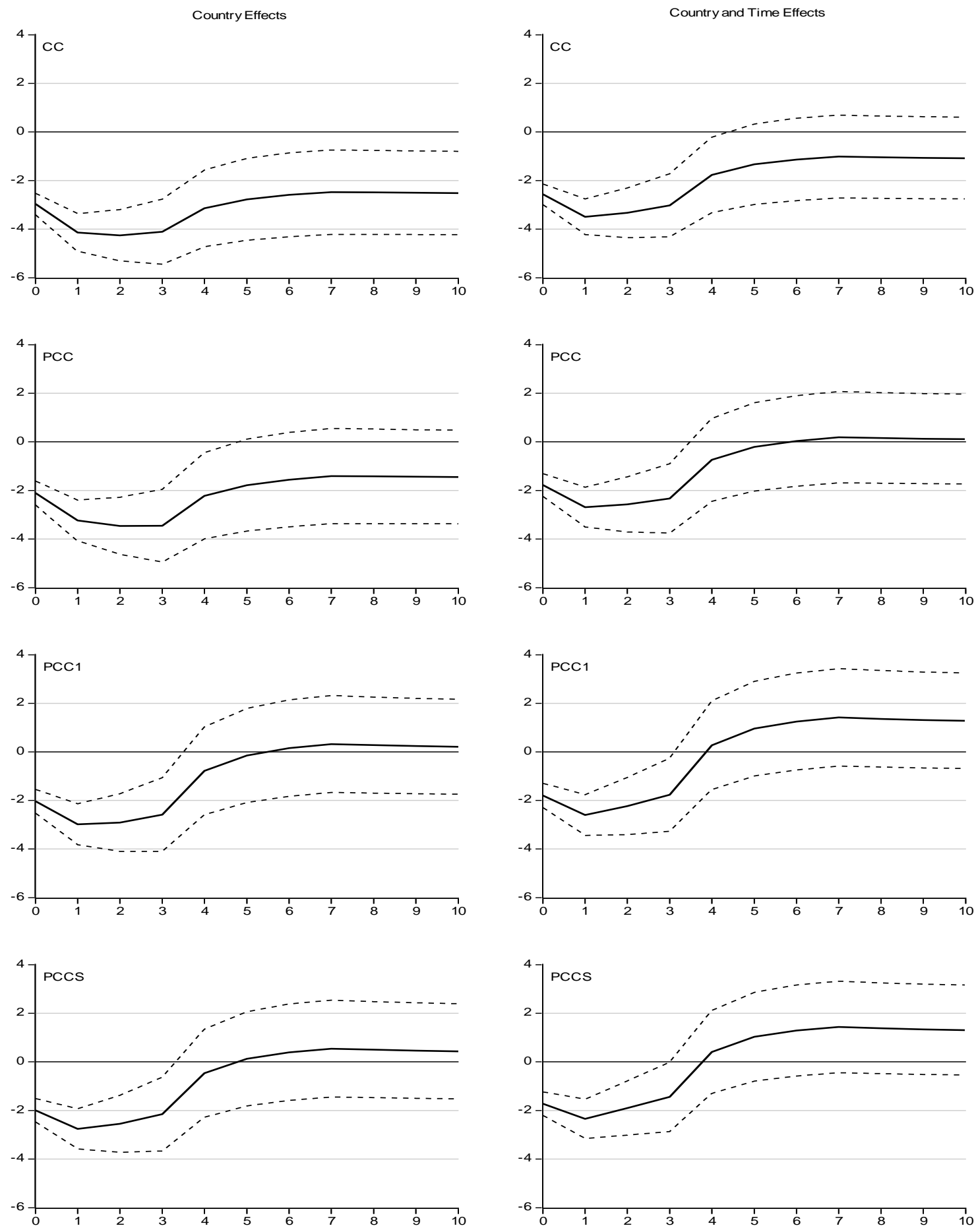

Note: The horizontal axes indicate time in years. The vertical axes measure responses in percentages. The left panels show cumulative impulse responses to currency crisis with country fixed effects only. The right panels show cumulative impulse responses to currency crisis with country fixed effects and time effects. The dotted lines represent one standard error bands based on 1000 Monte Carlo simulations. 


\section{Figure 2.2: Private GDP Response to Currency Crisis}
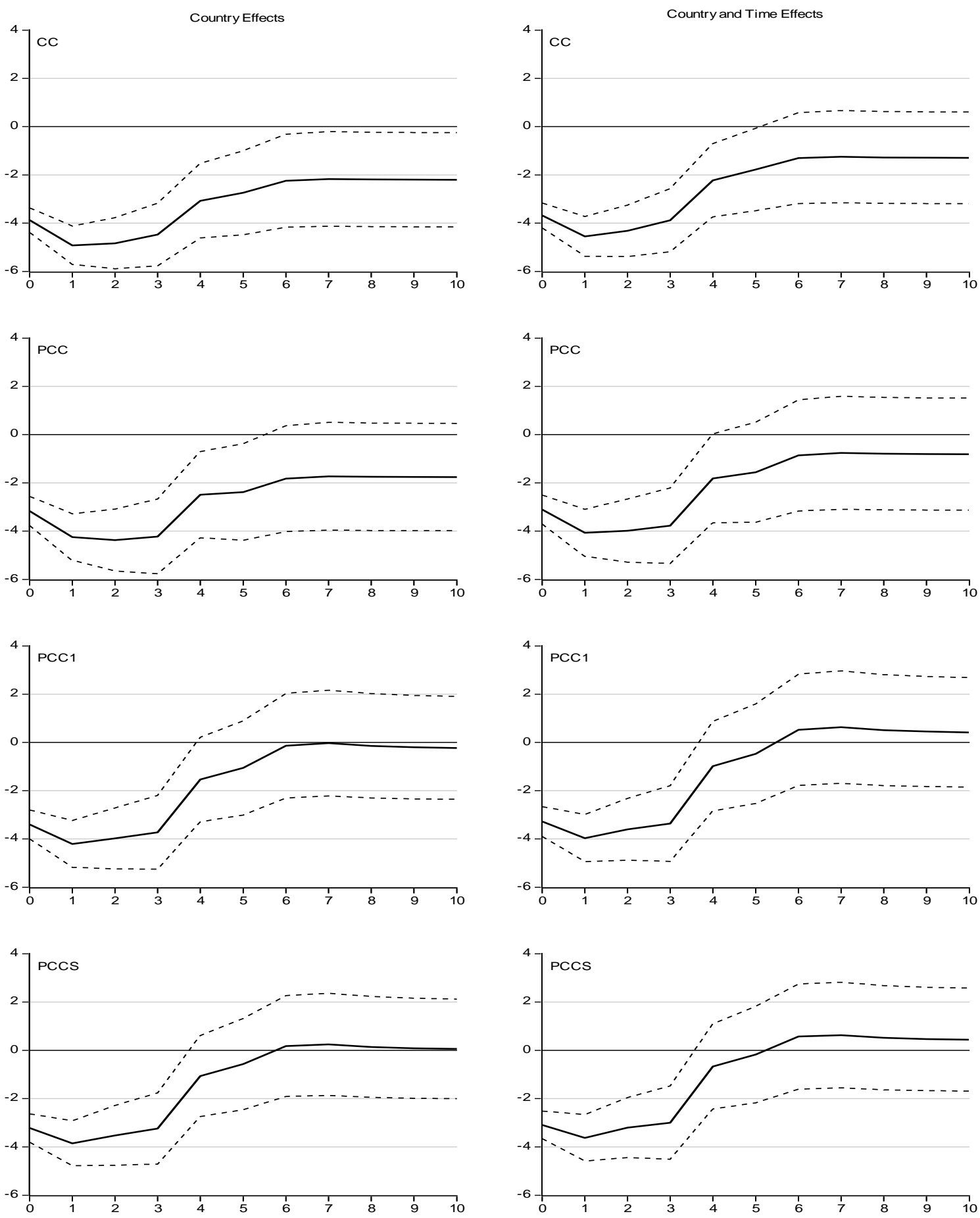

Note: The horizontal axes indicate time in years. The vertical axes measure responses in percentages. The left panels show cumulative impulse responses to currency crisis with country fixed effects only. The right panels show cumulative impulse responses to currency crisis with country fixed effects and time effects. The dotted lines represent one standard error bands based on 1000 Monte Carlo simulations. 


\section{Figure 2.3: Consumption Response to a Currency Crisis}
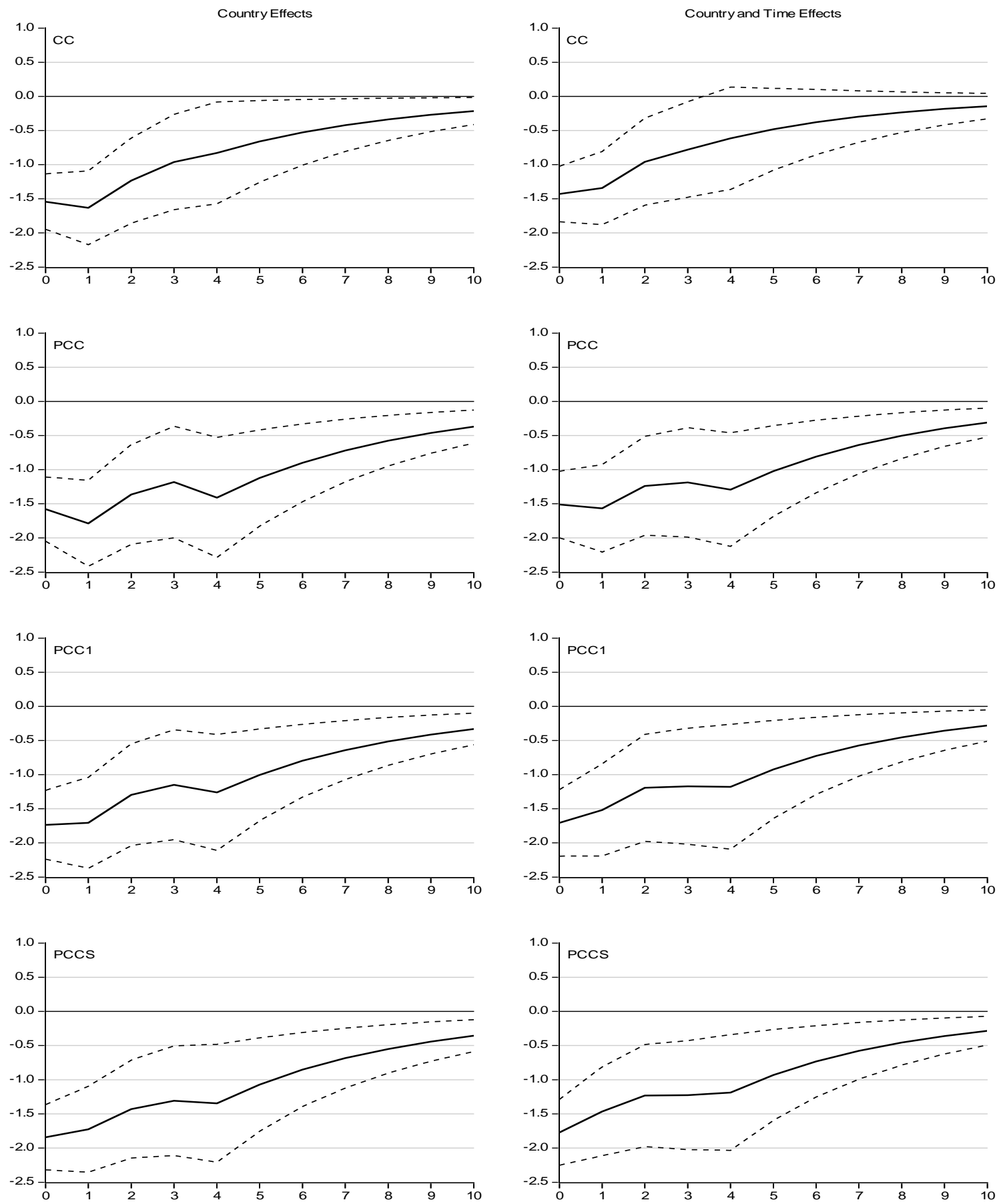

Note: The horizontal axes indicate time in years. The vertical axes measure responses in percentages. The left panels show impulse responses of consumption as a share of GDP to currency crisis with country fixed effects only. The right panels show impulse responses to currency crisis with country fixed effects and time effects. The dotted lines represent one standard error bands based on 1000 Monte Carlo simulations. 


\section{Figure 2.4: Investment Response to Currency Crisis}
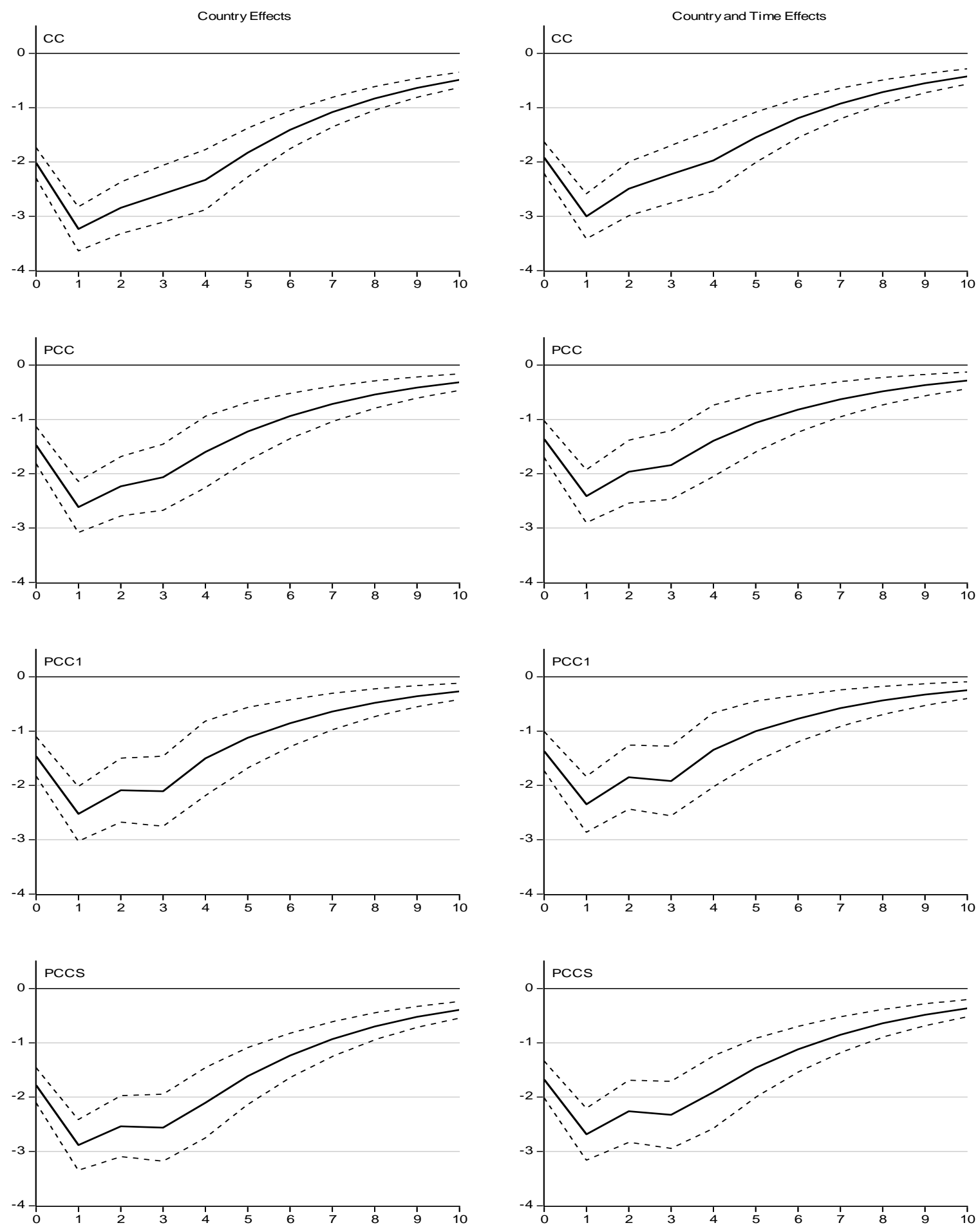

Note: The horizontal axes indicate time in years. The vertical axes measure responses in percentages. The left panels show impulse responses of investment as a share of GDP to currency crisis with country fixed effects only. The right panels show impulse responses to currency crisis with country fixed effects and time effects. The dotted lines represent one standard error bands based on 1000 Monte Carlo simulations. 


\section{Figure 2.5: Government Expenditure Response to a Currency Crisis}
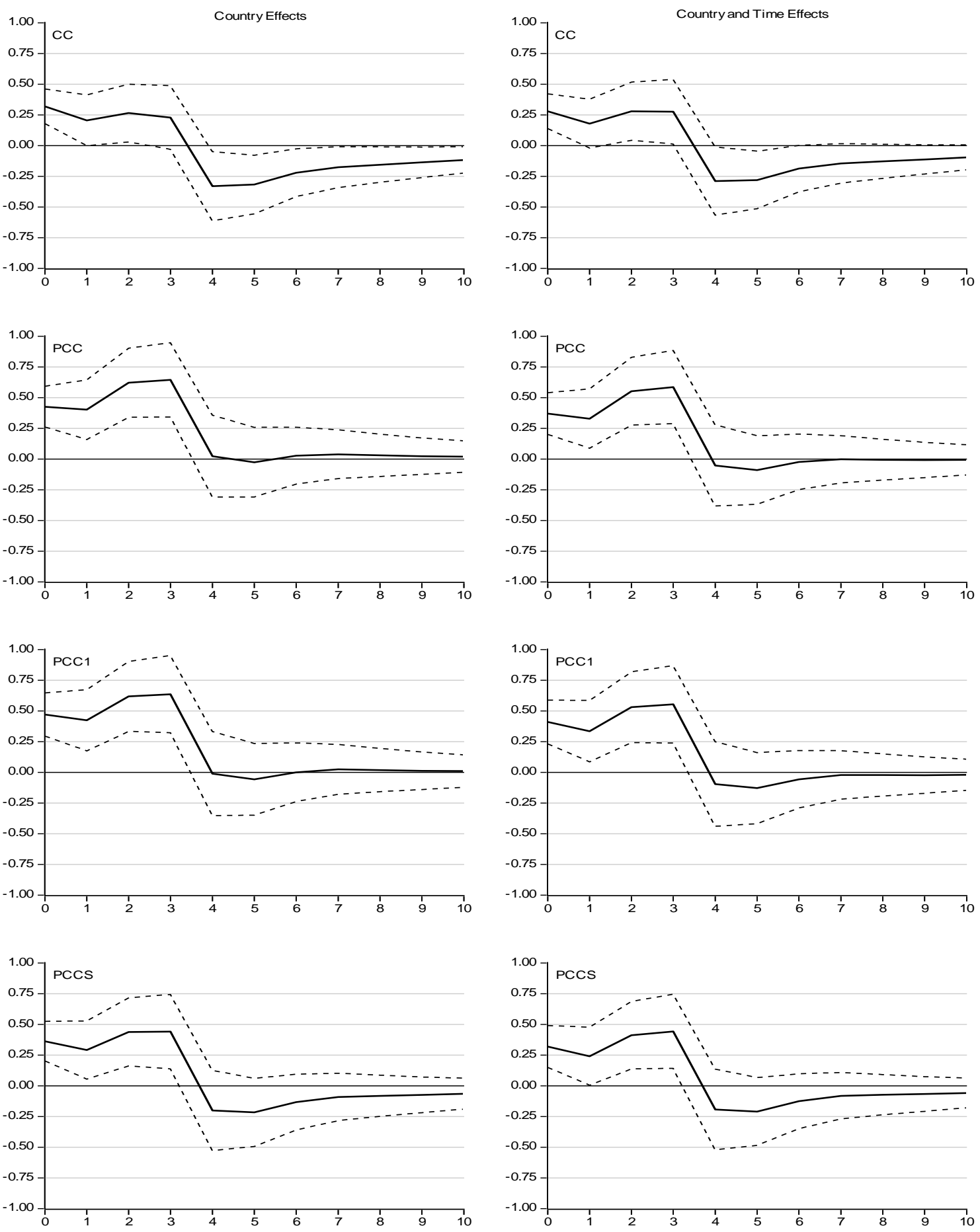

Note: The horizontal axes indicate time in years. The vertical axes measure responses in percentages. The left panels show impulse responses of government expenditure as a share of GDP to currency crisis with country fixed effects only. The right panels show impulse responses to currency crisis with country fixed effects and time effects. The dotted lines represent one standard error bands based on 1000 Monte Carlo simulations. 
Figure 2.6: Net Exports Response to Currency Crisis
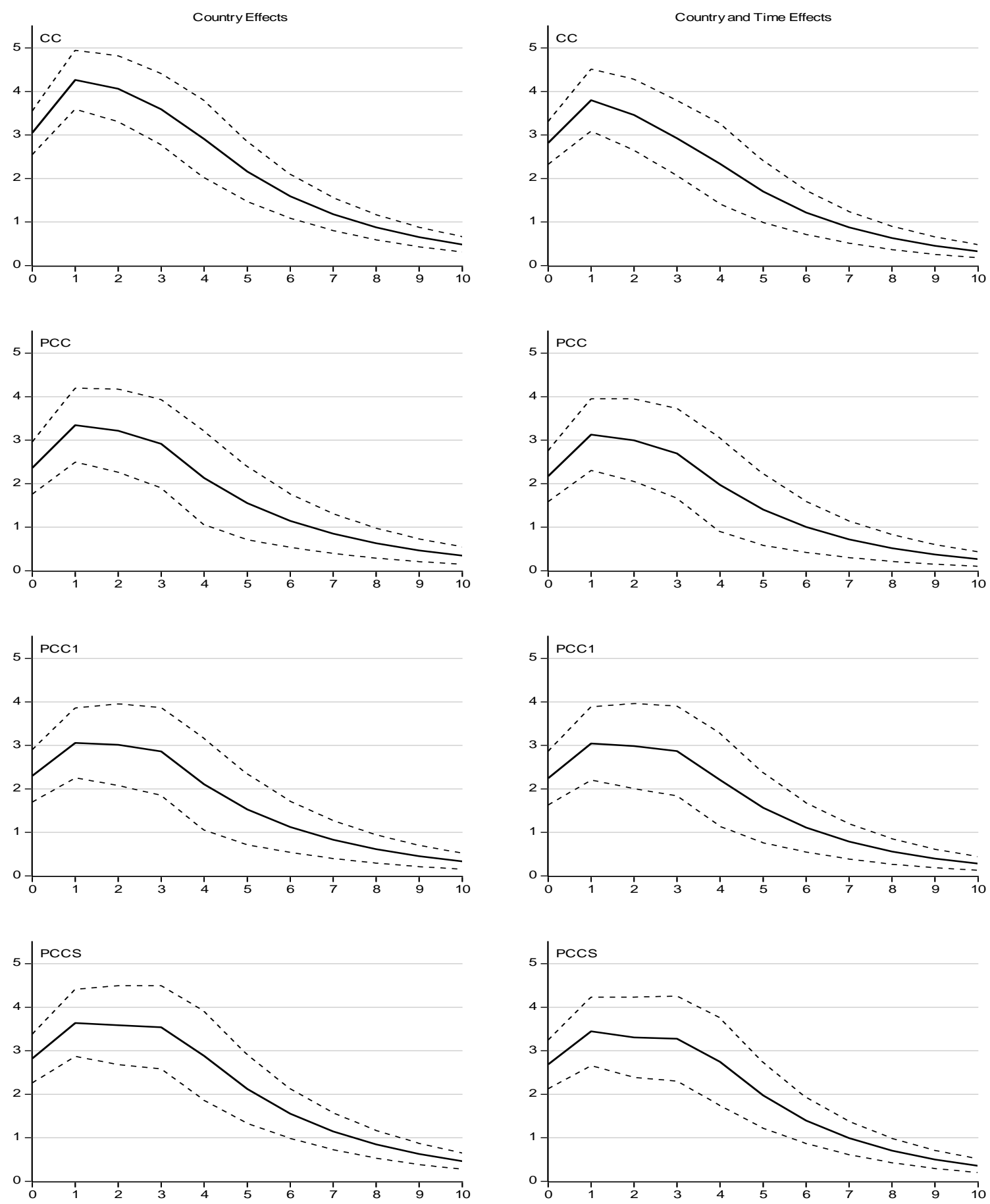

Note: The horizontal axes indicate time in years. The vertical axes measure responses in percentages. The left panels show impulse responses of net exports as a share of GDP to currency crisis with country fixed effects only. The right panels show impulse responses to currency crisis with country fixed effects and time effects. The dotted lines represent one standard error bands based on 1000 Monte Carlo simulations. 


\section{APPENDIX:}

The following graph simulates and compares the responses of investment level following a CC episode and a PCC1 episode with time effects based on the impulse responses reported in the text. The horizontal axis denotes time in years. Year zero denotes the crisis impact year. For ease of comparison, we assume that the pre-crisis level of investment is 100 for both cases as measured in the vertical axis. This case is highlighted because this is the biggest difference in the reported impulse responses between $\mathrm{CC}$ and non-CC cases. As discussed in the text, the drop in the investment level for CC after 10 years is still 4.7 percent whereas PCC1 with time effects fully recovers to 100 .

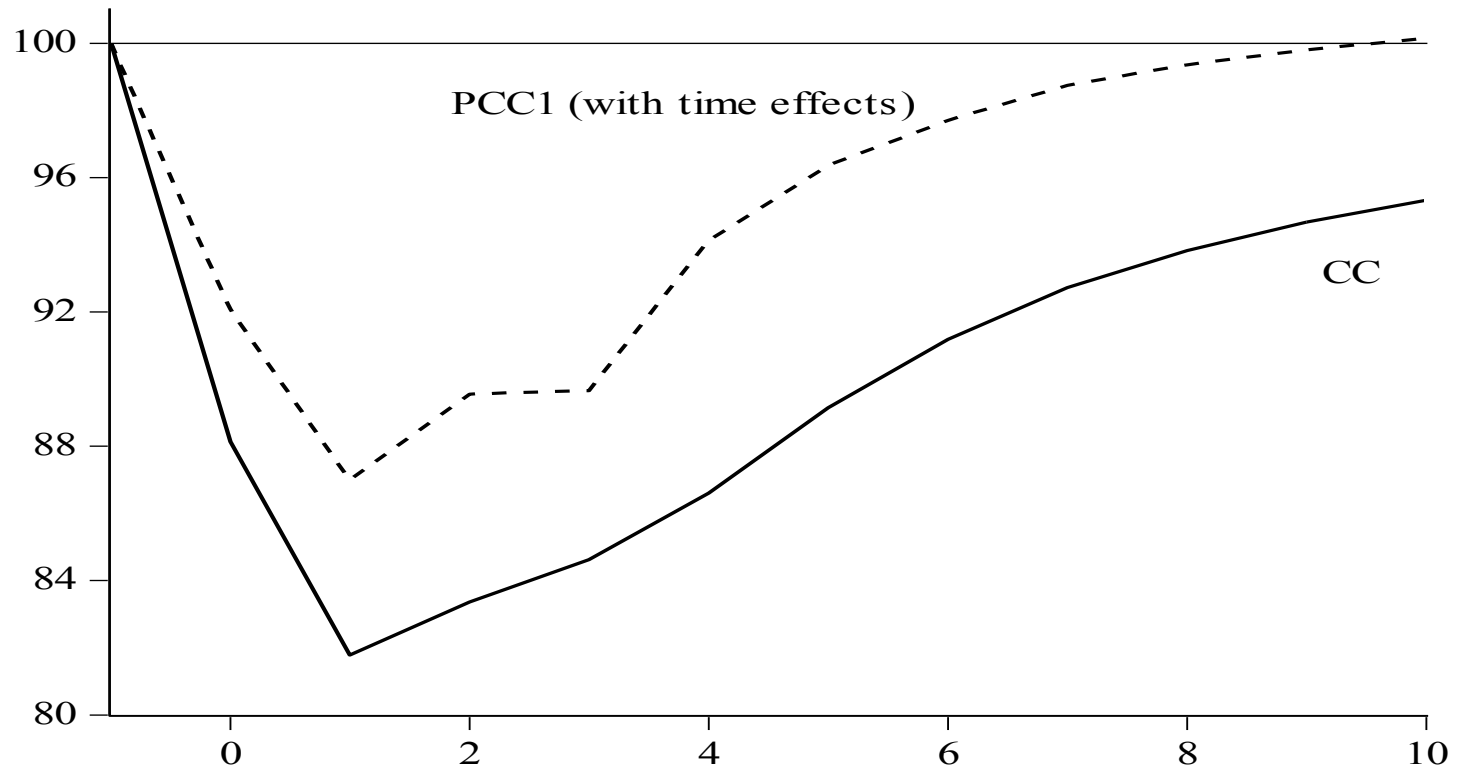




\section{CHAPTER 3. CURRENCY CRISIS AND DYNAMICS OF REAL WAGES}

\subsection{Introduction}

Currency crises affect household welfare in a variety of ways. While one impact of currency crises on households can be through the decline in employment, the other channel is the

decline in real wages ${ }^{5}$. After a large devaluation of nominal exchange rate, excess rigidity of wages relative to prices implies a drop in real wages (Krugman and Taylor (1978)). To the extent real wages decline following currency crises, these events can have substantial impact on the welfare of households. Moreover, as argued by Bazillier and Najman (2010), Harrison (2002), and Diwan (2001), financial crises lead to lower bargaining power of labor and hence labor share (or real wages). The argument is that in the crisis-hit country, the return to capital relative to abroad decreases. With higher mobility, it is easier for capital than for labor to flee away. Therefore, while capital flees, labor remains and bears the cost of a crisis. Dafour and Orhangazi (2009) confirm this hypothesis by finding a 26 percent drop in labor share following the Turkish crisis in 2001.

Despite the importance of labor market variables in determining household's welfare, there are only few studies assessing the impacts of financial crises on these variables. These studies are mainly divided into two categories of panel and country case studies.

Among panel studies, Furceri and Mourougane (2009b) and Gamberoni et al. (2010) examine the role of institution's quality in determining the impact of financial crises on unemployment across OECD countries. They found that the extent of initial shock and the pattern of adjustment to the shock depend on the quality of institutions.

1 Recent studies on the real impact of currency crises (Bussiere et al. (2011), Cerra \& Saxena (2008), Hong $\&$ Tornell (2005)) show large output losses following these events. 
Kilponen, et al. (2010) compare the dynamic adjustment of unemployment and long-term unemployment during normal downturns and financial crises. Their results suggest that labor market reaction is much stronger and the recovery is slower during times of financial crises.

In another panel study, Choudhry et al. (2010) examine employment and unemployment rates of females versus males and also different income groups following various types of financial crises in a large panel of countries. They find that financial crises impact females and young adults more than other groups. Moreover, their results show that only high and middle income countries experience a significant unemployment after financial crises. Queralto (2011) estimates a panel VAR by decomposing output losses into employment and productivity losses. He finds large productivity decline is the main reason behind the output loss in emerging markets after a currency crisis. Conversely, the labor market impact of financial crises in rich countries is mostly on employment.

While the panel studies mainly focus on employment or unemployment rate to assess the impact of financial crises on labor market ${ }^{6}$, the country case studies provide a broader perspective by exploring other variables such as real wages, labor participation rate, hours worked, etc. Nonetheless, these studies only focus on the short-term impact of these events.

Among the country case studies, Fallon and Locus (2002) explore the labor market impacts of currency crises in Mexico (1994), East Asia (1998), Argentina (1995), and Turkey (1995) in the short-run. Their results suggest that the drop in employment was far less than the drop in GDP and the adjustment in labor market following these crises was primarily through substantial real wage cuts. They report a decline of about 44 percent and 31 percent in manufacturing real wages after the crises in Indonesia and Turkey, respectively. In a similar study, Smith et al. (2002) examine Indonesian crisis of 1997-1998. They find that aggregate

\footnotetext{
${ }^{6}$ Moreover, most of the panel studies focus on OECD countries.
} 
employment has remained remarkably stable while there has been a significant movement within sectors. Their results also show a real wage cut of almost 35-40 percent following the Indonesian crisis. Furthermore, Cunningham and Maloney (2000) addressing Mexico financial crisis of 1994, find similar results. David McKenzie (2004) decomposes the change in labor income of households into changes in wages, hours of work, job entry and exit, and work programs. The results indicate that Three-quarters of average fall in labor income is because of real wage cuts. They find that although individual working hours fell on average, households were able to maintain their income by sending more members to the labor force. Therefore, household hours declined by only 5 hours per week after the crisis.

This paper expands the panel literature on labor market impact of currency crises by exploring the post-crisis behavior of not only employment but also real wages and labor productivity in a panel of 66 countries during 1990-2010. Moreover, unlike country case studies that only focus on the short-term, we also investigate the medium-and long-term impact of currency crises on real wages.

Our results broadly support the case studies' results; while the decline in employment is trivial, real wages drop substantially. In particular, 30 percent depreciation depending on the estimation method leads to a drop of 11-19 percent in the level of real wages just one year after a crisis. The long-term analysis reveals that the dynamics of recovery in real wages is sluggish and a full recovery takes at least three and at most eight years ${ }^{7}$. Regardless of currency crises definition, labor productivity initially drops by 3-4 percent, but returns to pre-crisis trend within three to five years. The initial decline may be due to reallocation of labor across sectors after a crisis that can lead to a loss in labor productivity. Employment declines by about one percentage

\footnotetext{
${ }^{7}$ The length of recovery varies depending on the definition of a currency crisis. However, in all definitions real wages is fully recovered after eight years. The recovery takes at least three years.
} 
point and recovers swiftly within one to three years. The small change in employment after a crisis can imply that employers favor cuts in hours to laying off their employees due to high turnover costs. Therefore, the real wage losses may partly be because of the decline in working hours of households. In a case study, Horton \& Mazumdar (2001) find that in Korea, the average number of hours worked per week fell from 46.7 in 1997 , to 45.9 in 1998 . We test to see if our results on real wage cuts are driven by shorter working hours. Thus, we examine the dynamics of real wage per hour after currency crises episodes for a sub-sample of 33 countries during 1990$2010 .{ }^{8}$ The results provide some evidence that most of the adjustment in labor market is still through real wages rather than cut in hours worked. Moreover, our main results remain robust to different definition of currency crisis and estimation methods.

The paper is organized as follows. Section II describes the data and methodology. Section III reports the main results on real wages following a currency crisis. Section IV examines whether or not the results are driven by the cut in hours rather than in real wages. Section V presents robustness of results using a different estimation method. Section VI discusses the results on employment and labor productivity. Section VII concludes with a policy discussion.

\subsection{Data and Empirical Model}

We obtain the data on employment, labor productivity and total annual hours worked from Conference Board Total Economy Database. ${ }^{9}$ Employment figures in this dataset include all employees, the self-employed, unpaid family members that are economically engaged, apprentices, and the military. Labor productivity is defined as output per worker. Although output per hour worked is a better indicator of productivity, the data on hours worked is not very

\footnotetext{
${ }^{8}$ Unfortunately the data for hours worked is not available for more countries.

${ }^{9}$ http://www.conference-board.org/data/economydatabase/
} 
reliable in most countries. Thus, we use output per worker as an alternative measure of labor productivity.

As a proxy for nominal wages, we obtain compensation of employees ${ }^{10}$ (Current LCU) from World Development Indicator (WDI) database for the 1990-2010 period. As pointed out by Diwan (2001), using the compensation of employees as a proxy for nominal wages has some drawbacks. The fact that this measure excludes earnings of self-employed and unpaid family workers limits our analysis. In developing countries, many people move to more informal sectors such as agriculture or become self-employed in crises times. Since the wages in the informal sector are not included in the compensation of employees, we are likely to observe a decline in nominal wages following a crisis even if it may not be the case. Despite the data limitations, our investigation can still shed some light on the dynamics of real wages after currency crises.

We calculate real wage per person employed by dividing nominal compensation of employees by employment and then by a price deflator. For robustness purposes, we use both Consumer Price Index (CPI) and GDP deflator to deflate nominal wages. 'Consumption Wage' is real wage per person employed deflated by CPI and is labeled "RWC". Alternatively, 'Product Wage' is real wage per person employed deflated by GDP deflator and is labeled "RWG". The data on CPI and GDP deflator are obtained from International Monetary Fund (IFS) CDROM and World Development Indicator (WDI) datasets, respectively. Moreover, we limit our analysis to the countries which have at least nine years of consecutive data on real wages. Thus, we end up with 66 countries in our dataset. ${ }^{11}$

\footnotetext{
${ }^{10}$ Compensation of employees in the WDI dataset consists of all payments in cash, as well as in kind (such as food and housing), to employees in return for services rendered, and government contributions to social insurance schemes such as social security and pensions that provide benefits to employees.

${ }^{11}$ List of countries is provided in the Appendix. Moreover, the data on hours worked is only available for only half of the countries in our dataset.
} 
We identify currency crises episodes over the 1990-2010 period with four different identification criteria. First, following Leaven and Valencia (2008), a currency crisis is defined as "a nominal exchange rate depreciation of 30 percent or more which is also 10 percent higher than the rate of depreciation in the previous period". The first condition guarantees that we are capturing episodes of large depreciations. The second condition excludes episodes of hyperinflation in which nominal exchange rate constantly depreciates to catch up with higher inflation. The dummy variable LV, is constructed based on this definition of crisis and is equal to one when the two criteria are met and zero otherwise. As Table 1 shows, the characterization yields 32 episodes of currency crises during 1990-2010 in the 66 countries $^{12}$.

Second, we follow Diwan (2001) to form another dummy which we label "Diwan". This dummy defines a financial crisis broadly as "30 percent or more depreciation in nominal exchange rate during a calendar year". The definition yields 84 currency crises over the 19902010 period. In contrast with LV, Diwan dummy does not rule out episodes of hyperinflation (Table 1).

Finally, following Cerra and Saxena (2008), an Exchange Market Pressure Index (EMPI) is constructed. This index is based on the percentage depreciation in nominal exchange rate plus the percentage loss in foreign exchange reserves. The data on reserves and nominal exchange rates are both obtained from IFS CDROM. ${ }^{13}$ Cerra and Saxena (2008) form a dummy variable, labeled "CS", which is equal to one any time EMPI is in the upper quartile of all observations across the panel. In contrast with Diwan and LV dummies, their dummy captures both the speculative attacks that led to a large depreciation (successful attacks) and those that were neutralized through utilizing central bank's foreign reserves (unsuccessful attacks). Therefore, in

\footnotetext{
${ }^{12}$ Out of 66 countries, only 23 of them experienced at least one currency crisis characterized by LV during the 1990-2010 period, the rest of the countries are used as the 'control group'.

${ }^{13}$ The nominal exchange rate is the average of the period exchange rates.
} 
order to make CS dummy more compatible with the other two indicators of currency crises, we construct CRISIS2 and CRISIS3 dummies. CRISIS2 dummy is equal to one if the currency depreciation component of EMPI accounts for at least 50 percent of the index when the index signals a crisis. ${ }^{14}$ Moreover, the depreciation of currency crisis must be at least 30 percent. $^{15}$ Alternatively, CRISIS3 is formed and is equal to one when EMPI is higher than 90 percent of all observations across the panel. Therefore, CRISIS3 captures episodes of severe pressure on exchange market.

Our empirical approach follows Cerra and Saxena (2008) approach that builds on Romer and Romer (1989) study of real impact of monetary policy; we estimate an autoregressive lag distributed model allowing for country fixed effects and country specific time trends:

1.

$$
g_{i t}=\alpha_{i}+\lambda_{i} t+\sum_{j=1}^{j} \beta_{j} g_{i, t-j}+\sum_{s=0}^{s} \delta_{s} D_{i, t-s}+\varepsilon_{i t}
$$

Where $g_{\text {it }}$ is our labor market variable of interest (real wage, employment or labor productivity) for country $\mathrm{i}, \mathrm{D}_{i t}$ is the currency crisis dummy for country $\mathrm{i}, \alpha_{i}$ is the country fixed effects, and $\lambda_{i} t$ is the country specific time trend. The model facilitates the short-run and long-run analysis through estimations of the equation and the impulse responses, respectively. Hence, we estimate equation (1) and calculate response of each labor market variable to one unit shock to the currency crisis dummy.

Panel Unit root tests for the log level of each variable are reported in Table 2. We report Levin, Lin and Chu (2002) t-test and Maddala and Wu (1999) Chi Square statistic for real wages deflated with CPI and GDP deflator, employment, and labor productivity. Levin, Lin and Chu

\footnotetext{
${ }^{14}$ Similar method has been used by Aziz et al. (2001) to separate currency crashes and reserve crises in their 'event study' analysis of currency crises.

${ }^{15}$ This condition guarantees that we are not capturing moderate depreciation episodes where EMPI is in the upper quartile and currency component of EMPI is more than 50 percent of the index. We also, look at the cases where depreciation is at least 20 percent and the results are robust to this change of threshold.
} 
(2002) assumes identical autoregressive coefficient and pools the data to calculate the pooled Dickey Fuller statistic. The unit root t-test of Levin, Lin and Chu (2002) for our data can reject the null hypothesis of common unit root for all these variables at any significance level. Furthermore, we perform Maddala and Wu (1999) unit root test which relaxes the common unit root assumption of Levin, Lin and Chu (2002) and performs a Fisher type test by combining the p-values from panel specific unit root tests. The chi-square statistic of Maddala and Wu (1999) also rejects the null of individual specific unit root for all the variables under the study at all significance levels. ${ }^{16}$

Since panel unit root test reject the presence of unit root in all our labor market variables, we will use these variables in log levels in equation (1) and estimate the model controlling for panel fixed effects and country specific time trends. Thereafter, we will estimate the impulse functions to analyze long-run behavior of each variable following a currency crisis.

The autoregressive lags and the lags of dummy variables in equation (1) are selected based on: Schwarz Information Criteria (SIC), their significance at five percent or ten percent level of significance, and the considerations concerning the length of our time series. Based on these criteria, we estimated $\operatorname{ADL}(1,3)$ for real wages $(\operatorname{RWC}$ and $\operatorname{RWG})$, ADL $(2,1)$ for employment and $\operatorname{ADL}(3,0)$ for labor productivity. ${ }^{17}$

\subsection{Real Wage Dynamics following a Currency Crisis}

In this section we estimate equation (1) with one autoregressive lag and three lags of the dummy variable for real wage per person employed. Thereafter, we calculate the impulse

\footnotetext{
${ }^{16}$ We also performed Pesaran, Im and Shin (2003) panel unit root test but did not report it since Maddala and $\mathrm{Wu}(1999)$ panel unit root test is similar to IPS and has more power in unbalanced panels. Based on the IPS (2003) W statistic we can reject the null hypothesis of individual specific unit root.

${ }^{17}$ In ADL (p, q), p corresponds to autoregressive lag and q corresponds to the lags of the dummy variable. In the case of labor productivity only the current dummy variable is included as all higher lags were insignificant and SIC test also strongly favored the exclusion of higher lags.
} 
responses and graph the ten year loss (in percentage) of RWC and RWG in the first and second column of Figure 1, respectively. The estimation method is panel fixed effects. We also include country specific time trend to further control for the heterogeneity in our panel of countries. We estimate the model and impulses using LV, Diwan, CRISIS2, and CRISIS3 dummies. The results indicate that the loss in real wages is negligible ten years following a currency crisis. However, the dynamics of the adjustment is more informative and is illustrated in Figure 1.

The top-left panel of Figure 1 shows the impulse response of real consumption wage, RWC, to a currency crisis identified by Laeven and Valencia (2008) dummy, LV. This dummy represents all the large devaluation episodes (successful attacks) excluding the episodes of hyperinflation. The estimates show an initial drop of 3.65 percentage points in the level of real wages. In the second year of a crisis, the real wage cut reaches to about 18 percentage points. The slow recovery begins in the third year and real wages finally fully recover seven to eight years following a crisis. In the top-right panel of Figure 1, we report the impulse response of crisis real product wage, RWG, to a currency shock identified by LV. The results are very similar to RWC response. The estimation results of equation (1) for RWC and RWG are reported in the first columns of Table 3 and Table 4, respectively.

Left panel in the second row of Figure 1 shows the response of RWC to one unit currency crisis shock identified by Diwan (2001). From Figure 1, it is evident that the impact of these episodes on real wages is different from LV currency crisis episodes in two ways. First, there is a larger initial cut in real wages (about 11 percentage points). Second, the recovery is faster; the initial recovery starts just a year after a crisis and real wages fully recover within five years. The quantitative difference in outcome is due to the difference in the crisis identification criterion. Diwan dummy captures all large devaluation episodes including the episodes of hyperinflation. During hyperinflation episodes, nominal wages are likely to be somewhat 
indexed to inflation and thus more flexible. Therefore, it is not surprising to observe a faster recovery of real wages following Diwan currency crises episodes. However, the large initial decline in real wages implies that nominal wages are not automatically indexed to the price level.

Right panel in the second row of Figure 1 shows the response of RWG to the Diwan currency crisis dummy. The initial drop in RWG is larger than RWC and is about 14 percent. The recovery dynamics however, is very similar except that the recovery begins immediately after a crisis. The estimation results of equation (1) for RWC and RWG with Diwan dummy is reported in the second column of Table 3 and Table 4, respectively.

The third row of Figure 1 presents the impulse response of RWC and RWG to a currency crisis identified by CRISIS2. This dummy characterizes all the episodes where exchange market is under pressure and depreciation plays an important role to feature this pressure. The initial real wage loss in these episodes is large, significant, and about 16 percentage points. The recovery starts right after a crisis which implies that nominal wages are somewhat indexed to inflation. However, the sluggish dynamics means that the indexation is not complete and it takes four to five years for nominal wages to fully catch up with higher prices. The estimation results of equation (1) for RWC and RWG using CRISIS2 dummy are reported in the third column of Table 3 and Table 4, respectively.

The fourth row of Figure 1 shows the response of RWC and RWG to a currency shock characterized by CRISIS3. The dummy captures episodes of high pressure on exchange market characterized by large depreciations or large reserve losses. The initial loss is lower and about 8 percentage points. The second year of a crisis the loss reaches to 11 percentage points. Again, real wage fully recovers within five years. The lower real wage drop during CRISIS3 episodes can be due to the fact that this dummy captures more large reserve losses rather than large 
depreciation episodes ${ }^{18}$. In fact, further investigation reveals that more than half of the episodes captured by CRISIS3 represent large reserve losses and small or moderate nominal exchange rate depreciation. The estimation results of equation (1) for RWC and RWG using CRISIS3 dummy are reported in the fourth column of Table 3 and Table 4, respectively.

Overall, the results indicate that regardless of currency crises characterization, real wages initially drop after these events. The magnitude of decline however, depends on the crisis identification criteria and varies between $11-15$ percent just one year after a crisis. The dynamics of recovery is sluggish and again depends on the characterization of currency crises. While full recovery occurs within five years following a crisis characterized by Diwan, CRISIS2, and CRISIS3 episodes, the recovery from LV episodes takes place within seven to eight years.

The possible explanations for the large drop in real wages following a currency crisis can be excessive upward stickiness of nominal wages or lower bargaining power of labor following the event. After a large devaluation, in attempt to clean out their balance sheets, firms cut nominal wages or at least do not raise them for a while. ${ }^{19}$ Cleaning the balance sheets occurs mainly through lower real wages rather than lower profits because-as argued by Bazillier and Najman (2010), Harrison (2002), and Diwan (2001) - capital is more mobile relative to labor and flees away if profits are lower than abroad. This is merely one possible explanation for lower real wages following a currency crisis and since we do not explicitly include an indicator for bargaining power of labor in our model, we cannot reject or accept this hypothesis.

\footnotetext{
${ }^{18}$ There is no apriori reason to assume real wage drops following reserve losses.

${ }^{19}$ In Turkey after currency crises of 2001, wages of public employees were cut and number of unionized workers decreased by about one-sixth (Dafour and Orhangazi (2009)). Within the same context, Kang et al. in the book "East Asian labor markets and the economic crisis: impacts, responses \& lessons" in the chapter on labor outcome of the Korean (1997-1998) financial crisis note:

“.... Of 3,337 workplaces 2,259 agreed to a (nominal) wage freeze, and another 559 agreed to wage cuts. In 1998 , inflation rose to 7.5 percent, real wages dropped by almost 10 percent. As growth in real wages fell, so did the rate of unionization..."
} 


\subsection{Real Wage per Hour Dynamics}

The real wage per person results must be interpreted with caution. This is because the changes in employment rate only partly reflect the quantity adjustment in the labor market, the other part of adjustment is through a decline in hours worked ((Ramesh, 2009), (Feridhanusetyawan, 2002), (Horton \& Mazumdar, 2001)). In fact, Horton \& Mazumdar (2001) investigation of Indonesian and Korean crises of 1997-1998 confirms the fall in hours worked after these crises. They find that in Korea, the average number of hours worked per week fell from 46.7 in 1997, to 45.9 in 1998 . Therefore, our real wage drop estimations may be overstated by ignoring the cut in working hours. We investigate if this is the case by exploring the dynamics of real wage per hour after currency crises in a sub-sample of 33 countries during 1990-2010 period. ${ }^{20}$ The data on total annual hours worked is obtained from Conference Board Total Economy Database. We calculate real wage per hour by dividing real wage deflated by CPI and GDP deflator by total hours worked per year.

The first and second columns in Figure 3 show the impulse responses of real wage per hour deflated by CPI and GDP deflator to a currency shock. Each row corresponds to a different definition of a crisis. ${ }^{21}$ We estimate the results using fixed effects with country specific time trends. The results are similar to real wage per person results.

Comparison of Figure 3 with Figure 1 suggests that there is a large drop in both real wage per hour and per person after currency crises. The initial drop in real wage per hour implies that after a currency crisis, labor earns less for each hour worked. Moreover, the average full recovery of real wage per hour takes about eight years regardless of crisis identification criteria. The dynamics of recovery is somehow different from that of real wage per person. For example, the

\footnotetext{
${ }^{20}$ The data on total annual hours worked was only available for a sub-sample of 33 countries of 66 countries included in the analysis.

${ }^{21}$ With LV, Diwan, CRISIS2, and CRISIS3 definitions of currency crises, we identify 7, 20, 12, 42 episodes of crises.
} 
recovery in real wage per hour after a currency crisis characterized by LV is sharper than the recovery of real wage per person. After two years the loss in real wage per hour shrinks to about five percentage points while in the second year of a crisis the loss in real wage per person is still about 15 percentage points. The different dynamics can also be related to the difference in the sample size and fewer occurrences of currency crises in the smaller sample.

Overall, our investigation provides some suggestive evidence that the large drop in real wages is mainly attributed to the decline in nominal wages rather than changes in employment or hours worked.

\subsection{Robustness Check}

In this section we check the robustness of our results using a different estimation method and re-calculate our impulse functions. As Nickell (1981) points out, using fixed effect estimator for autoregressive dynamic models leads to inconsistent estimate of coefficients when number of periods is kept fixed. ${ }^{22}$ For this reason we re-estimate equation (1) for real wages using Arellano and Bond (1991) estimator which is consistent estimator of dynamic panel models. Arellano and Bond GMM estimator eliminates the unobserved heterogeneity across the panel by first-differencing the data. Thereafter, by assuming lagged levels of the dependent variables are orthogonal to the first differenced error term, moment conditions are constructed. We estimate Equation (1) for RWC and RWG using the Arellano and Bond (1991) GMM method and each of the currency crises dummies. Moreover, country specific time trends are included in all specifications. The results are reported in Table 5 and Table 6. The impulse functions based on Arellano and Bond (1991) estimation of equation (1) for RWC and RWG are shown in Figure 2.

\footnotetext{
${ }^{22}$ Fixed effects estimators are biased downward in dynamic panel models. The order of bias is $1 / \mathrm{T}$ and thus is serious in short panels $(\mathrm{T}=3,4)$.
} 
The first row and the left panel of Figure 2 represent the response of RWC to the LV currency crisis dummy. It is evident that the initial cut in real wages is higher than the previous section and is about 8.22 percent. In the second year of a crisis, workers experience on average 20 percent cuts in their real wages. The recovery dynamics is sluggish and follows the same pattern as the previous section. The right panel in the first row of Figure 2 shows the response of RWG to LV dummy which also registers a higher initial loss compared to fixed effect results and a sluggish recovery.

Overall, response of real wages to LV currency crises periods is very similar to the presented results in the previous section. The main difference is that using Arellano and Bond GMM estimator to estimate equation (1) implies a larger cut in real wages in the shortand medium-run. The full recovery is still within seven to eight years.

The left panels in the second and third row of Figure 2 represent the response of RWC to Diwan and CRISIS2 dummies, respectively. Alternatively, the second and third columns of Table 5 show the estimation result of equation (1) using Diwan and CRISIS2 dummies. The initial cuts in real wages in these cases are roughly the same or somewhat smaller than the fixed effect estimation results. Figure 2 indicates that the full recovery takes within three to five years. The last rows in Table 5 report the Sargan test and the related Pvalue. Based on the P-values, the Sargan test fails to reject the null that the over-identifying instruments are valid. Therefore the estimates are efficient and unbiased.

The right panels in the second and third row of Figure 2 show the response of RWG to Diwan and CRISIS2 dummies. The estimation results are reported in the second and third column of Table 6. The Sargan test in this case rejects the null of valid over-identifying instruments. Therefore, the instruments are weak and thus estimations are inefficient. The 
dynamics of recovery is similar to fixed effect estimations but the full recovery takes three years. $^{23}$

In sum, our results are robust to the estimation method employed. The magnitude of initial losses are somewhat different using Arellano and Bond GMM estimator but the pattern of adjustment after a crisis is similar to the fixed effect results.

\subsection{Dynamics of Employment and Labor Productivity following Currency Crises}

In this section, we present the results on the dynamic adjustment of employment and labor productivity following currency crises episodes characterized by different criteria. Therefore, we estimate equation (1) for logarithm of employment with two autoregressive lags and one lag of the dummy variable $(\operatorname{ADL}(2,1))$. The impulse function for employment is presented in Figure 3. The left panels in Figure 3 report fixed effects estimation whereas the right panels represent the Arellano and Bond GMM estimation method. Country specific time trends are included in all regressions. Row one through three in Figure 3 corresponds to the response of employment to LV, Diwan, and CRISIS2, respectively.

Figure 3 shows that the initial response of employment to a currency shock is negative and although statistically significant in some cases, the error bands are relatively large and the magnitude of the decline in employment is economically negligible. One explanation for such a small drop in employment is that employers may prefer to cut on hours worked by their employees rather than laying them off. Moreover, lower real wages allow employers to adjust without laying off their workers. These results are in contrast with Queralto (2011) who found

\footnotetext{
${ }^{23}$ We also correct the standard errors to be robust to autocorrelation, heteroskedasticity, and crosscorrelation between panels and repeat the Monte-Carlo simulations to draw the errors bands based on our robust errors. The results are similar to the reported results. Thus for brevity, we did not report them. They are available upon request.
} 
that employment is substantially affected following a crisis in developed economies. However, our datset includes developing and emerging countries as well as developed countries.

Finally, Figure 4 shows the response of labor productivity to one unit currency crisis shock. The presentation of the results follows the same format of employment. There is an initial loss of about 3-4 percent in productivity regardless of estimation method or currency crises criteria. Dynamics of recovery is more volatile and recovery is swifter when Arellano and Bond (1991) method is used.

Overall results suggest that the impact of currency crises on employment is negligible. This can be due to the fact that employers cut on hours rather than laying off their workers. Moreover, while lower labor productivity can explain lower real wages to some extent, the magnitude and length of the decline in real wages is much larger to be explained by productivity losses alone.

\subsection{Conclusion}

To date, the empirical literature on the aftermath of currency crises has measured the welfare implications of crises only in terms of losses to aggregate output or employment. However, focusing on other labor market variables, real wages in particular, after a crisis may provide a better picture of costs borne by households. The study on the impact of currency crises on real wages is limited to country case studies and only focuses on the short-term effects of these events. This paper moves beyond case studies and explores the dynamic adjustment of real wages, employment and labor productivity in a panel of 66 countries during the 1990-2010 period.

The results put forth in this paper suggest that currency crises initially lead to a loss in real wages. The magnitude of loss after 30 percent depreciation, depending on estimation method 
used, varies between 11-19 percent just a year after a crisis. Full recovery of real consumption wage usually occurs within at least three and at most eight years. The results are robust to the estimation method used.

Employment and labor productivity initially drop after a currency crisis. The loss in employment, although in some cases statistically significant, is not economically meaningful. This may imply that employers favor cut in hours to firing the workers. Furthermore, lower real wages somewhat shields workers against losing their jobs. Initial productivity losses are statistically significant and about 3-4 percent. However, labor productivity fully recovers within three to five years. Although part of the loss in real wages can be explained by the drop in productivity, the magnitude of decline in real wages implies that there are other factors in work as well.

We can derive some policy implication from our results. First, since households experience a large drop in their purchasing power, policies to retrieve their purchasing power, such as income transfers to poor families can ameliorate the impact of financial crisis on households. Second, as Krugman and Taylor (1979) argue, lower real wages after a currency crisis can lead to a decline in output. This is because lower real wages imply a transfer of income from high propensity to consume individuals (labor) to low propensity to consume individuals (capital). Therefore, consumption and aggregate demand decrease. By finding a mechanism to transfer income to affected household, we also limit the output cost of a currency crisis. 


\section{Table 3.1- Data Description and List of Countries}

Data

Definition

Count

A nominal exchange rate depreciation of 30 percent or more

LV Currency Crisis

which is also 10 percent higher than the rate of depreciation in the previous period. (Laeven and Valencia (2008)).

Diwan Currency Crisis

CS Currency Crisis

CRISIS2

CRISIS3

\section{$\begin{array}{ll}\text { CRISIS2 }=1 & \text { if } \mathrm{CS}=1 \& \\ \text { CRISIS } 2=0 & \text { Otherwise }\end{array}$}

A depreciation of 30 percent or more in nominal exchange rate during a calendar year. Diwan (2001).

EMPI $=$ The percentage depreciation in the exchange rate + the percentage loss in foreign exchange reserves.

$\mathrm{CS}=1$ if EMPI> Upper quartile of all observations

$\mathrm{CS}=0$ if EMPI $<$ Upper quartile of all observations in the panel. (Cerra and Saxena (2008)).

CRISIS $3=1 \quad$ if EMPI $>90$ th percentile of all observations

\section{List of Countries:} CRISIS $3=0 \quad$ Otherwise

Australia, Austria, Bahrain, Bangladesh, Belarus, Belgium, Brazil, Bulgaria, Canada, Colombia, Congo, Croatia, Cyprus, Czech Republic, Denmark, Estonia, Ethiopia, France, Georgia, Germany, Ghana, Greece, Guatemala, Hungry, Iceland, India, Indonesia, Iran, Ireland, Israel, Italy, Jordan, Kazakhstan , Kenya, Korea, Kuwait, Latvia ,Lithuania , Luxembourg, Madagascar, Malaysia, Mali, Mexico, Moldova, Netherlands, Norway, Pakistan, Peru, Poland, Portugal, Singapore, Slovenia, South Africa, Spain, Sri Lanka, Sweden, Switzerland, Tunisia, Uganda, Ukraine, United Kingdom, United States, Uruguay, Venezuela, Yemen. 
Table 3.2 - Panel Unit Root Tests

\begin{tabular}{|c|c|c|}
\hline Tests & Levin, Lin, Chu -t test & Maddala and Wu- Chi Square \\
\hline \multicolumn{3}{|l|}{ Variables: } \\
\hline $\log (\mathrm{RWC})$ & $-7.28249 \quad(0.00)$ & $208.68 \quad(0.00)$ \\
\hline $\log (\mathrm{RWG})$ & $-6.35776(0.00)$ & $199.869(0.00)$ \\
\hline Log (Employment) & -3.69909 & $247.415(0.00)$ \\
\hline Log(Labor Productivity) & -4.78059 & $225.724(0.00)$ \\
\hline \multicolumn{3}{|c|}{$\begin{array}{l}\text { Note: The sample range is } 1990-2010 \text { and includes } 66 \text { countries. Real Consumption Wage (RWC) is real wage per } \\
\text { person employed deflated by Consumer Price Index (CPI). Real Product Wage (RWG) is real wage per person } \\
\text { deflated by GDP deflator. Compensation of Employees (Current LCU) is obtained from World Bank Development } \\
\text { database and used as a proxy for nominal wages. CPI and GDP deflator are from International Monetary Fund and } \\
\text { World Bank Development, respectively. Employment and labor productivity are taken from Conference Board Total } \\
\text { Economy (TED) database. Labor productivity is defined as output per person employed. The panel unit root tests } \\
\text { allow for individual intercept and time trend. The lags are selected based on SIC. P-values are indicated in } \\
\text { parenthesis. Levin, Lin and Chu t-test assumes homogenous autoregressive coefficient across countries. Maddala } \\
\text { and Wu use Fisher type tests and allow for heterogeneous autoregressive coefficient across the panel. }\end{array}$} \\
\hline
\end{tabular}


Table 3.3- Real Consumption Wages after Currency Crises

\begin{tabular}{|c|c|c|c|c|}
\hline $\begin{array}{l}\text { Model } \\
\text { Dependent Variable }\end{array}$ & $\begin{array}{c}(1) \\
\log (\mathrm{RWC})\end{array}$ & $\begin{array}{c}(2) \\
\log (\text { RWC })\end{array}$ & $\begin{array}{c}(3) \\
\log (\text { RWC })\end{array}$ & $\begin{array}{c}(4) \\
\log (\text { RWC })\end{array}$ \\
\hline L.log(RWC) & $\begin{array}{l}0.458^{* * * *} \\
(0.0314)\end{array}$ & $\begin{array}{l}0.397^{* * * *} \\
(0.0351)\end{array}$ & $\begin{array}{l}0.353 * * * \\
(0.0379)\end{array}$ & $\begin{array}{l}0.365^{* * * *} \\
(0.0378)\end{array}$ \\
\hline LV & $\begin{array}{l}-0.0365 \\
(0.0292)\end{array}$ & & & \\
\hline L.LV & $\begin{array}{l}-0.136^{* * *} \\
(0.0281)\end{array}$ & & & \\
\hline L2.LV & $\begin{array}{l}-0.109^{* * *} \\
(0.0279)\end{array}$ & & & \\
\hline L3.LV & $\begin{array}{l}-0.0806^{* * *} \\
(0.0275)\end{array}$ & & & \\
\hline Diwan & & $\begin{array}{l}-0.113 * * * \\
(0.0256)\end{array}$ & & \\
\hline L.Diwan & & $\begin{array}{l}-0.0933 * * * \\
(0.0239)\end{array}$ & & \\
\hline L2.Diwan & & $\begin{array}{l}-0.0396^{*} \\
(0.0233)\end{array}$ & & \\
\hline L3.Diwan & & $\begin{array}{l}-0.00459 \\
(0.0221)\end{array}$ & & \\
\hline CRISIS2 & & & $\begin{array}{l}-0.163 * * * \\
(0.0333)\end{array}$ & \\
\hline L.CRISIS2 & & & $\begin{array}{l}-0.0754 * * \\
(0.0302)\end{array}$ & \\
\hline L2.CRISIS2 & & & $\begin{array}{l}-0.0267 \\
(0.0303)\end{array}$ & \\
\hline L3.CRISIS2 & & & $\begin{array}{l}-0.0200 \\
(0.0275)\end{array}$ & \\
\hline CRISIS3 & & & & $\begin{array}{l}-0.0779 * * * \\
(0.0233)\end{array}$ \\
\hline L.CRISIS3 & & & & $\begin{array}{l}-0.0870^{* * * *} \\
(0.0226)\end{array}$ \\
\hline L2.CRISIS3 & & & & $\begin{array}{l}-0.0253 \\
(0.0214)\end{array}$ \\
\hline L3.CRISIS3 & & & & $\begin{array}{l}-0.0305 \\
(0.0202)\end{array}$ \\
\hline $\mathrm{N}$ & 858 & 704 & 656 & 656 \\
\hline R2 & 0.823 & 0.802 & 0.801 & 0.799 \\
\hline $\mathrm{F}$ & 47.36 & 32.92 & 30.42 & 30.07 \\
\hline
\end{tabular}

Note: Standard errors are in parentheses, ${ }^{*} p<0.10,{ }^{* *} p<0.05,{ }^{* * *} p<0.01$. The Table shows the estimation results of equation (1) with different currency crises dummies. For definition of each dummy see Table 1. L(p) represent lag $\mathrm{p}$ of each variable. The estimation method is panel fixed effect with country specific time trends. RWC is real wage per person deflated by CPI. 66 countries during 1990-2010 are included. 
Table 3.4- Real Product Wages after Currency Crises

\begin{tabular}{|c|c|c|c|c|}
\hline $\begin{array}{l}\text { Model } \\
\text { Dependent Variable }\end{array}$ & $\begin{array}{c}(1) \\
\log (\mathrm{RWG}) \\
\end{array}$ & $\begin{array}{c}(2) \\
\log (\mathrm{RWG}) \\
\end{array}$ & $\begin{array}{c}(3) \\
\log (\text { RWG }) \\
\end{array}$ & $\begin{array}{c}(4) \\
\log (\mathrm{RWG}) \\
\end{array}$ \\
\hline L.log(RWG) & $\begin{array}{l}0.409 * * * \\
(0.0327)\end{array}$ & $\begin{array}{l}0.327 * * * \\
(0.0369)\end{array}$ & $\begin{array}{l}0.299 * * * \\
(0.0389)\end{array}$ & $\begin{array}{l}0.315^{* * *} \\
(0.0390)\end{array}$ \\
\hline LV & $\begin{array}{l}-0.0589^{* *} \\
(0.0294)\end{array}$ & & & \\
\hline L.LV & $\begin{array}{l}-0.124 * * * \\
(0.0283)\end{array}$ & & & \\
\hline L2.LV & $\begin{array}{l}-0.113 * * * \\
(0.0281)\end{array}$ & & & \\
\hline L3.LV & $\begin{array}{l}-0.0848^{* * *} \\
(0.0276)\end{array}$ & & & \\
\hline Diwan & & $\begin{array}{l}-0.142 * * * \\
(0.0258)\end{array}$ & & \\
\hline L.Diwan & & $\begin{array}{l}-0.0728^{* * *} \\
(0.0242)\end{array}$ & & \\
\hline L2.Diwan & & $\begin{array}{l}-0.0436^{*} \\
(0.0234)\end{array}$ & & \\
\hline L3.Diwan & & $\begin{array}{l}-0.00455 \\
(0.0222)\end{array}$ & & \\
\hline CRISIS2 & & & $\begin{array}{l}-0.186^{* * *} \\
(0.0334)\end{array}$ & \\
\hline L.CRISIS2 & & & $\begin{array}{l}-0.0653 * * \\
(0.0305)\end{array}$ & \\
\hline L2.CRISIS2 & & & $\begin{array}{l}-0.0388 \\
(0.0304)\end{array}$ & \\
\hline L3.CRISIS2 & & & $\begin{array}{l}-0.0120 \\
(0.0276)\end{array}$ & \\
\hline CRISIS3 & & & & $\begin{array}{l}-0.0717^{* * *} \\
(0.0236)\end{array}$ \\
\hline L.CRISIS3 & & & & $\begin{array}{l}-0.0878^{* * * *} \\
(0.0229)\end{array}$ \\
\hline L2.CRISIS3 & & & & $\begin{array}{l}-0.0240 \\
(0.0216)\end{array}$ \\
\hline L3.CRISIS3 & & & & $\begin{array}{l}-0.0152 \\
(0.0204)\end{array}$ \\
\hline $\mathrm{N}$ & 855 & 701 & 653 & 653 \\
\hline R2 & 0.788 & 0.769 & 0.771 & 0.766 \\
\hline $\mathrm{F}$ & 37.57 & 26.92 & 25.42 & 24.64 \\
\hline
\end{tabular}

Note: Standard errors are in parentheses, $* p<0.10, * * p<0.05$, $* * * p<0.01$. Equation (1) is estimated using each crisis dummy (see Table 1). L (p) represents lag $\mathrm{p}$ of a variable. The estimation method is panel fixed effects with country specific time trends.RWG is real wage per person deflated by GDP deflator. 66 countries during 1990-2010 are included. 
Table 3.5- Real Consumption Wages after Currency Crises

\begin{tabular}{|c|c|c|c|c|}
\hline Model & (1) & (2) & (3) & (4) \\
\hline Dependent Variable & $\log (\mathrm{RWC})$ & $\log ($ RWC $)$ & $\log (\mathrm{RWC})$ & $\log (\mathrm{RWC})$ \\
\hline L.log(RWC) & $\begin{array}{l}0.476^{* * *} \\
(0.0764)\end{array}$ & $\begin{array}{l}0.504 * * * \\
(0.0846)\end{array}$ & $\begin{array}{l}0.581 * * * \\
(0.0891)\end{array}$ & $\begin{array}{l}0.598^{* * * *} \\
(0.0882)\end{array}$ \\
\hline LV & $\begin{array}{l}-0.0823 * * \\
(0.0340)\end{array}$ & & & \\
\hline L.LV & $\begin{array}{l}-0.152 * * * \\
(0.0323)\end{array}$ & & & \\
\hline L2.LV & $\begin{array}{l}-0.118^{* * *} \\
(0.0321)\end{array}$ & & & \\
\hline L3.LV & $\begin{array}{l}-0.103^{* * *} \\
(0.0318)\end{array}$ & & & \\
\hline Diwan & & $\begin{array}{l}-0.105^{* * *} \\
(0.0312)\end{array}$ & & \\
\hline L.Diwan & & $\begin{array}{l}-0.0703 * * \\
(0.0283)\end{array}$ & & \\
\hline L2.Diwan & & $\begin{array}{l}-0.0188 \\
(0.0279)\end{array}$ & & \\
\hline L3.Diwan & & $\begin{array}{l}0.00399 \\
(0.0272)\end{array}$ & & \\
\hline CRISIS2 & & & $\begin{array}{l}-0.150^{* * * *} \\
(0.0394)\end{array}$ & \\
\hline L.CRISIS2 & & & $\begin{array}{l}-0.0468 \\
(0.0363)\end{array}$ & \\
\hline L2.CRISIS2 & & & $\begin{array}{l}0.0202 \\
(0.0373)\end{array}$ & \\
\hline L3.CRISIS2 & & & $\begin{array}{l}0.0165 \\
(0.0347)\end{array}$ & \\
\hline CRISIS3 & & & & $\begin{array}{l}-0.0962 * * * \\
(0.0291)\end{array}$ \\
\hline L.CRISIS3 & & & & $\begin{array}{l}-0.0813^{* * *} \\
(0.0277)\end{array}$ \\
\hline L2.CRISIS3 & & & & $\begin{array}{l}-0.0116 \\
(0.0266)\end{array}$ \\
\hline L3.CRISIS3 & & & & $\begin{array}{l}-0.00294 \\
(0.0254)\end{array}$ \\
\hline $\mathrm{N}$ & 785 & 632 & 586 & 586 \\
\hline Sargan & 20.68 & 13.77 & 21.10 & 21.31 \\
\hline Sargan p-value & 0.191 & 0.616 & 0.134 & 0.127 \\
\hline
\end{tabular}

Note: Standard errors are in parentheses, ${ }^{*} p<0.10, * * p<0.05, * * * p<0.01$. Equation (1) is estimated using each crisis dummy (see Table 1). L (p) represents lag p of a variable. The estimation method is Arellano and Bond (1991) with country specific time trends.RWC is real wage per person deflated by CPI. 66 countries during 19902010 are included. 
Table 3.6- Real Product Wages after Currency Crises

\begin{tabular}{|c|c|c|c|c|}
\hline $\begin{array}{l}\text { Model } \\
\text { Dependent Variable }\end{array}$ & $\begin{array}{c}(1) \\
\log (\mathrm{RWG})\end{array}$ & $\begin{array}{c}(2) \\
\log (\mathrm{RWG})\end{array}$ & $\begin{array}{c}(3) \\
\log (\mathrm{RWG})\end{array}$ & $\begin{array}{c}(4) \\
\log (\mathrm{RWG}\end{array}$ \\
\hline L.log(RWG) & $\begin{array}{l}0.348^{* * * *} \\
(0.0703)\end{array}$ & $\begin{array}{l}0.373^{* * *} \\
(0.0761)\end{array}$ & $\begin{array}{l}0.394^{* * * *} \\
(0.0737)\end{array}$ & $\begin{array}{l}0.402 * * * \\
(0.0735)\end{array}$ \\
\hline LV & $\begin{array}{l}-0.0949 * * * \\
(0.0331)\end{array}$ & & & \\
\hline L.LV & $\begin{array}{l}-0.137^{* * *} \\
(0.0315)\end{array}$ & & & \\
\hline L2.LV & $\begin{array}{l}-0.130^{* * * *} \\
(0.0311)\end{array}$ & & & \\
\hline L3.LV & $\begin{array}{l}-0.110^{* * * *} \\
(0.0310)\end{array}$ & & & \\
\hline Diwan & & $\begin{array}{l}-0.122^{* * * *} \\
(0.0305)\end{array}$ & & \\
\hline L. Diwan & & $\begin{array}{l}-0.0428 \\
(0.0282)\end{array}$ & & \\
\hline L2.Diwan & & $\begin{array}{l}-0.0176 \\
(0.0270)\end{array}$ & & \\
\hline L3.Diwan & & $\begin{array}{l}0.0152 \\
(0.0265)\end{array}$ & & \\
\hline CRISIS2 & & & $\begin{array}{l}-0.186 * * * \\
(0.0366)\end{array}$ & \\
\hline L.CRISIS2 & & & $\begin{array}{l}-0.0409 \\
(0.0339)\end{array}$ & \\
\hline L2.CRISIS2 & & & $\begin{array}{l}0.00662 \\
(0.0339)\end{array}$ & \\
\hline L3.CRISIS2 & & & $\begin{array}{l}0.0382 \\
(0.0320)\end{array}$ & \\
\hline CRISIS3 & & & & $\begin{array}{l}-0.0845 * * * \\
(0.0272)\end{array}$ \\
\hline L.CRISIS3 & & & & $\begin{array}{l}-0.0789 * * * \\
(0.0258)\end{array}$ \\
\hline L2.CRISIS3 & & & & $\begin{array}{l}-0.00308 \\
(0.0248)\end{array}$ \\
\hline L3.CRISIS3 & & & & $\begin{array}{l}0.0227 \\
(0.0236)\end{array}$ \\
\hline $\mathrm{N}$ & 782 & 629 & 583 & 583 \\
\hline Sargan & 23.71 & 37.78 & 45.07 & 49.50 \\
\hline Sargan p-value & 0.0959 & 0.00162 & 0.0000746 & 0.0000145 \\
\hline
\end{tabular}

Note: Standard errors are in parentheses, ${ }^{*} p<0.10,{ }^{* *} p<0.05,{ }^{* * *} p<0.01$. Equation (1) is estimated using each crisis dummy (see Table 1). L (p) represents lag p of a variable. The estimation method is Arellano and Bond (1991) with country specific time trends.RWG is real wage per person deflated by GDP deflator. 66 countries during 1990-2010 are included. 
Figure 3.1- Response of Real Wages to a Currency Crisis (Fixed effect)

RWC

LV

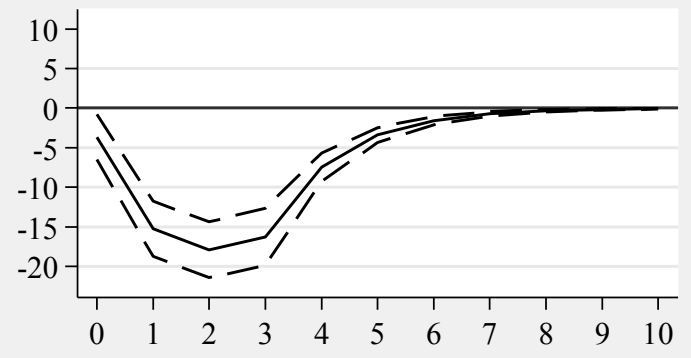

Diwan

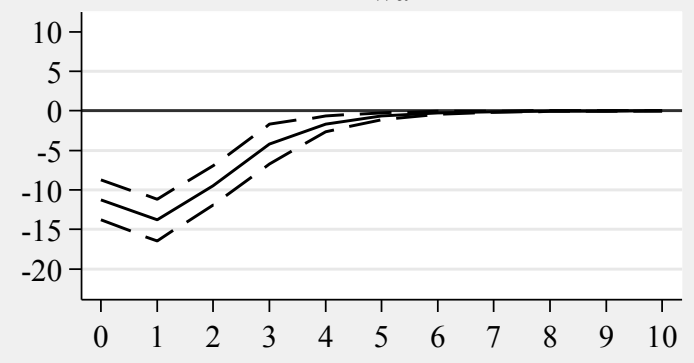

CRISIS2

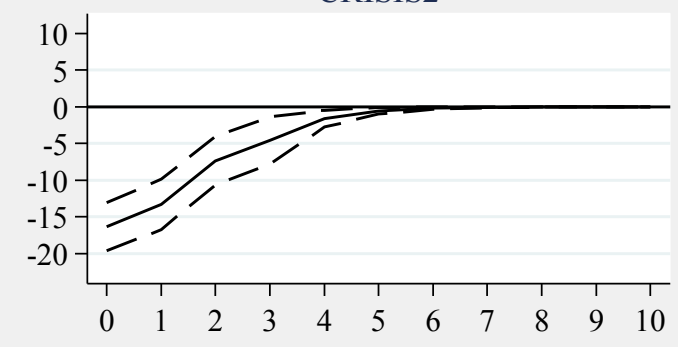

CRISIS3

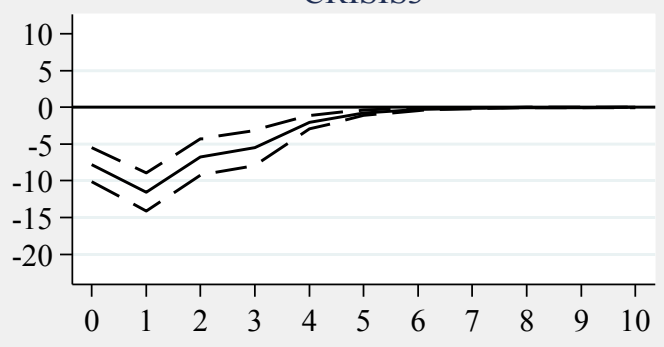

RWG

LV

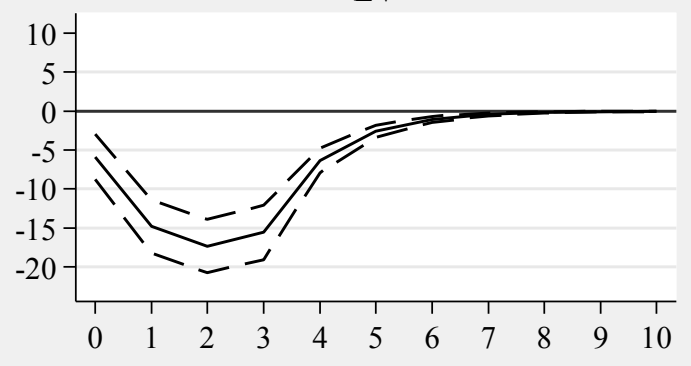

Diwan

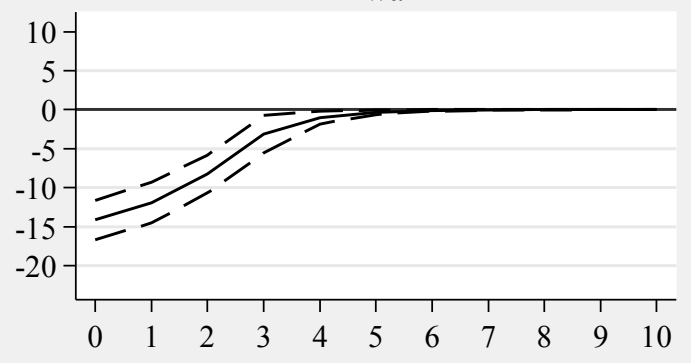

CRISIS2

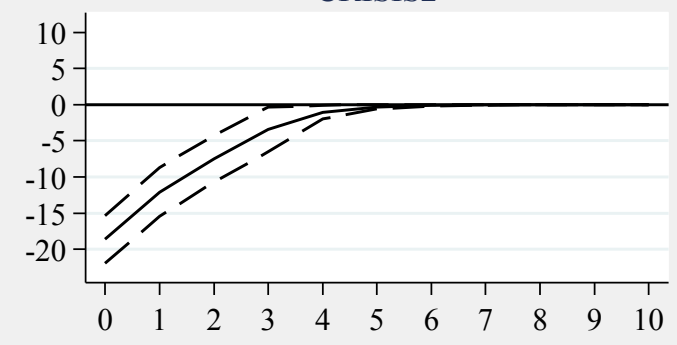

CRISIS3

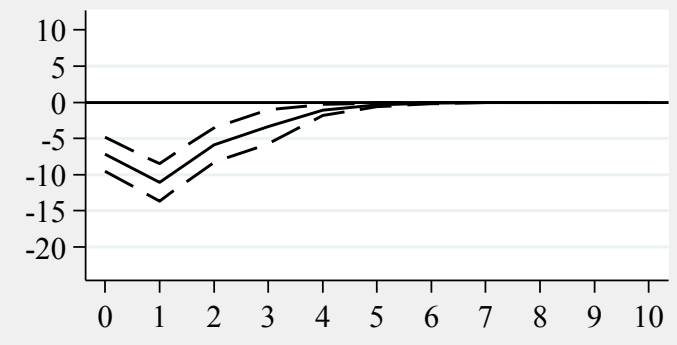

Note: The horizontal axes indicate time in years. The vertical axes measure responses in percentages. The left panels show impulse responses of real wage per person employed deflated by CPI (RWC) and the right panels show impulse responses of real wage per person employed deflated by GDP deflator (RWG). The estimation method is panel fixed effect with country specific time trends. The dotted lines represent one standard error bands based on 1000 Monte Carlo simulations. . The sample includes 66 countries during the 1990-2010 period. 
Figure 3.2- Response of Real Wages to a Currency Crisis (Arellano \& Bond)

RWC

LV

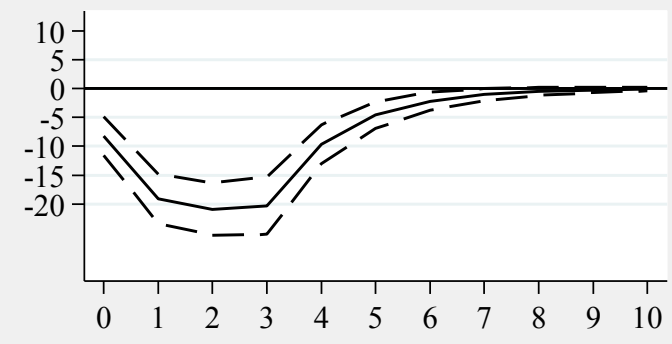

Diwan

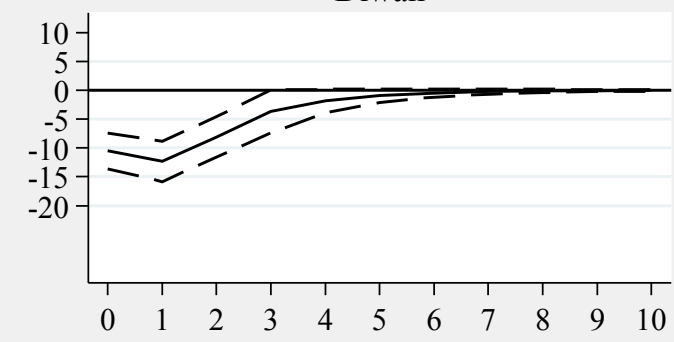

CRISIS2

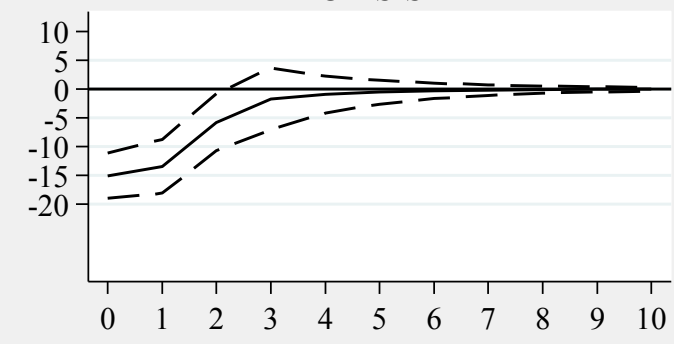

CRISIS3

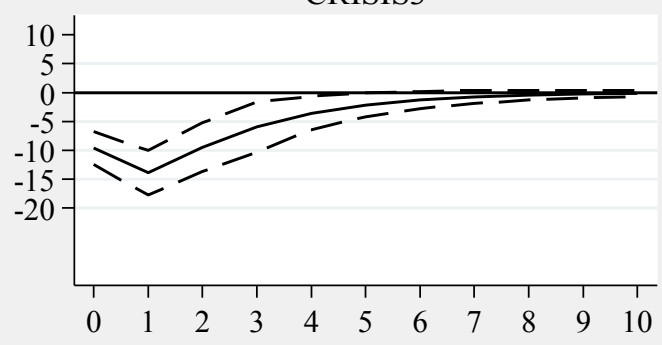

RWG

LV

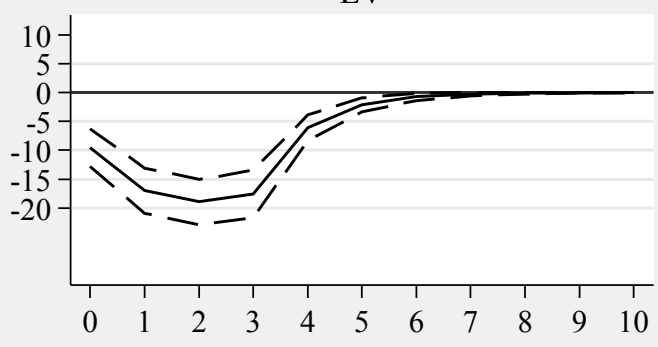

Diwan

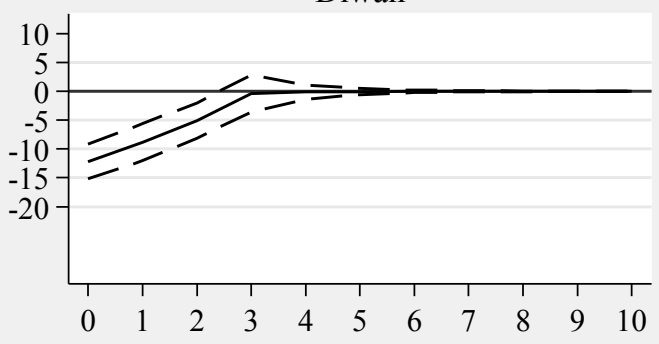

CRISIS2

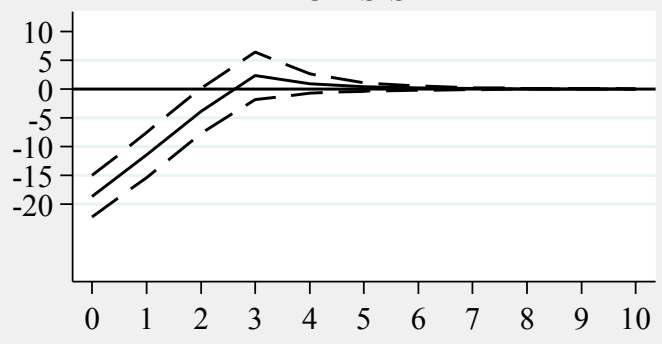

CRISIS3

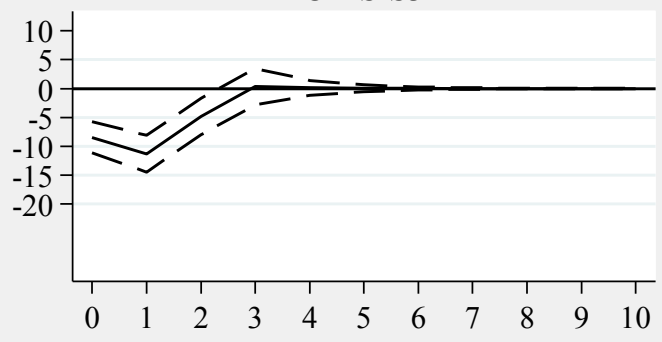

Note: The horizontal axes indicate time in years. The vertical axes measure responses in percentages. The left panels show impulse responses of real wage per person employed deflated by CPI (RWC) and the right panels show impulse responses of real wage per person employed deflated by GDP deflator (RWG). The estimation method is Arellano and Bond GMM with country specific time trends. The dotted lines represent one standard error bands based on 1000 Monte Carlo simulations. The sample includes 66 countries during the 1990-2010 period. 


\section{Figure 3.3- Real Wage per Hour Response to a Currency Crisis}

RWC per hour

LV

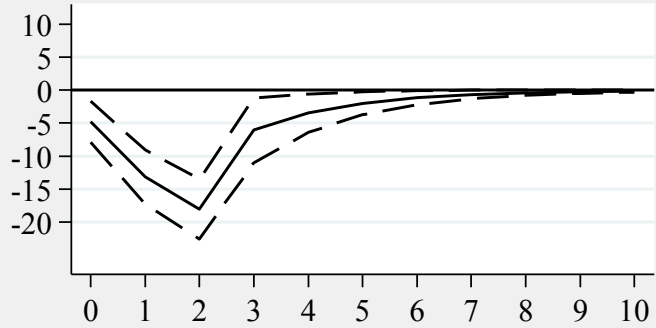

Diwan

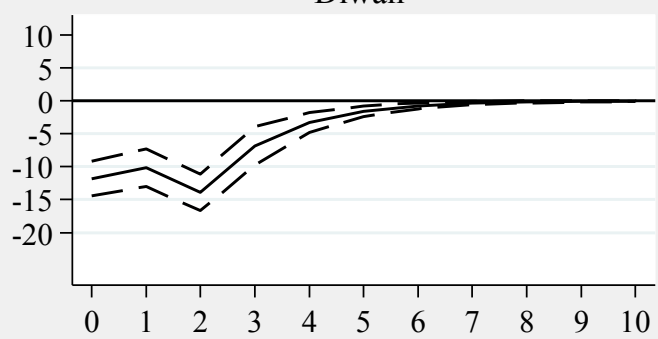

CRISIS2

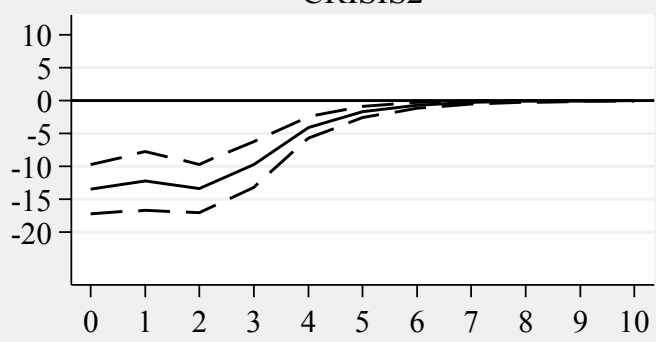

CRISIS3

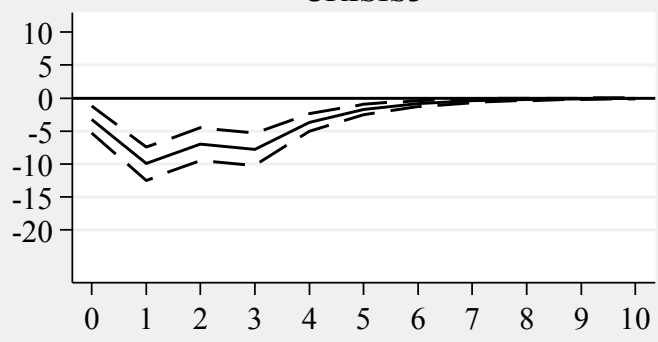

RWG per hour

LV

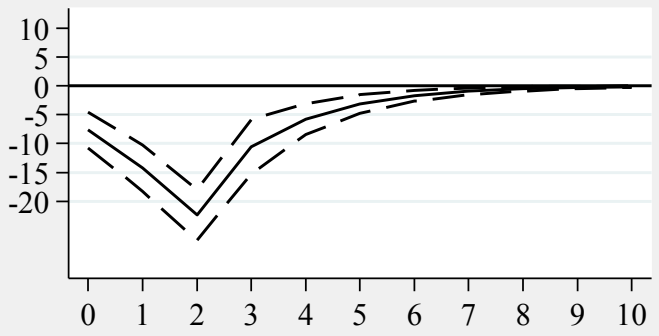

Diwan

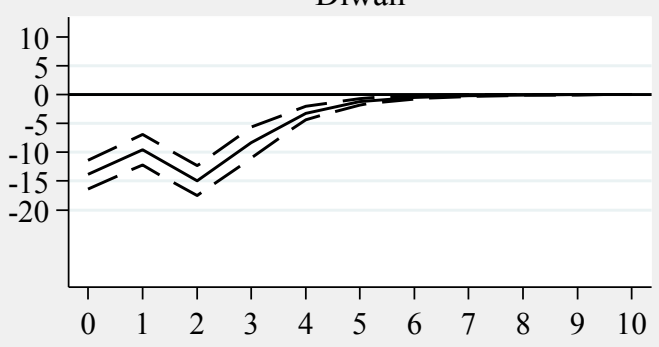

CRISIS2

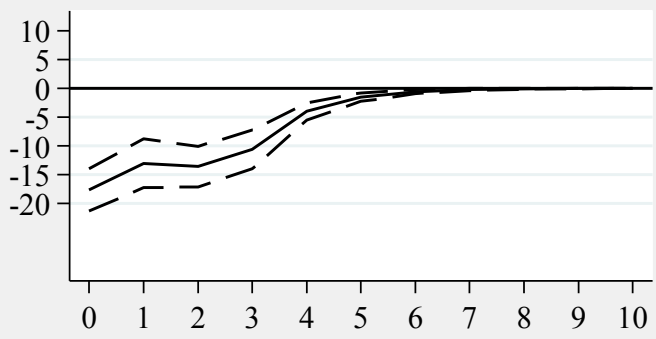

CRISIS3

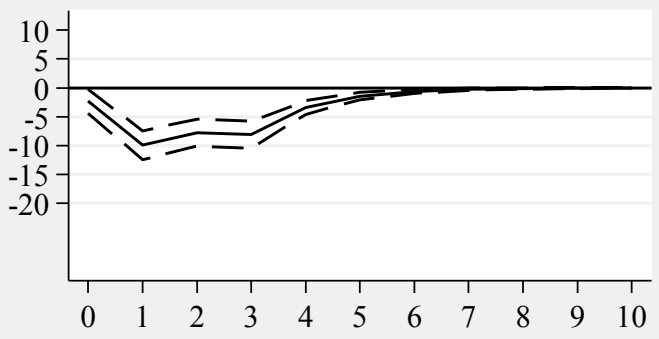

Note: The horizontal axes indicate time in years. The vertical axes measure responses in percentages. The left panels show impulse responses of real wage per hour deflated by CPI and the right panels show impulse responses of real wage per hour deflated by GDP deflator. The estimation method is fixed effect with country specific time trends. The dotted lines represent one standard error bands based on 1000 Monte Carlo simulations. The sample includes 33 countries during the 1990-2010 period. 


\section{Figure 3.4- Employment Response to a Currency Crisis}

Fixed effect

LV

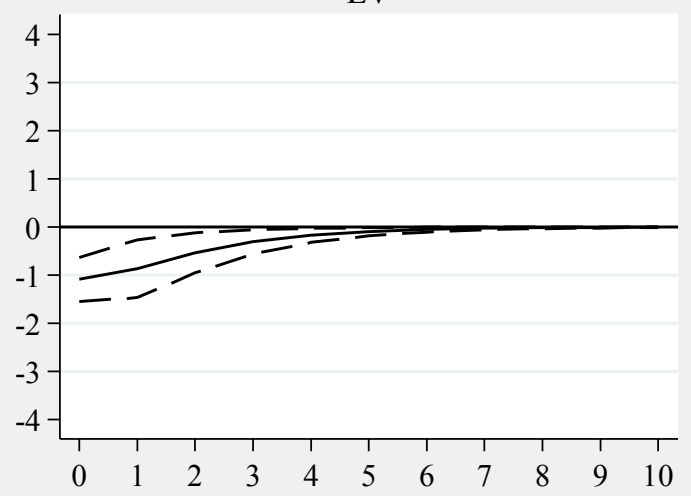

Diwan

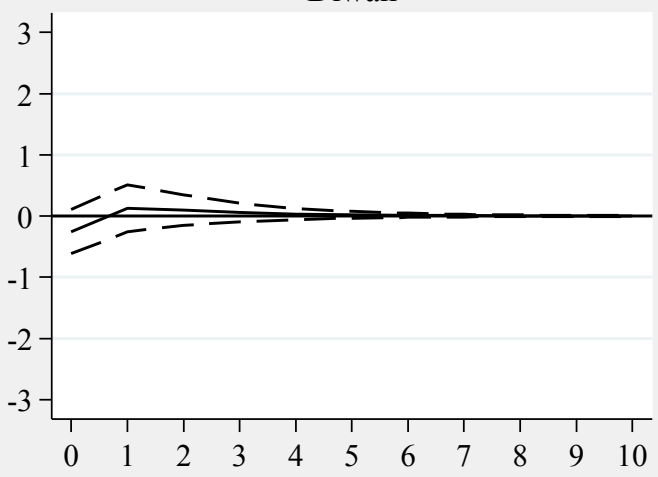

CRISIS2

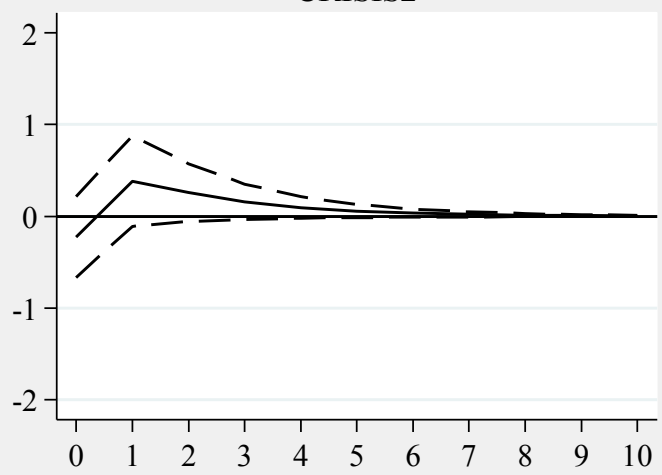

\section{Arellano and Bond}

LV

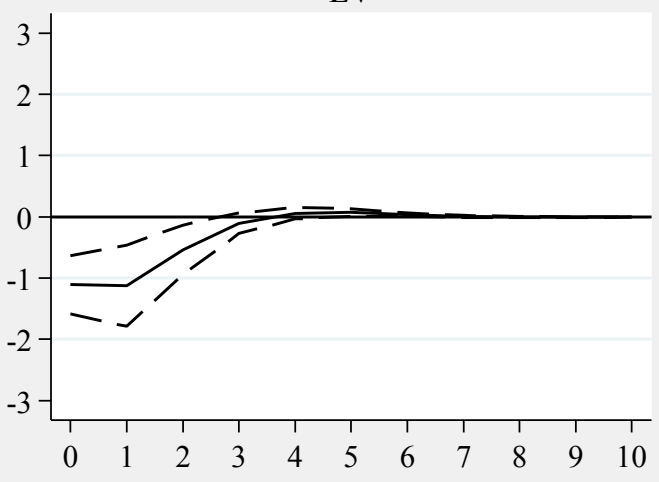

Diwan

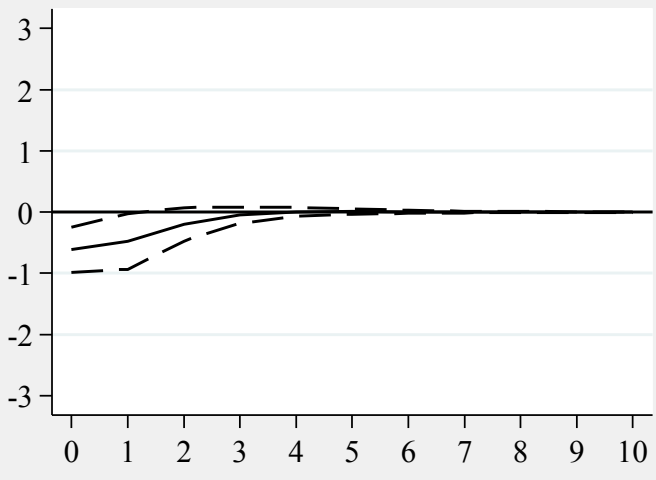

CRISIS2

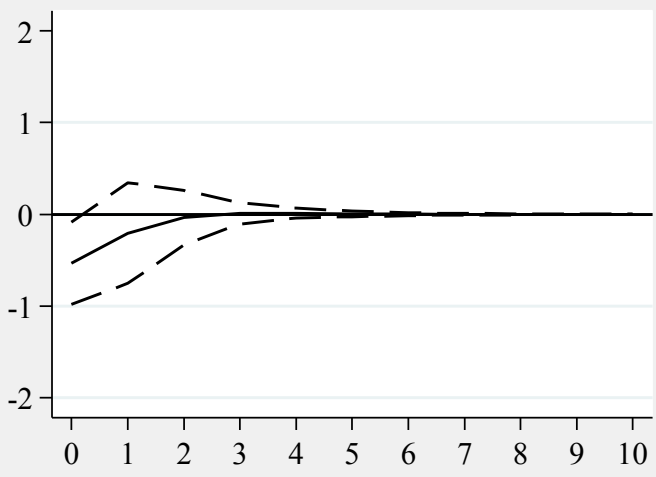

Note: The horizontal axes indicate time in years. The vertical axes measure responses in percentages. The left panels show impulse responses of employment with fixed effect estimation and country specific trends and the right panels show impulse responses of employment using Arellano and Bond GMM with country specific time trends. The dotted lines represent one standard error bands based on 1000 Monte Carlo simulations. . The sample includes 66 countries during the 1990-2010 period. 


\section{5- Labor Productivity Response to a Currency Crisis}

Fixed effect

LV

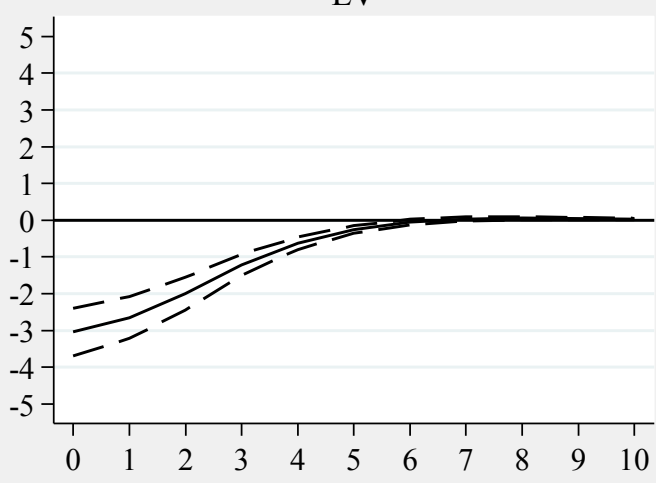

Diwan

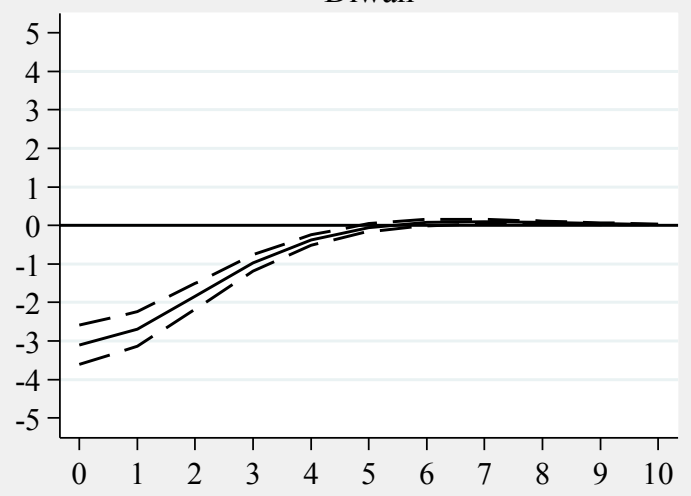

CRISIS2

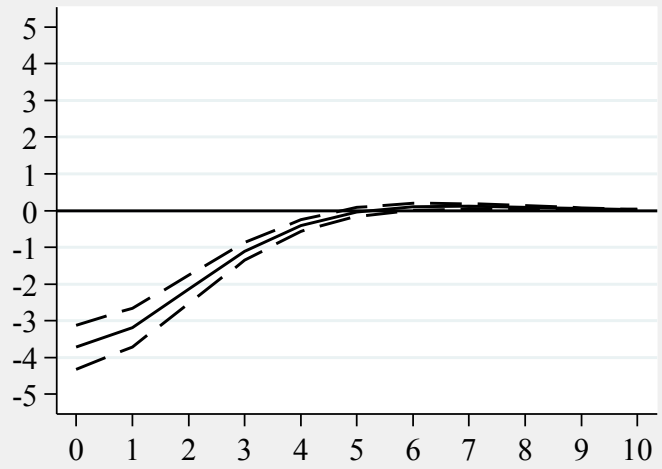

Arellano and Bond

LV

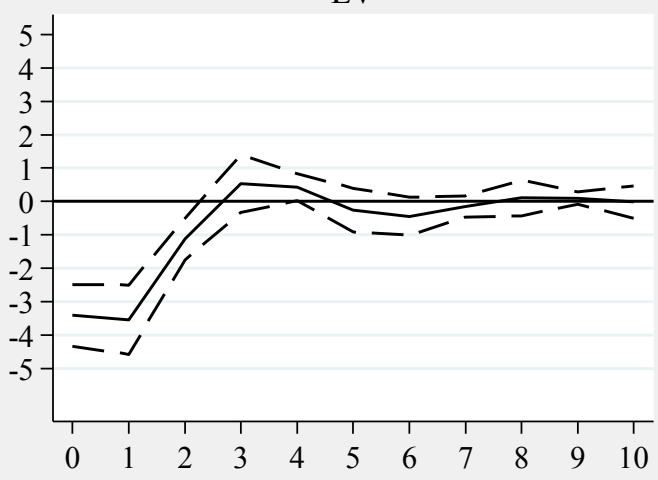

Diwan

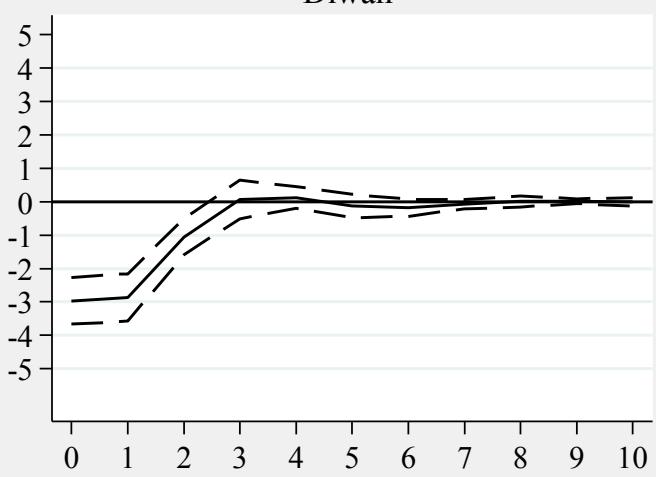

CRISIS2

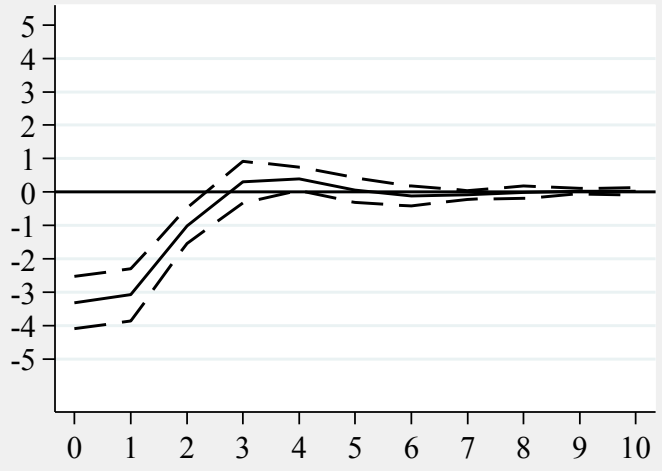

Note: The horizontal axes indicate time in years. The vertical axes measure responses in percentages. The left panels show impulse responses of labor productivity $(\mathrm{Y} / \mathrm{L})$ with fixed effect estimation and country specific trends and the right panels show impulse responses of labor productivity using Arellano and Bond GMM with country specific time trends. The dotted lines represent one standard error bands based on 1000 Monte Carlo simulations. . The sample includes 66 countries during the 1990-2010 period. 


\section{CHPATER 4. SHAPE OF GROWTH RECOVERY FOLLOWING CURRENCY CRISES}

\subsection{Introduction}

In the growth literature it is well-established that output behavior is asymmetric during expansions and recessions. Hamilton (1989) is the first to model this asymmetry using nonlinear approaches such as Markov-Switching model. In his model, mean of GDP growth depends on the state of the economy which is endogenously estimated. The empirical evidence based on his model documents a relatively large output loss for the post war United States. However, follow up research revealed that the estimates based on Hamilton's model may be large as it does not allow for output growth rate in recovery phase to be higher than average growth rate in expansion years. To account for high growth recovery phase, Sichel (1994) considers three states of recession, recovery, and expansion for an economy. Beaudry and Koop (1993) instead allow for a "bounce-back" term which is related to the depth of recession. The bounce-back term in their model is positive and significant indicating deep recessions are followed by faster recoveries.

More recently, Kim et al. (2005) introduced another approach in modeling the output behavior following recessions. They simply augment Hamilton's model with a bounce back function which is proportional to the length or strength of a recession. The "bounce-back" functions correspond to "U-" or "V-" shaped recessions and nonlinear recoveries based on “depth" of a recession. Bec et al. (2011) build their model based on Kim et al. (2005), but allow

for a bounce-back effect to boost growth a few quarters after the trough of a recession (long Ushape). 
Despite the abundance of research modeling the behavior of output growth following recessions, the research examining the behavior of output growth following financial crisis, currency crisis in particular, is limited.

On the theoretical ground the shape of output growth recovery following currency crises is ambiguous. On one hand, first and second generation models (Krugman and Tyler (1978), Obstfeld (1994)) of currency crises predict a temporary drop in the level of output and therefore a "U- or "V-shaped" GDP growth recovery. On the other hand, third generation models of currency crises (Aghion, Bacchetta and Banerjee (2001), Chang and Velasco (2001)) imply a long-term drop in the level of output and therefore a "V- or "U- or "L-shaped" recovery of output growth. Given the theoretical ambiguity, the shape of output growth recovery following a currency crisis is ultimately an empirical question.

Empirical literature on the issue is divided into panel and "event-studies". Cerra and Saxena (2008), Bussiere et al. (2010), and Furceri and Mourougane (2009) estimate the loss in the level of output following financial crises in a panel setting. However, these panel studies do not address the shape of output growth recovery. In addition, they ignore the possibility of high growth recovery phase after financial crises in their models and thus may have over-estimated the output loss.

Alternatively, event-studies examine the shape of output growth recovery but use a univariate approach. Park and Lee (2001) focus on output growth and report a V-shaped recovery ${ }^{24}$. Radelet and Sachs (1998) relate the shape of growth recovery to the cause of a crisis. They argue that currency crises triggered by insolvency take longer to recover compared to the crises triggered by illiquidity. Using a univariate approach, Tornell and Hong (2005) empirically

24 The recovery in just growth rates still can result in permanent loss in the level. 
test and confirm Radelet and Sachs (1998) hypothesis. In fact, they find that illiquidity triggered crises are V-shaped, whereas insolvency triggered crises are U-shaped.

The contribution of this paper is to use a multivariate approach and a panel setting to investigate the shape of growth recovery empirically. Our dataset consists of 159 countries over the period 1970-2005.

We follow the approach proposed by Kim et al. (2005) and estimate "U-shape", "Vshape" and "L-shape" models of growth recovery in the context of currency crises. Kim et al. (2005) use a Markov switching approach to model the shape of post-recession recovery and estimate the timing of a recession endogenously. However, we take on a more deterministic approach and use our exogenous currency crises dates. Thereafter, based on the information criteria we allow the data to select the appropriate model. The model allows us to test for the significance of 'bounce-back' term and re-evaluate the output losses following currency crises.

We find that the bounce-back term related to the length of crises is positive and statistically significant. In particular, after a drop of 2.3 percentage points in the growth rate following a currency crash, there is a bounce-back of 0.7 percentage point in output growth which is scaled by the length of each crisis. Furthermore, the model selection criteria select a "Ushaped" recovery over a "V-" or "L-" shaped or the model proposed by Cerra and Saxena (2008). The sub-sample analysis confirms our results; recovery shape is a variety of a U-shaped model in different regions and income groups. This result is in contrast with some event sudies which report a $\mathrm{V}$-shaped growth recovery.

In addition, we distinguish between the two forms of currency crises; currency crashes and reserve crises. ${ }^{25}$ We find that while reserve crises are initially less costly, they entail a larger

\footnotetext{
${ }^{25}$ Aziz et al. (2001) is the first to make this distinction. They use an 'event-study' approach to explore the development of macroeconomic variables during currency crashes and reserve crises.
} 
cost in the subsequent years. Therefore, the recovery resembles a long $U$ after such events. Furthermore, there is no 'bounce-back' in growth rates following reserve crises. In fact, there is a drag term that dampens output growth. This implies that defending a currency is a costly strategy that should be done with caution.

Moreover, we explore the factors affecting the pace of recovery following currency crises. The previous literature (Hong and Tornell (2005), Gupta et al.(2007) Park and Lee (2001)) addresses the issue only in a cross-sectional framework. Therefore, by compiling all crises observations across countries and running a cross-sectional regression of growth, these studies fail to account for the unobserved country-specific factors that affect the growth rates across countries. In addition, they do not make use of all the available data on the historical behavior of output growth in each country.

Our methodology enables us to use a panel framework and therefore, use the full range of data and control for the country-specific and time-specific factors in our growth regression. ${ }^{26} \mathrm{We}$ find that pre-crisis short term debt relative to total external debt and the pre-crisis share of exports in GDP are the best predictors of post-crisis recovery.

The paper is organized as follows: in Section II we describe the data and the empirical models used in the analysis. In Section III we examine the shape of recovery following currency crashes and reserve losses across the entire panel. In Section IV we divide the sample into different income groups and regions and explore the shape of recovery in each sub-sample. In Section V we investigate the macroeconomic factors which influence the post-crisis growth rate. We conclude in Section V.

\footnotetext{
${ }^{26}$ Out of the 159 countries, 41 countries never experienced any currency crisis (by Laeven and Valencia (2008) criteria)) thereby forming our 'control group'.
} 


\subsection{Data Description and Empirical Model}

\subsubsection{Data:}

We obtain macroeconomic data for 159 countries between 1970-2005 from World Bank`s World Development Indicators. The variables are real GDP growth in constant 2000 US dollars, short-term debt ( $\%$ of total external debt), broad money to total reserves ratio, export (\% of GDP), total private capital inflows ( $\%$ of GDP), domestic credit to private sector (\% of GDP), total reserves minus gold (current US\$), and official exchange rate (LCU per US\$, period average).

The currency crises dates are obtained from Laeven and Valencia (2008). They identify currency crises based on Frankel and Rose (1996) approach defined as:"a nominal depreciation of at least 30 percent that is at least 10 percent increase in the rate of depreciation compared to the year before". ${ }^{27}$ Moreover, if countries meet the criteria for several continuous years, only the first year of each 5-year window is used to identify the crisis. Their definition yields 209 currency crises during the period 1970-2005 as shown in Table 1. The dummy corresponding to Laeven and Valencia (2008) identification scheme is labeled LV. We also define another dummy labeled EVENT which is constructed the same way as LV, but no window is imposed around each crisis. Therefore, if countries meet the criteria for several continuous years, the EVENT dummy identify all these years as crises years (291 episodes). The reason we construct this dummy is that the serial correlation of crises is important in distinguishing a U-shaped and Vshaped recoveries from one another.

Moreover, we form another dummy variable labeled DIWAN. This dummy is based on Diwan (2001) and defines a financial crisis broadly as 30 percent or more depreciation in

\footnotetext{
${ }^{27}$ They use the percent change of end-of-period official nominal bilateral dollar exchange rate.
} 
nominal exchange rate during a calendar year. Similar to EVENT dummy, DIWAN captures the serial correlation of crises. However, DIWAN captures all episodes of hyperinflation which are excluded in the EVENT dummy by the second crisis-identification condition.

For robustness analysis, we employ another identification scheme used in the literature which also incorporates reserve losses in the definition of currency crises. Cerra and Saxena (2008), construct an Exchange Market Pressure Index (EMP) which is based on the percentage depreciation in nominal exchange rate plus the percentage loss in foreign exchange reserves. The dummy CS is formed based on Cerra and Saxena (2008) and is equal to one any time EMPI is in the upper quartile of all observations across the panel. The dummy is equal to zero otherwise. The criteria yield 1099 episodes of crises over the 1970-2005 period (Table 1).

Unlike LV, EVENT, and DIWAN dummies, CS dummy captures the currency crises featured by currency crashes and those featured by large reserve losses (reserve crises). Since the shape of recovery might be influenced by the type of a currency crisis, we follow Aziz et al. (2001) and distinguish between the two by constructing four more currency crises dummies.

CRISIS dummy is constructed to capture the currency crises characterized by a crash in the value of a domestic currency. If the currency component of EMPI accounts for 50 percent of the index when the index signals a crisis, CRISIS dummy is equal to one. Otherwise it is zero. ${ }^{28}$ CRISISE dummy is constructed the same way only that the currency component of EMPI must account for at least 75 percent of the index. Therefore, CRISISE compared to CRISIS dummy is more likely to capture larger depreciation episodes.

To capture reserve crises episodes, we construct CRISISR dummy. The dummy captures the episodes where the reserves component of EMPI accounts for 50 percent of the index when

\footnotetext{
${ }^{28}$ It is possible that EMPI signal a crisis in case of a moderate depreciation and a small reserve loss. In this case, CRISIS dummy is equal to one even though the depreciation is moderate.
} 
the index signals a crisis. On the other hand, CRISISRE captures extreme episodes of reserves losses. The dummy is constructed the same way only that the reserves component of EMPI must account for at least 75 percent of the index.

\subsubsection{Empirical Model:}

We follow Kim et al. (2005) and Bec et al. (2011) and estimate different 'bounce-back' models of growth within a panel data framework: $\quad \Phi(\mathrm{L})\left(\Delta \mathrm{y}_{\mathrm{it}}-\mu_{\mathrm{it}}\right)=\varepsilon_{\mathrm{it}}$ Where:

(1) Hamilton Model : "L” Shaped Crisis (L) :

$$
\mu_{i t}=\alpha_{i}+\theta_{t}+\gamma_{1} D_{i t}
$$

(2) “U” Shaped Crisis (BBU):

$$
\mu_{i t}=\alpha_{i}+\theta_{t}+\gamma_{1} D_{i t}+\lambda \sum_{j=1}^{m} D_{i, t-j}
$$

(3) Long "U" Shaped Crisis (LBBU):

$$
\mu_{i t}=\alpha_{i}+\theta_{t}+\gamma_{1} D_{i t}+\lambda \sum_{j=1+1}^{m+1} D_{i, t-j}
$$

(4) "V" Shaped Crisis (BBV):

$$
\mu_{i t}=\alpha_{i}+\theta_{t}+\gamma_{1} D_{i t}+\left(1-D_{i t}\right) \lambda \sum_{j=1}^{m} D_{t-j}
$$

Where $\Delta \mathrm{y}_{\mathrm{i}}$ is the growth rate of real GDP in country $i, \Phi(\mathrm{L})$ is a lag polynomial of order $p$ with roots lying outside the unit circle, $\mathrm{D}_{i}$ is the currency crisis dummy for country $i$, $\alpha_{i}$ is the country fixed effects, and $\theta_{\mathrm{t}}$ is the common global shocks. The $\mathrm{m}$ and $\lambda$ parameters represent the duration and magnitude of the bounce-back effect, respectively. A positive and 
statistically significant $\lambda$ implies that the growth rate of GDP is in fact higher than its non-crisis average in post-crisis recovery phase.

The BBV function of model (4) is different from other bounce-back (BB) functions in

that, due to the $\left(1-\mathrm{D}_{\mathrm{it}}\right)$ term, the bounce-back term kicks in only when the crisis is over and $\mathrm{D}_{\mathrm{it}}$ is zero. The LBBU function, model (3), is identical to the BBU function only that in LBBU the bounce-back term becomes active with a lag following the start of a crisis. We consider $l=\{2,3\}$ corresponding to model (3a) and (3b) respectively, so that the high growth recovery phase starts two or three years after the beginning of a currency crisis.

Kim et el. (2005) and Bec et al. (2011) use these nonlinear models in the context of business cycles modeling and with a Markov switching approach. In this paper, we follow a more deterministic approach based on our currency crises dates and estimate each of these models using a panel two way fixed effect method.

Moreover, we compare each of the above models with Cerra and Saxena (2008) model:

$$
\mu_{i t}=\alpha_{i}+\theta_{t}+\sum_{j=1}^{4} D_{i, t-j}
$$

To be consistent with Cerra and Saxena (2008) model, we choose L=4 (autoregressive lags) and $\mathrm{m}=4$ (duration of bounce-back term). This $(\mathrm{m}=4)$ means that we allow for the bounceback term to generate a higher growth than pre-crisis trend for four years. Thereafter, following Morley and Piger (2009) we select the appropriate model using various information criteria.

\subsection{Shape of Recovery after Currency Crises}

In this section, we estimate equation (1) through (5) using LV dummy and report the Akaike (AIC) and Schwarz (SIC) information criterion corresponding to each model in Table 2. The information criteria are reported such that the lower values represent the preferred model. 
Table 2 shows that a long U-shaped recovery is the model selected by the data. The bounceback effect in the selected model is positive, significant and becomes active two years after the beginning of a crisis. Therefore, the results suggest that growth rate in the recovery phase is in fact higher than non-crisis growth rate. This suggests that Cerra and Saxena (2008) overestimated output loss following currency crises. Moreover, Table 2 indicates that distinguishing between the U- and V-shaped recoveries is impossible once the serial correlation of crises is ignored. For this reason, we re-estimate each model using the EVENT dummy which is similar to LV only that it accounts for the serial correlation of crises.

Table 3, presents the estimation results for each model when currency crises episodes are identified by the EVENT dummy. To control for fixed country-specific effects and common global shocks, each model is estimated using a panel two way fixed effects method. Estimation results indicate a decline of 2.3 percentage points in growth rate during a crisis. The bounce-back term in all specifications is positive and significant. The bounce-back can be the result of a boom in net export following a large depreciation. The SIC information criteria favors model (2) over the other models. However, the AIC selects Cerra and Saxena (2008) model. This is because the AIC imposes smaller penalty on the extra parameters. The bounce-back term implies that a year after a crisis, the average growth rate gets a boost of about 0.7 percentage point which is scaled by the duration of each crisis.

For further robustness check, we re-estimate the models with Diwan (2001) dummy and report the results in Table 4. The DIWAN dummy is similar to EVENT in that it takes the serial correlation of crises into account. However, unlike EVENT, it considers all the hyperinflation episodes as individual crises. The information criteria indicate that the U-shaped recovery is again the preferred model. Bounce-back effect is positive and significant in all specifications and in the selected model it is about 0.63 percentage point. This means that the first year after a 
crisis, output growth gets an extra boost of about 0.63 percentage point and as the crisis persists the boost increases proportionally.

Overall, these results suggest growth recovery from currency crises featured by large exchange rate depreciations is U-shaped. The positive and significant bounce-back term suggests that in the post-currency crises recovery phase, output growth is higher than the non-crisis average growth. Therefore, output losses are not as large as estimated by Cerra and Saxena (2008).

In currency crises literature, it is also common to characterize crises by not only large depreciation but also large foreign reserves losses. For this reason, we use the CS dummy which includes both reserves losses and large depreciations episodes, and re-estimate each of the models. Table 5 shows that the results are different from the previous results in two main ways. First, the initial decline of output growth is lower. Second, the bounce-back term, although still significant, is much smaller or even negative. The information criteria select model (3b), a long U-shaped recovery over the other models. The bounce-back effect is 0.17 percentage point which is significant at ten percent level. The initial drop in output growth is about one percentage point. The long U-shaped model implies that the extra boost in output growth rate does not kick in until three years after the start of a crisis. The extra boost is proportional to the duration of each crisis and by construction lasts for four years.

Next, we separate the currency crashes episodes and reserves crises episodes to further compare the shape of recovery after these events. Table 6 and Table 7 report the estimation results for each model using CRISIS and CRISISR dummies, respectively. The results indicate that the initial loss is lower in currency crises associated with reserve losses. However, the estimated parameters from model (5) suggest that output losses materialize in the next few years 
following these events. Alternatively, in the next few years following currency crashes, there is not a significant decline in output growth.

Moreover, following Cerra and Saxena (2008), we use the parameter estimates of model (5) in Table 6 and Table 7 to calculate the cumulative impulse responses for output. For brevity the results are not reported, however we find that the loss in the level of output is on average about four percent ten years following reserve losses. The output loss is 0.34 percent ten years after currency crashes.

The bounce-back effect following currency crashes is positive and significant in all specifications. Conversely, there is no bounce-back after reserve losses. In fact, there is a drag effect which is statistically significant in most specifications. Information criteria select a long U-shaped model as the preferred model for both characterizations of currency crises.

In Table 8 and Table 9 we repeat our analysis using CRISISRE and CRISISE. The CRISISE (CRISISRE) dummy is constructed such that it picks up higher depreciation episodes (reserve losses) as opposed to CRISIS (CRISISR) dummy. The estimation results further confirm our previous results. Moreover, the cumulative impulse functions based on estimation of model (5) with CRISISE and CRISISRE dummies indicate that output losses are about 4.22 percent ten year after severe reserve losses, while it is still less than 0.5 percent for severe currency crashes. (Not reported).

The results indicate that defending a currency is costly and the cost materializes after a crisis. This is because defense requires central banks to intervene in the foreign exchange market through raising interest rates or selling foreign reserves. Both of these actions reduce the money supply and contract the economy. Central banks can engage in sterilization of their intervention and prevent the decrease in the money supply. However, doing so does not allow the domestic interest rate to increase. Therefore, the pressure on the exchange market is not eliminated and 
devaluation may still occur. Only non-sterilized interventions in the foreign exchange market can be potentially effective to avoid large devaluation.

Moreover, in some cases loosing reserves only postpones devaluation (unsuccessful defense). Bauer et al (2012) evaluate the costs associated with currency crashes, successful defenses and unsuccessful defense and find that unsuccessful defenses are the most costly. ${ }^{29}$ Our reserve crises identification scheme does not distinguish between successful and unsuccessful defenses. Therefore, our results on output cost of reserve crises can partly be due to that fact that some reserve crises were followed by large depreciations and therefore entailed more cost. To check for this, we exclude all reserve crises episodes that proceeded large devaluations by one or two years. The results (not reported) did not change; reserve crises not followed by a large devaluation (successful defenses) are still costly in the long-run.

Another explanation for observing output loss after reserve crises (defenses) is that many times to defend a currency, governments either directly borrowed from the IMF or managed to roll-over and restructure the short-term debt with the help of the IMF. In return, governments agreed to make some sort of structural reform or were forced to restructure their debt under unfavorable conditions. For example, as Kihwan (2006) discussion of the Korean crisis of 199798 points out; although the IMF agreed to bail the Korean government out, only $\$ 9.1$ billion out of $\$ 35$ billion was initially allowed to be withdrawn by the government. The rest of the bail out money was conditioned upon the success of Korean government to impose structural reforms and tight monetary and fiscal policies. This amount proved to be inadequate to restore investors' confidence as the foreign banks refused to roll-over short-term debt of the Korean government. Eventually, with the help of the United States, the government managed to persuade the foreign

\footnotetext{
${ }^{29}$ According to Bauer (2012), unsuccessful defenses are costly because after such events the growth rate slows down and inflation hikes. Successful defense only slows down growth and successful attack (currency crash) leads to higher inflation.
} 
lenders to roll-over the short-term debts. In return, the government promised to reach an agreement with the lenders to restructure the debt. In March 1998, 95 percent of the debt was restructured. However, the interest rate charged by foreign banks was extraordinarily high.

Overall, our results in contrast with the previous literature that estimates a V-shaped growth recovery, suggest that recovery after currency crises is a variety of a U-shaped model. The dynamics of the U-shaped recovery depends on the characterization of currency crises. Currency crises that are featured by reserve losses entail a smaller initial output loss. However, the long-run loss following such events is larger and the dynamics of growth recovery resembles a long U-shaped model. The loss can be because of the contractionary policies that are implanted to defend the currency or the structural reforms that are usually imposed on a country in return for the assistance it receives to defend its currency.

There is still one issue to consider when interpreting the output cost associated with reserve losses. If the output loss is due to a reduction in money supply, then one would expect this impact on output holds only in the short-run. Nevertheless, cumulative impulse functions estimating output losses after such events suggest that the contractionary impact remains even after ten years. This implies that the other factors are in work. For example, reserve defense may impact the velocity of money or worsen the credit constraints and impact output in the long-run.

Alternatively, currency crises characterized by large depreciations lead to a larger initial output loss but a lower long-run loss. The literature identifies many channels in which currency crises can lead to output contraction in the short-run. Some of these channels include: balance sheet deteriorations and bankruptcies, higher imports prices, and credit crunch. However, the competitive gains from depreciation can eventually help the economy to rebound in the longterm. The growth recovery is U-shaped in these cases. The bounce-back term is positive and statistically meaningful after currency crashes but not reserve crises. In fact following reserve 
crises, the growth rate is slower than its non-crisis average. These results imply that defending a currency against devaluation although initially seems like a better option, in the long-run it entails a larger output loss.

\subsection{Sub-Sample Analysis}

In this section, we disaggregate the data based on the World Bank classifications. First, we split the data into four income groups of high (per capita real GDP over 9,075 dollars), upper middle income (per capita real GDP between 2,936 and 9,075 dollars), lower middle income (per capita real GDP between 736 and 2,935 dollars), and low income (per capita real GDP less than 736 dollars). Second, we look at the four regions of Industrial countries, Asia, Latin America and transition economies. For each income group and region, we estimate models (1)-(5) using a panel two way fixed effects method. The dummy variable used in the estimation is EVENT. We report the estimation results for each model and each region in Table (10)-(13). Nonetheless, for different income groups we only report the information criteria corresponding to each estimated model. The control group in each regression is the same and consists of 55 countries that have never experienced a currency crisis characterized by EVENT during the 1970-2005 period.

The regional analyses reported in Table (10)-(13) indicate that the shape of recovery is again a variety of a U-shaped model. Table (10) indicates that the decline in GDP growth rate is on average 3.5 percentage points following currency crises in industrial countries. Moreover, information criteria select model (2), U-shaped recovery, as the preferred model. On the other hand, in Latin America, transition and Asian economies the average drop in growth rate is higher and about four to five percentage points. The information criteria report a mixed result for the shape of growth recovery in the other regions. Nevertheless, the shape is still a variety of a Ushaped model. For Latin American countries, while the AIC selects model (3a), SIC chooses 
model (2). The adjusted $\mathrm{R}^{2}$ is higher in model (3a). Similarly Table (12) indicates that in transition economies, the AIC picks model (3b) but SIC selects model (2). The adjusted $\mathrm{R}^{2}$ favors model (3b). In Asian economies AIC selects U-shaped model, however SIC picks Lshaped model of recovery. The adjusted $\mathrm{R}^{2}$ is higher in model (2). One reason for picking an Lshaped recovery in Asia can be because most countries experienced a simultaneous banking crisis.

Overall, the regional investigation of recovery dynamics confirms the results in the previous section. Therefore, following currency crises characterized by large depreciations, the recovery dynamics of output growth in different regions represents one of the varieties of a U-shaped model of recovery. Only in Asia, the growth recovery was an L-shaped.

The results in table (14)-(17) present the information criteria for each model and income group. Results show that the recovery is U-shaped in high income group. For upper middle income countries the recovery dynamics is more sluggish and resembles a long U-shaped model (model (3b)). For lower middle income group, SIC selects U-shaped model. However, AIC picks model (3a) as the preferred model. The adjusted $\mathrm{R}^{2}$ is higher in model (3a). In low income group, the AIC selects Cerra and Saxena (2008) model, However, SIC picks the L-shaped model of recovery (model (4)). Moreover, the adjusted $\mathrm{R}^{2}$, although quite low for all specifications, is higher for L-shaped model. The low adjusted $\mathrm{R}^{2}$ implies that in low income countries, crises account for a small part of output growth variations.

In sum, the results in this section further confirmed our previous results. Output growth recovery from currency crises is slow and more of a U-shaped. These results are in contrast with the previous literature which estimates a V-shaped recovery of growth rates following currency 
crises. Moreover, the U-shape recovery of growth rate can still imply a permanent drop in the level of GDP. Therefore, the results do not contradict the studies that estimate a permanent loss in the level of GDP after currency crises (Cerra and Saxena (2008), Bussiere et al. (2010) and Furceri and Mourougane (2009)). However, our results suggest that these studies may have overestimated the loss in output as they do not allow for a bounce-back in growth rate in the recovery phase.

\subsection{Determinant of Growth after Currency Crises}

This section explores the factors that determine the pace of recovery after currency crises characterized by Laeven and Valencia (2008) criteria. There are few studies in the previous literature addressing the post-crisis recovery. Park and Lee (2001) use the real GDP growth rate averaged over the post-crisis periods of $\mathrm{K}$ years as a measure of recovery pace and relate it to variety of contemporaneous macroeconomic variables. They found that higher world growth, lower initial real per capita GDP, and expansionary fiscal policy improve post-recovery growth. Gupta et al. (2007) use the deviation of output growth in the two post-crisis years from the average growth rate in the three pre-crisis years as their dependent variable and regress it on a set of pre-crisis macroeconomic variables. Their result suggest that high capital inflow before and increase in external debt during a crisis, lead to a slow recovery. Tornell and Hong (2005) argue that both Park and Lee (2001) and Gupta et al. (2007) results are subject to endogeneity bias. Therefore, they measure the pace of recovery as the deviation of post-crisis growth rate from the tranquil year's growth rate to reduce the endogeneity problem. Their results suggest that precrisis credit growth and reserve inadequacy aggravate the post-crisis recession.

While Hong and Tornell (2005) results are less prone to endogeneity problem, their analysis is limited to the crises times. Therefore, they do not make use of all the available data on 
the historical behavior of output growth in each country. Moreover, by compiling all crises observations across countries and running a cross-sectional regression of growth, they fail to account for the unobserved country-specific factors that affect the growth rates across countries. We overcome these short-comings in the previous literature by estimating equation (a) using our panel of 159 over the period 1970-2005: ${ }^{30}$

(a) $\Delta y_{i t}=\alpha_{i}+\theta_{t}+\beta \sum_{i=1}^{4} \Delta y_{i, t-j}+\gamma_{1} D_{i t}+\gamma_{2} D_{i, t-1}+\sigma \cdot D_{i, t-1} \cdot X_{i,(t-1-t-3)}$

Where $\Delta y_{i}$ is the growth rate of real GDP in country $i$ and $D_{i}$ is the currency crisis dummy characterized by Laeven and Valencia (2008) for country $i$. Previous literature relates the pace of recovery to: (i) pre-crisis conditions such as lending booms or the extent of currency mismatches, (ii) contemporaneous external condition such as the world's GDP growth rate, foreign interest rates, and (iii) policy factors.

Therefore, in our model vector $X$ represents a set of pre-crisis conditions which can potentially affect post-currency crises growth recovery. Since we are using a panel data framework, we control for the unobserved heterogeneity in the growth rates by including country- fixed effects, $\alpha_{i}$. The external shocks and global conditions are accounted for by timefixed effects, $\theta_{t}$. We do not include policy factors due to data limitations and the endogeneity problem. $^{31}$

We rely on the previous literature and use the following set of pre-crisis conditions which can potentially impact post-crisis recovery: pre-crisis investment rate and real credit growth

\footnotetext{
${ }^{30}$ Out of 159 countries, according to Laeven and Valencia (2008) criteria, 41 countries never experienced currency crises.

${ }^{31}$ The previous literature (Lee and Park (2001), Cerra and Saxena (2010)) do not find any significant impact of policy factors on post-crisis growth.
} 
(deflated by CPI) as measures of pre-crisis solvency or pre-crisis overheating of an economy ${ }^{32}$, short term foreign debt to total external debt ratio and reserves to broad money ratio to capture the extent of pre-crisis illiquidity ${ }^{33}$, and share of exports in GDP to measure the impact of trade openness on the recovery pace. Moreover, the impact of financial openness on post-crisis recovery is captured by the pre-crisis capital inflow. In order to estimate equation (a) and avoid endogeneity problems, we use the average of three pre-crisis years for these variables. For share of exports in GDP the lagged value is used.

We estimate equation (a) using panel two way fixed effects bivariately and then estimate the multivariate regression by using all possible combinations of variables. When the two variables measure the same factor, we only include one of them in the regression. For example, reserves-to-M2 ratio and short-term debt are both measures of illiquidity and therefore, we include only one of them in the regression at the same time.

The results are reported in Table (18). For brevity, we only include the multivariate results. Table (18) shows that the export share coefficient is positive and significant almost across all specifications. This implies that higher share of exports before a crisis which represents higher pre-crisis degree of openness is positively associated with output growth after a crisis. Alternatively, higher short-term debt ratio dampens output growth and delays the recovery. This result is in line with Rodrik and Velasco (1999) who build a theoretical model and show that the short-term foreign debt exposure increases both the likelihood and the severity of a financial crisis. Radelet and Sachs (1998) also find that higher short-term debt exposure is positively and statistically related to occurrence of currency crises. Moreover, they argue that the

\footnotetext{
${ }^{32}$ As mentioned in Hong and Tornell (2005): " As investment and credit expand at an abnormally high rate, the possibility of misinvestment or overinvestment increases, thereby gradually weakening the financial sector's balance sheet until the boom eventually turns into a bust."

${ }^{33}$ Aziz at al. argue that the reserves- to- M2 ratio represents the ability of an economy to withstand an attack on its total domestic liabilities without a sharp depreciation. Therefore, it also is an indicator of investors' confidence in the domestic financial system
} 
countries with higher foreign short-debt exposure experience larger depreciation as was the case for Korea and Indonesia in the Asian crises of $1997-1998 .{ }^{34}$ High investment rate, real domestic credit, private capital inflows, and reserves-to-M2 ratio are found to have no significant affect on post-crisis recovery.

\subsection{Conclusion}

The recovery of output growth from recessions is a well-studied subject in the growth literature. However, there are only few papers exploring recovery of output growth from currency crises. On the theoretical ground, the shape of growth recovery is not clear. On the other hand, the empirical literature suggests that while the recovery of growth rates is V-shaped, output level never recovers. However, these empirical studies are mainly 'event-study' analyses. Few multivariate studies of the issue fail to account for the possibility of high growth recovery phase. Alternatively, there are few papers exploring the factors that determine the pace of recovery. Nonetheless, these papers focus only on the currency episodes and use a crosssectional analysis. Therefore, they fail to make use of all available data and account for unobserved country-specific factors affecting growth rates of countries.

Using a panel of 159 countries over 1970-2005, this paper investigates the shape of growth recovery following currency crises in a multivariate framework that allows for the possibility of higher than average growth in the recovery phase. Moreover, the paper examines the factors impacting output growth after currency crises in a panel framework.

\footnotetext{
${ }^{34}$ Radelet and Sachs (1998) argue that: “...When confidence disappears and debt rollovers become difficult, the entire stock of a country's short-term foreign debt may have to be paid back within a year. A country with a short-term debt-GDP ratio of, say, 15 percent, could in principle have to pay 15 percent of its GDP to its creditors in a single year."
} 
We employ different types of "bounce-back" models proposed by Kim et al. (2005) and Bec et al. (2011) in the context of currency crises and with a more deterministic approach which make use of our exogenous currency crises dates. We estimate a U-shaped, long U-shaped, Vshaped, and an L-shaped models of post-currency crisis recovery .Thereafter, we allow the data to select the appropriate model. The methodology enables us to apply a panel estimation rather than cross-sectional and control for the country-specific and time-specific factors in our growth regression.

We find that output growth follows a U-shaped or a long U-shaped recovery depending on the characterization of currency crises. This is in contrast with the previous literature that using univariate analysis, finds a V-shaped growth recovery. Further, we split the data and repeat the analysis for different income groups and regions. The results suggest that post-crisis growth rates in different income groups and regions follow a variety of a U-shaped model.

In addition, we distinguish between the two forms of currency crises; currency crashes and reserve crises. Our results suggest that reserve losses are initially less costly than large depreciations. However, in the long-term, reserve crises are associated with higher output loss. Therefore, the defense strategy should be taken with more caution and by taking into account the long-run costs associated with it. The examination of factors affecting post-crisis recovery reveals that the extent of pre-crisis short-term foreign debt relative to total external debt and precrisis share of exports in GDP are the two influential factors for post-crisis recovery. 


\section{Table 4.1- Data Description and List of Countries}

LV Currency Crisis

EVENT

Diwan Currency

Crisis

CS Currency Crisis

CRISIS

CRISISE

CRISISR

CRISISRE
A nominal exchange rate depreciation of 30 percent or more which is also 10 percent higher than the rate of depreciation in the previous period with a 5 years window around each crisis. (Laeven and Valencia (2008)).

The same as LV with no window around each crisis

A depreciation of 30 percent or more in nominal exchange rate during a calendar year. Diwan (2001).

EMPI=The percentage depreciation in the exchange rate 1099 + the percentage loss in foreign exchange reserves. $\mathrm{CS}=1$ if EMPI $>$ Upper quartile of all observations $\mathrm{CS}=0$ if EMPI $<$ Upper quartile of all observations in the panel. (Cerra and Saxena (2008)).

$\begin{array}{ll}\text { CRISIS }=1 & \text { if } \quad \text { CS }=1 \\ \text { CRISIS }=0 & \text { Otherwise }\end{array} \quad$ \& $\quad$ dle $/$ EMPI $>50 \%$

CRISISE $=1 \quad$ if $\quad \mathrm{CS}=1 \quad \& \quad$ dle $/ \mathrm{EMPI}>75 \%$ CRISISE $=0 \quad$ Otherwise

CRISISR $=1$

CRISISR $=0$

if $\quad \mathrm{CS}=1 \quad \& \quad$ dle $/ \mathrm{EMPI}>50 \%$

716

CRISISRE $=1 \quad$ if $\quad \mathrm{CS}=1 \quad \& \quad$ dle $/ \mathrm{EMPI}>75 \%$ 
Table 4.2- Shape of Recovery Using Laeven and Valencia (2008) Dummy

\begin{tabular}{lcc}
\hline Model & AIC & SIC \\
\hline (1) L-Shaped & 6.2215 & 6.51572 \\
(2) U-Shaped & 6.22114 & 6.51687 \\
(3a) Long U-Shaped(2yrs) & $\mathbf{6 . 2 1 3 0 5}$ & $\mathbf{6 . 5 1 2 6 5}$ \\
(3b) Long U-Shaped(3yrs) & 6.21393 & 6.51858 \\
(4) V-shaped & 6.22114 & 6.51687 \\
(5) Cerra and Saxena & & 6.5217 \\
\hline
\end{tabular}

Note: The sample range is 1970-2005 and 159 countries. Models (1)-(5) which are explained in detail in section II are estimated using a panel two way fixed effects. The currency crises dates are the same as Laeven and Valencia (2008) without imposing any window around crises times. The information criteria for each model are reported above. AIC and AIC correspond to Akaike and Schwarz criterion, respectively. The lower values of AIC and SIC represent the preferred model. 
Table 4.3- Models Estimates Using EVENT Dummy

\begin{tabular}{|c|c|c|c|c|c|c|}
\hline Model & (1) & (2) & (3a) & (3b) & (4) & (5) \\
\hline L.GDP & $0.245^{*}$ & $0.22 *$ & $0.21^{*}$ & $0.22 *$ & $0.23^{*}$ & $0.23^{*}$ \\
\hline L2.GDP & $0.046^{*}$ & $0.03 * *$ & $0.03 * *$ & 0.02 & $0.03 * *$ & $0.03 * * *$ \\
\hline L3.GDP & $0.051^{*}$ & $0.05 *$ & $0.04 *$ & $0.04 *$ & $0.05^{*}$ & $0.05 *$ \\
\hline L4.GDP & $-0.063^{*}$ & $-0.06^{*}$ & $-0.07 *$ & $-0.07^{*}$ & $-0.07^{*}$ & $-0.07 *$ \\
\hline EVENT & $-2.270 *$ & $-2.38^{*}$ & $-2.33^{*}$ & $-2.31 *$ & $-1.89^{*}$ & $-2.37^{*}$ \\
\hline L. EVENT & & & & & & 0.14 \\
\hline L2. EVENT & & & & & & 0.49 \\
\hline L3. EVENT & & & & & & $0.82 * *$ \\
\hline L4. EVENT & & & & & & $1.38 *$ \\
\hline$\sum_{t=1}^{4} L(t) . E V E N T$ & & $0.71 *$ & & & & \\
\hline$\sum_{t=2}^{5} L(t) \cdot E V E N T$ & & & $0.65^{*}$ & & & \\
\hline$\sum_{t=3}^{6} L(t) . E V E N T$ & & & & $0.49 *$ & & \\
\hline$(1-\text { EVENT })^{*} \sum_{t=1}^{4} L(t) . E V E N T$ & & & & & $0.72 *$ & \\
\hline Fixed effects & Yes & Yes & Yes & Yes & Yes & Yes \\
\hline Time effects & Yes & Yes & Yes & Yes & Yes & Yes \\
\hline$A I C$ & 6.18075 & 6.15556 & 6.15829 & 6.16159 & 6.15603 & 6.15548 \\
\hline SIC & 6.48685 & 6.47335 & 6.48203 & 6.49333 & 6.47383 & 6.47819 \\
\hline Adjusted $\mathrm{R}^{2}$ & 0.2116 & 0.2151 & 0.2152 & 0.2133 & 0.2147 & 0.2157 \\
\hline
\end{tabular}

Note: Sample range is 1970-2005. 159 countries are included. The estimation method is panel two way fixed effects. Model (1)-(5) correspond to L-shape recovery, BBU, BBU (2yrs), BBU (3yrs), BBV, and Cerra and Saxena model, respectively. For more details on each model see section II. EVENT is equal to one if nominal exchange rate depreciation is at least 30 percent and the depreciation rate is at least 10 percent higher than the year before. There is no window around each individual crisis. For further details on the variable Event, see Table1. AIC and SIC correspond to Akaike and Schwarz criterion, respectively. The lower values of AIC and SIC represent the preferred model (highlighted in bold). ${ }^{*}, * *$, and $* * *$ represent significant at 1,5 , and 10 percent, respectively. 
Table 4.4- Models Estimates Using Diwan Dummy

\begin{tabular}{|c|c|c|c|c|c|c|}
\hline Model & (1) & (2) & (3a) & (3b) & (4) & (5) \\
\hline L.GDP & $0.24 *$ & $0.23^{*}$ & $0.22 *$ & $0.22^{*}$ & $0.23^{*}$ & $0.23^{*}$ \\
\hline L2.GDP & $0.04 *$ & $0.03 * * *$ & $0.03 * *$ & 0.02 & $0.03^{* * *}$ & $0.03 * * *$ \\
\hline L3.GDP & $0.05^{*}$ & $0.05^{*}$ & $0.05^{*}$ & $0.04 * *$ & $0.05^{*}$ & $0.05^{*}$ \\
\hline L4.GDP & $-0.06^{*}$ & $-0.06^{*}$ & $-0.07 *$ & $-0.08 *$ & $-0.07 *$ & $-0.07 *$ \\
\hline DIWAN & $-1.76^{*}$ & $-1.99 *$ & $-1.62 *$ & $-1.46^{*}$ & $-1.03^{*}$ & $-1.97 *$ \\
\hline L. DIWAN & & & & & & 0.57 \\
\hline L2. DIWAN & & & & & & $0.60^{* * *}$ \\
\hline L3. DIWAN & & & & & & 0.28 \\
\hline L4. DIWAN & & & & & & $1.08^{*}$ \\
\hline$\sum_{t=1}^{4} L(t) \cdot$ DIWAN & & $0.63^{*}$ & & & & \\
\hline$\sum_{t=2}^{5} L(t) \cdot$ DIW AN & & & $0.48^{*}$ & & & \\
\hline$\sum_{t=3}^{6} L(t) \cdot$ DIWAN & & & & $0.30 * *$ & & \\
\hline$(1-\text { DIWAN })^{*} \sum_{t=1}^{4} L(t) \cdot$ DIW AN & & & & & $0.57^{*}$ & \\
\hline Fixed effects & Yes & Yes & Yes & Yes & Yes & Yes \\
\hline Time effects & Yes & Yes & Yes & Yes & Yes & Yes \\
\hline$A I C$ & 6.18277 & 6.15807 & 6.1631 & 6.1674 & 6.1608 & 6.1590 \\
\hline SIC & 6.48887 & 6.47587 & 6.48686 & 6.49924 & 6.47866 & 6.4817 \\
\hline Adjusted $\mathrm{R}^{2}$ & 0.2100 & 0.2131 & 0.2114 & 0.2087 & 0.2109 & 0.2129 \\
\hline
\end{tabular}

Note: Sample range is 1970-2005. 159 countries are included. The estimation method is panel two way fixed effects. Model (1)-(5) correspond to L-shape recovery, BBU, BBU (2yrs), BBU (3yrs), BBV, and Cerra and Saxena model, respectively. For more details on each model see section II. DIWAN is equal to one if nominal exchange rate depreciation is at least 30 percent. There is no window around each individual crisis. For further detail on the variable DIWAN, see Table1. AIC and SIC correspond to Akaike and Schwarz criterion, respectively. The lower values of AIC and SIC represent the preferred model (highlighted in bold). *, **, and ${ }^{* * *}$ represent significant at 1 , 5 , and 10 percent, respectively. 
Table 4.5- Models Estimates Using CS Dummy

\begin{tabular}{|c|c|c|c|c|c|c|}
\hline Model & (1) & (2) & (3a) & $(3 b)$ & (4) & (5) \\
\hline L.GDP & $0.22 *$ & $0.18 *$ & $0.18 *$ & $0.18 *$ & $0.19 *$ & $0.19 *$ \\
\hline L2.GDP & $0.06^{*}$ & 0.02 & $0.03 * * *$ & $0.05^{*}$ & 0.02 & $0.03 * * *$ \\
\hline L3.GDP & $0.04 *$ & 0.014 & 0.015 & $0.05^{*}$ & 0.01 & 0.01 \\
\hline L4.GDP & $-0.06^{*}$ & $-0.09 *$ & $-0.08^{*}$ & $-0.05^{*}$ & $-0.08^{*}$ & $-0.09 *$ \\
\hline $\mathrm{CS}$ & $-1.10^{*}$ & $-1.05^{*}$ & $-1.035^{*}$ & $-0.95^{*}$ & $-1.30 *$ & $-1.00^{*}$ \\
\hline L. CS & & & & & & $-1.08 *$ \\
\hline L2. CS & & & & & & -0.02 \\
\hline L3. CS & & & & & & -0.05 \\
\hline L4. CS & & & & & & -0.15 \\
\hline$\sum_{t=1}^{4} L(t) . C S$ & & $-0.320^{*}$ & & & & \\
\hline$\sum_{t=2}^{5} L(t) \cdot C S$ & & & 0.038 & & & \\
\hline$\sum_{t=3}^{6} L(t) \cdot C S$ & & & & $0.17 * * *$ & & \\
\hline$(1-\mathrm{CS}) * \sum_{\mathrm{t}=1}^{4} \mathrm{~L}(\mathrm{t}) . \mathrm{CS}$ & & & & & $-0.19 * * *$ & \\
\hline Fixed effects & Yes & Yes & Yes & Yes & Yes & Yes \\
\hline Time effects & Yes & Yes & Yes & Yes & Yes & Yes \\
\hline$A I C$ & 6.11693 & 6.08472 & 6.09348 & 5.97226 & 6.087 & 6.08118 \\
\hline$S I C$ & 6.43032 & 6.41598 & 6.43415 & 6.3229 & 6.42159 & 6.41767 \\
\hline Adjusted $\mathbf{R}^{2}$ & 0.2097 & 0.2034 & 0.2027 & 0.2255 & 0.202 & 0.2069 \\
\hline
\end{tabular}

Note: Sample range is 1970-2005. 159 countries are included. The estimation method is panel two way fixed effects. Model (1)-(5) correspond to L-shape recovery, BBU, BBU (2yrs), BBU (3yrs), BBV, and Cerra and Saxena model, respectively. For more details on each model see section II. CS is equal to one if Exchange Market Pressure Index (EMPI) exceeds the upper quartile of all observations across the panel. For further detail on variable CS, see Table1. AIC and SIC correspond to Akaike and Schwarz criterion, respectively. The lower values of AIC and SIC represent the preferred model (highlighted in bold). ${ }^{* * *}$, and $* * *$ represent significant at 1,5 , and 10 percent, respectively. 
Table 4.6- Model Estimates Using CRISIS Dummy

\begin{tabular}{|c|c|c|c|c|c|c|}
\hline Model & (1) & (2) & (3a) & (3b) & (4) & (5) \\
\hline L.GDP & $0.22 *$ & $0.19^{*}$ & $0.18^{*}$ & $0.17 *$ & $0.19^{*}$ & $0.19^{*}$ \\
\hline L2.GDP & $0.06^{*}$ & 0.03 & $0.03 * * *$ & $0.04 * *$ & $0.03 * *$ & 0.03 \\
\hline L3.GDP & $0.04 *$ & 0.02 & 0.01 & $0.05^{*}$ & 0.02 & 0.02 \\
\hline L4.GDP & $-0.07 *$ & $-0.09 *$ & $-0.09 *$ & $-0.05^{*}$ & $-0.08 *$ & $-0.08^{*}$ \\
\hline CRISIS & $-1.59^{*}$ & $-1.67^{*}$ & $-1.53 *$ & $-1.41^{*}$ & $-1.16^{*}$ & $-1.6^{*}$ \\
\hline L. CRISIS & & & & & & -0.11 \\
\hline L2. CRISIS & & & & & & 0.35 \\
\hline L3. CRISIS & & & & & & 0.47 \\
\hline L4. CRISIS & & & & & & $0.6^{* * *}$ \\
\hline$\sum_{t=1}^{4} L(t) . C R I S I S$ & & $0.34^{*}$ & & & & \\
\hline$\sum_{t=2}^{5} L(t) . C R I S I S$ & & & $0.41^{*}$ & & & \\
\hline$\sum_{t=3}^{6} \mathrm{~L}(\mathrm{t}) \cdot \mathrm{CRISIS}$ & & & & $0.39 *$ & & \\
\hline$(1-$ CRISIS $) * \sum_{t=1}^{4} L(t)$. CRISIS & & & & & $0.51^{*}$ & \\
\hline Fixed effects & Yes & Yes & Yes & Yes & Yes & Yes \\
\hline Time effects & Yes & Yes & Yes & Yes & Yes & Yes \\
\hline$A I C$ & 6.1179 & 6.0866 & 6.0921 & 5.9715 & 6.0854 & 6.0875 \\
\hline SIC & 6.4313 & 6.4178 & 6.4327 & 6.322 & 6.4199 & 6.4240 \\
\hline Adjusted $\mathrm{R}^{2}$ & 0.2089 & 0.2019 & 0.2015 & 0.2260 & 0.2039 & 0.2018 \\
\hline
\end{tabular}

Note: Sample range is 1970-2005. 159 countries are included. The estimation method is panel two way fixed effects. Model (1)-(5) correspond to L-shape recovery, BBU, BBU (2yrs), BBU (3yrs), BBV, and Cerra and Saxena model, respectively. For more details on each model see section II. CRISIS dummy is equal to one if the currency depreciation component of the Exchange Market Pressure Index (EMPI) is at least 50 percent when the index signals a crisis. For further detail on the variable CRSIS, see Table1. AIC and SIC correspond to Akaike and Schwarz criterion, respectively. The lower values of AIC and SIC represent the preferred model (highlighted in bold). *, **, and $* * *$ represent significant at 1,5 , and 10 percent, respectively. 
Table 4.7- Models Estimates Using CRISISR

\begin{tabular}{|c|c|c|c|c|c|c|}
\hline Model & (1) & (2) & (3a) & (3b) & (4) & (5) \\
\hline L.GDP & $0.22 *$ & $0.19^{*}$ & $0.19 *$ & $0.18^{*}$ & $0.19^{*}$ & $0.19^{*}$ \\
\hline L2.GDP & $0.06^{*}$ & 0.03 & $0.03 * *$ & $0.05^{*}$ & 0.03 & $0.03 * * *$ \\
\hline L3.GDP & $0.04 *$ & 0.01 & 0.01 & $0.05^{*}$ & 0.01 & 0.01 \\
\hline L4.GDP & $-0.06^{*}$ & $-0.09 *$ & $-0.09 *$ & $-0.06^{*}$ & $-0.08^{*}$ & $-0.08^{*}$ \\
\hline CRISISR & $-0.56^{* *}$ & $-0.58 * *$ & $-0.58 * *$ & $-0.50 * *$ & $-1.03^{*}$ & $-0.57 * *$ \\
\hline L. CRISISR & & & & & & $-1.31^{*}$ \\
\hline L2. CRISISR & & & & & & -0.32 \\
\hline L3. CRISISR & & & & & & $-0.42 * * *$ \\
\hline L4. CRISISR & & & & & & $-0.54 * *$ \\
\hline$\sum_{t=1}^{4} \mathrm{~L}(\mathrm{t}) \cdot$ CRISISR & & $-0.65^{*}$ & & & & \\
\hline$\sum_{t=2}^{5} L(t) . C R I S I S R$ & & & $-0.23 * *$ & & & \\
\hline$\sum_{t=3}^{6} L(t) \cdot$ CRISISR & & & & -0.03 & & \\
\hline$(1-$ CRISISR $) * \sum_{t=1}^{4} \mathrm{~L}(\mathrm{t})$. CRISISR & & & & & $-0.55^{*}$ & \\
\hline Fixed effects & Yes & Yes & Yes & Yes & Yes & Yes \\
\hline Time effects & Yes & Yes & Yes & Yes & Yes & Yes \\
\hline$A I C$ & 6.1233 & 6.0851 & 6.0980 & 5.9786 & 6.0888 & 6.0834 \\
\hline$S I C$ & 6.4366 & 6.4163 & 6.4386 & 6.3292 & 6.4233 & 6.41994 \\
\hline Adjusted $\mathbf{R}^{2}$ & 0.2046 & 0.2031 & 0.1968 & 0.2205 & 0.201 & 0.2051 \\
\hline
\end{tabular}

Note: Sample range is 1970-2005. 159 countries are included. The estimation method is panel two way fixed effects. Model (1)-(5) correspond to L-shape recovery, BBU, BBU (2yrs), BBU (3yrs), BBV, and Cerra and Saxena model, respectively. For more details on each model see section II. CRISISR dummy is equal to one if the reserves loss component of the Exchange Market Pressure Index (EMPI) is at least 50 percent when the index signals a crisis. AIC and SIC correspond to Akaike and Schwarz criterion, respectively. The lower values of AIC and SIC represent the preferred model (highlighted in bold). *, **, and *** represent significant at 1,5 , and 10 percent, respectively. 
Table 4.8- Models Estimates Using CRISISE

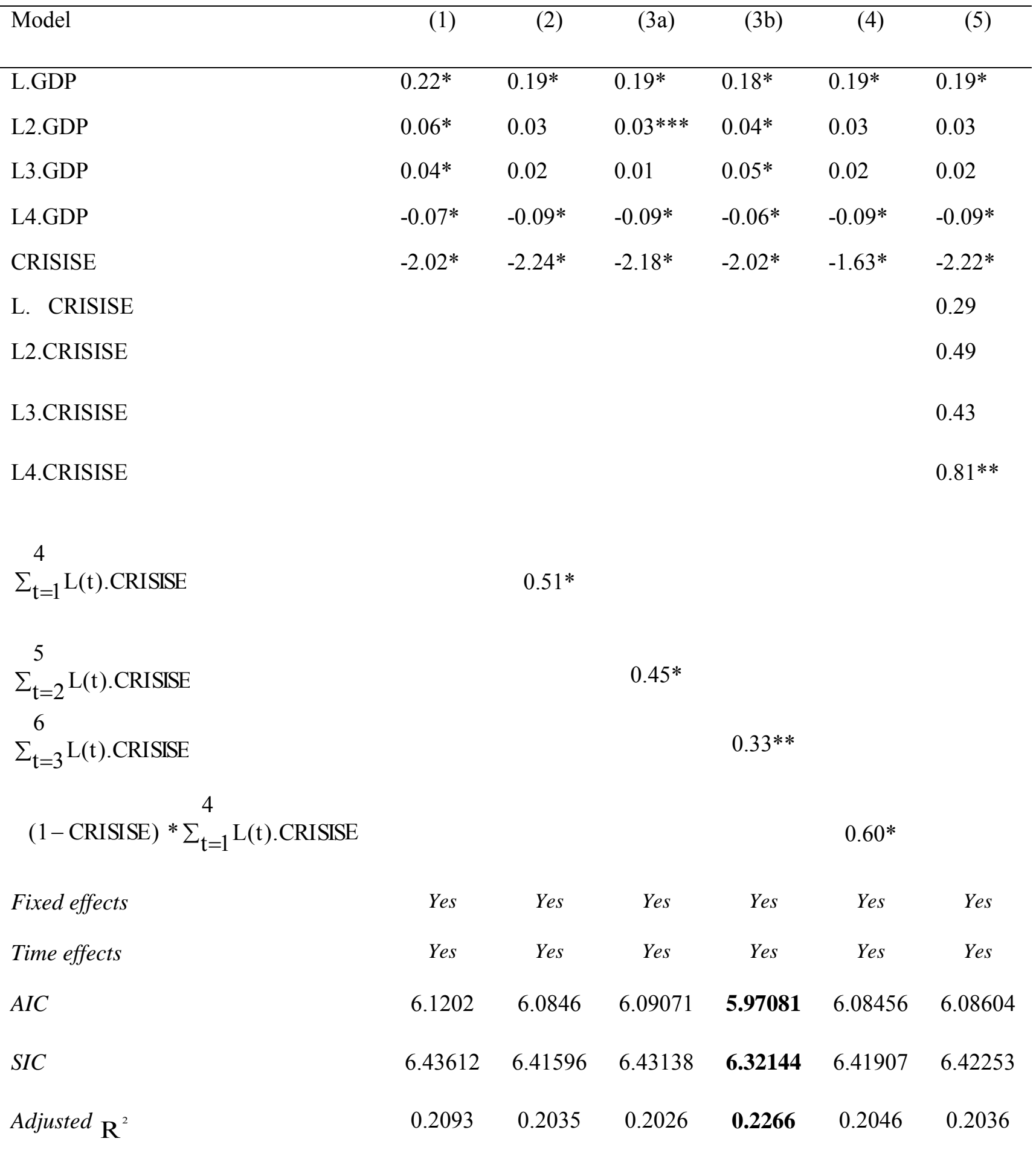

Note: Sample range is 1970-2005. 159 countries are included. The estimation method is panel two way fixed effects. Model (1)-(5) correspond to L-shape recovery, BBU, BBU (2yrs), BBU (3yrs), BBV, and Cerra and Saxena model, respectively. For more details on each model see section II. CRISISE dummy is equal to one if the currency depreciation component of the Exchange Market Pressure Index (EMPI) is at least 75 percent when the index signals a crisis. AIC and SIC correspond to Akaike and Schwarz criterion, respectively. AIC and SIC represent Akaike and Schwarz criterion, respectively. The lower values of AIC, SIC, and HQ represent the preferred model (highlighted in bold). *, **, and *** represent significant at 1,5 ,and 10 percent, respectively. 
Table 4.9- Models Estimates Using CRISISRE

\begin{tabular}{|c|c|c|c|c|c|c|}
\hline Model & (1) & (2) & (3a) & (3b) & (4) & (5) \\
\hline L.GDP & $0.23 *$ & $0.19^{*}$ & $0.19 *$ & $0.18^{*}$ & $0.18^{*}$ & $0.19^{*}$ \\
\hline L2.GDP & $0.06^{*}$ & 0.03 & $0.03 * *$ & $0.05^{*}$ & $0.05^{*}$ & $0.03 * * *$ \\
\hline L3.GDP & $0.04 *$ & 0.01 & 0.01 & $0.05^{*}$ & $0.05^{*}$ & 0.01 \\
\hline L4.GDP & $-0.07^{*}$ & $-0.09 *$ & $-0.09 *$ & $-0.06^{*}$ & $-0.06^{*}$ & $-0.09 *$ \\
\hline CRISISRE & $-0.57 * *$ & $-0.62 * *$ & $-0.62 * *$ & $-0.48^{* * *}$ & -0.43 & $-0.62 * *$ \\
\hline L. CRISISRE & & & & & & $-1.61^{*}$ \\
\hline L2.CRISISRE & & & & & & -0.26 \\
\hline L3.CRISISRE & & & & & & -0.41 \\
\hline L4.CRISISRE & & & & & & $-0.71 * *$ \\
\hline 4 & & & & & & \\
\hline$\sum_{t=1} \mathrm{~L}(\mathrm{t}) \cdot \mathrm{CRISISRE}$ & & $-0.75^{*}$ & & & & \\
\hline$\sum_{\mathrm{t}=2}^{5} \mathrm{~L}(\mathrm{t})$. CRISISRE & & & $-0.27 * * *$ & & & \\
\hline$\sum_{t=3}^{6} L(t)$.CRISISRE & & & & -0.11 & & \\
\hline$(1-$ CRISISRE $) * \sum_{t=1}^{4} L(t) . C R I S I S R E$ & & & & & 0.06 & \\
\hline Fixed effects & Yes & Yes & Yes & Yes & Yes & Yes \\
\hline Time effects & Yes & Yes & Yes & Yes & Yes & Yes \\
\hline$A I C$ & 6.12696 & 6.08540 & 6.09840 & 5.97892 & 5.97909 & 6.08252 \\
\hline SIC & 6.44287 & 6.41991 & 6.44079 & 6.32956 & 6.32972 & 6.42226 \\
\hline Adjusted $\mathrm{R}^{2}$ & 0.2046 & 0.2031 & 0.1968 & 0.2203 & 0.2019 & 0.2051 \\
\hline
\end{tabular}

Note: Sample range is 1970-2005. 159 countries are included. The estimation method is panel two way fixed effects. Model (1)-(5) correspond to L-shape recovery, BBU, BBU (2yrs), BBU (3yrs), BBV, and Cerra and Saxena model, respectively. For more details on each model see section II. CRISISRE dummy is equal to one if the reserves loss component of the Exchange Market Pressure Index (EMPI) is at least 75 percent when the index signals a crisis. For further detail on the variable CRSISRE, see Table1. AIC and SIC correspond to Akaike and Schwarz criterion, respectively. The lower values of AIC and SIC represent the preferred model (highlighted in bold). *, **, and *** represent significant at 1,5 ,and 10 percent, respectively. 
Table 4.10- Model Estimates Using EVENT for Industrial Countries

\begin{tabular}{|c|c|c|c|c|c|c|}
\hline 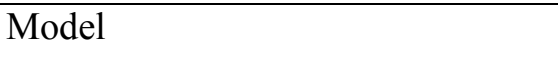 & (1) & (2) & $(3 a)$ & (3b) & (4) & (5) \\
\hline L.GDP & $0.19 *$ & $0.21 *$ & $0.21 *$ & $0.22 *$ & $0.21 *$ & $0.21 *$ \\
\hline L2.GDP & -0.02 & -0.04 & -0.03 & -0.02 & -0.04 & -0.04 \\
\hline L3.GDP & $0.08 *$ & $0.10^{*}$ & $0.10^{*}$ & $0.09 *$ & $0.10 *$ & $0.10 *$ \\
\hline L4.GDP & $-0.05 * *$ & $-0.08^{*}$ & $-0.08^{*}$ & $-0.09 *$ & $-0.08 *$ & $-0.08 *$ \\
\hline EVENT & $-3.45^{*}$ & $-3.42 *$ & $-3.51^{*}$ & $-3.43^{*}$ & $-2.79 * *$ & $-3.49 *$ \\
\hline L.EVENT & & & & & & 0.29 \\
\hline L2. EVENT & & & & & & 0.75 \\
\hline L3. EVENT & & & & & & 1.12 \\
\hline L4. EVENT & & & & & & 1.16 \\
\hline$\sum_{t=1}^{4} L(t) \cdot E V E N T$ & & 0.82 & & & & \\
\hline$\sum_{t=2}^{5} L(t) . E V E N T$ & & & 0.46 & & & \\
\hline$\sum_{t=3}^{6} L(t) \cdot E V E N T$ & & & & 0.53 & & \\
\hline$(1-\text { EVENT })^{*} \sum_{t=1}^{4} L(t) . E V E N T$ & & & & & 0.73 & \\
\hline Fixed effects & Yes & Yes & Yes & Yes & Yes & Yes \\
\hline Time effects & Yes & Yes & Yes & Yes & Yes & Yes \\
\hline$A I C$ & 5.382779 & 5.366726 & 5.37404 & 5.378814 & 5.367279 & 5.37074 \\
\hline SIC & 5.725792 & 5.720681 & 5.734531 & 5.746297 & 5.721233 & 5.735991 \\
\hline Adjusted $\mathrm{R}^{2}$ & 0.230706 & 0.240122 & 0.236361 & 0.241081 & 0.239702 & 0.238588 \\
\hline
\end{tabular}

Note: Sample range is 1970-2005 and includes 58 countries of which 55 never experienced a currency crisis and used as the 'control group'. There are 14 episodes of currency crisis characterized by EVENT dummy. Models (1)(5) are estimated using a panel two way fixed effect. The currency crises are characterized by EVENT. AIC and AIC correspond to Akaike and Schwarz criterion, respectively. The lower values of AIC and SIC represent the preferred model (highlighted in bold). ${ }^{* *},{ }^{*}$, and $* * *$ represent significant at 1,5 , and 10 percent. 
Table 4.11- Model estimates Using EVENT for Latin American Countries

\begin{tabular}{|c|c|c|c|c|c|c|}
\hline Model & (1) & (2) & (3a) & (3b) & (4) & (5) \\
\hline L.GDP & $0.24 *$ & 0.25 & $0.24 *$ & $0.25 *$ & $0.25 *$ & $0.24 *$ \\
\hline L2.GDP & $-0.06^{*}$ & $-0.07^{*}$ & $-0.08 *$ & $-0.08^{*}$ & $-0.07 *$ & $-0.07 *$ \\
\hline L3.GDP & $0.07 *$ & $0.07 *$ & $0.08 *$ & $0.06 *$ & $0.07 *$ & $0.08 *$ \\
\hline L4.GDP & $-0.05^{*}$ & $-0.07 *$ & $-0.07 *$ & $-0.07 *$ & $-0.07 *$ & $-0.07 *$ \\
\hline EVENT & $-4.46^{*}$ & $-4.45^{*}$ & $-4.63 *$ & $-4.60 *$ & $-4.25^{*}$ & $-4.49^{*}$ \\
\hline L.EVENT & & & & & & -0.77 \\
\hline L2. EVENT & & & & & & 0.55 \\
\hline L3. EVENT & & & & & & 0.53 \\
\hline L4. EVENT & & & & & & 0.50 \\
\hline$\sum_{t=1}^{4} L(t) . E V E N T$ & & 0.20 & & & & \\
\hline$\sum_{t=2}^{5} L(t) \cdot E V E N T$ & & & $0.51 * *$ & & & \\
\hline$\sum_{\mathrm{t}=3} \mathrm{~L}(\mathrm{t}) \cdot \mathrm{EVENT}$ & & & & 0.36 & & \\
\hline$(1-\text { EVENT })^{*} \sum_{t=1}^{4} L(t) . E V E N T$ & & & & & 0.24 & \\
\hline Fixed effects & Yes & Yes & Yes & Yes & Yes & Yes \\
\hline Time effects & Yes & Yes & Yes & Yes & Yes & Yes \\
\hline$A I C$ & 5.457243 & 5.4452 & 5.439476 & 5.450487 & 5.44511 & 5.489533 \\
\hline$S I C$ & 5.776416 & 5.774334 & 5.77502 & 5.792877 & 5.774245 & 5.822949 \\
\hline Adjusted $\mathbf{R}^{2}$ & 0.253266 & 0.262135 & 0.268842 & 0.270109 & 0.262201 & 0.226349 \\
\hline
\end{tabular}

Note: Sample range is 1970-2005 and includes 72 of which 55 never experienced a currency crisis and used as the 'control group'. There are 76 episodes of currency crisis characterized by EVENT dummy. Models (1)-(5) are estimated using a panel two way fixed effect. The currency crises are characterized by EVENT. AIC and AIC correspond to Akaike and Schwarz criterion, respectively. The lower values of AIC and SIC represent the preferred model (highlighted in bold). *, **, and *** represent significant at 1,5, and 10 percent. 
Table 4.12- Model Estimates Using Event for Transition Countries

\begin{tabular}{|c|c|c|c|c|c|c|}
\hline 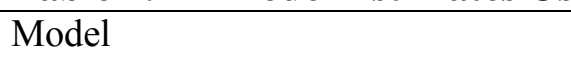 & (1) & (2) & (3a) & (3b) & (4) & (5) \\
\hline L.GDP & $0.30^{*}$ & $0.22^{*}$ & $0.21^{*}$ & $0.23^{*}$ & $0.22 *$ & $0.21^{*}$ \\
\hline L2.GDP & 0.04 & -0.02 & -0.02 & -0.03 & -0.02 & -0.02 \\
\hline L3.GDP & $0.06 * *$ & $0.11^{*}$ & $0.11 *$ & $0.09 *$ & $0.11 *$ & $0.11^{*}$ \\
\hline L4.GDP & $-0.05 * *$ & $-0.08^{*}$ & $-0.08^{*}$ & $-0.09 *$ & $-0.08^{*}$ & $-0.07^{*}$ \\
\hline EVENT & $-3.13^{*}$ & $-5.07 *$ & $-3.84 *$ & $-4.92 *$ & $-4.61 *$ & $-5.02 *$ \\
\hline L.EVENT & & & & & & 0.26 \\
\hline L2. EVENT & & & & & & 1.30 \\
\hline L3. EVENT & & & & & & 0.35 \\
\hline L4. EVENT & & & & & & $1.97 * *$ \\
\hline$\sum_{t=1}^{4} \mathrm{~L}(\mathrm{t}) \cdot \mathrm{EVENT}$ & & $0.98^{* *}$ & & & & \\
\hline$\Sigma_{\mathrm{t}=2} \mathrm{~L}(\mathrm{t}) \cdot \mathrm{EVENT}$ & & & $0.84 * *$ & & & \\
\hline$\sum_{t=3}^{6} L(t) \cdot$ EVENT & & & & 0.60 & & \\
\hline$(1-\text { EVENT })^{*} \sum_{t=1}^{4} L(t) \cdot$ EVENT & & & & & 0.65 & \\
\hline Fixed effects & Yes & Yes & Yes & Yes & Yes & Yes \\
\hline Time effects & Yes & Yes & Yes & Yes & Yes & Yes \\
\hline$A I C$ & 5.552109 & 5.395949 & 5.391177 & 5.383015 & 5.398159 & 5.397583 \\
\hline SIC & 5.92017 & 5.7859 & 5.787324 & 5.789531 & 5.78811 & 5.798366 \\
\hline Adjusted $\mathrm{R}^{2}$ & 0.319843 & 0.334073 & 0.329562 & 0.336364 & 0.332599 & 0.334238 \\
\hline
\end{tabular}

Note: Sample range is 1970-2005 and includes 72 of which 55 never experienced a currency crisis and used as the 'control group'. There are 72 episodes of currency crisis characterized by EVENT dummy. Models (1)-(5) are estimated using a panel two way fixed effect. The currency crises are characterized by EVENT. AIC and AIC correspond to Akaike and Schwarz criterion, respectively. The lower values of AIC and SIC represent the preferred model (highlighted in bold). *, **, and *** represent significant at 1,5, and 10 percent. 
Table 4.13- Model Estimates Using EVENT for Asian Countries

\begin{tabular}{|c|c|c|c|c|c|c|}
\hline Model & (1) & (2) & (3a) & (3b) & (4) & (5) \\
\hline L.GDP & $0.18 *$ & $0.19 *$ & $0.19 *$ & $0.20^{*}$ & $0.20 *$ & $0.20 *$ \\
\hline L2.GDP & -0.01 & -0.02 & -0.02 & -0.01 & -0.02 & -0.02 \\
\hline L3.GDP & $0.07 *$ & $0.08 *$ & $0.08 *$ & $0.07 *$ & $0.08 *$ & $0.08 *$ \\
\hline L4.GDP & $-0.04 * *$ & $-0.07 *$ & $-0.08^{*}$ & $-0.08^{*}$ & $-0.07 *$ & $-0.07 *$ \\
\hline EVENT & $-5.54^{*}$ & $-5.24^{*}$ & $-5.43^{*}$ & $-5.48^{*}$ & $-5.28 *$ & $-5.33^{*}$ \\
\hline L.EVENT & & & & & & 1.06 \\
\hline L2. EVENT & & & & & & -0.29 \\
\hline L3. EVENT & & & & & & -0.32 \\
\hline L4. EVENT & & & & & & 0.59 \\
\hline$\sum_{t=1}^{4} L(t) \cdot E V E N T$ & & 0.22 & & & & \\
\hline$\sum_{t=2}^{5} L(t) \cdot E V E N T$ & & & -0.54 & & & \\
\hline$\sum_{t=3} L(t) \cdot E V E N T$ & & & & -0.55 & & \\
\hline$(1-\text { EVENT })^{*} \sum_{t=1}^{4} L(t)$. EVENT & & & & & -0.04 & \\
\hline Fixed effects & Yes & Yes & Yes & Yes & Yes & Yes \\
\hline Time effects & Yes & Yes & Yes & Yes & Yes & Yes \\
\hline$A I C$ & 5.378044 & 5.370555 & 5.378215 & 5.380039 & 5.370676 & 5.373323 \\
\hline SIC & 5.712836 & 5.716244 & 5.730512 & 5.739394 & 5.716364 & 5.728983 \\
\hline Adjusted $\mathrm{R}^{2}$ & 0.255094 & 0.259458 & 0.257209 & 0.262911 & 0.259368 & 0.258682 \\
\hline
\end{tabular}

Note: Sample range is 1970-2005 and includes 68 of which 55 never experienced a currency crisis and used as the 'control group'. There are 23 episodes of currency crisis characterized by EVENT dummy. Models (1)-(5) are estimated using a panel two way fixed effect. The currency crises are characterized by EVENT. AIC and AIC correspond to Akaike and Schwarz criterion, respectively. The lower values of AIC and SIC represent the preferred model (highlighted in bold). ${ }^{* *}$, and $* * *$ represent significant at 1,5 , and 10 percent. 


\begin{tabular}{lccc}
\hline Model & AIC & SIC & Adjusted R^2 \\
\hline (1) L-Shaped & 5.384085 & 5.72709 & 0.235806 \\
(2) U-Shaped & $\mathbf{5 . 3 6 9 7 6 1}$ & $\mathbf{5 . 7 2 3 7 1}$ & 0.243705 \\
(3a) Long U-Shaped(2yrs) & 5.376982 & 5.73747 & 0.240259 \\
(3b) Long U-Shaped(3yrs) & 5.381027 & 5.7485 & 0.245889 \\
(4) V-shaped & 5.370067 & 5.72402 & 0.243473 \\
(5) Cerra and Saxena & 5.372932 & 5.73818 & 0.242817
\end{tabular}

Note: Sample range is 1970-2005 and includes 58 of which 55 never experienced a currency crisis and used as the 'control group'. There are 11 episodes of currency crisis characterized by EVENT dummy. Models (1)-(5) are estimated using a panel two way fixed effect. The information criteria for each model are reported above. AIC and AIC correspond to Akaike and Schwarz criterion, respectively. The lower values of AIC and SIC represent the preferred model (highlighted in bold).

Table 4. 15- Shape of Growth Recovery for Upper Middle Income Group

\begin{tabular}{lccc}
\hline Model & AIC & \multicolumn{1}{l}{ SIC } & \multicolumn{1}{c}{ Adjusted R^2 } \\
\hline (1) L-Shaped & 5.62642 & 5.95959 & 0.236285 \\
(2) U-Shaped & 5.57266 & 5.91627 & 0.253686 \\
(3a) Long U-Shaped(2yrs) & 5.5654 & 5.91551 & 0.256157 \\
(3b) Long U-Shaped(3yrs) & $\mathbf{5 . 5 3 2 2 5}$ & $\mathbf{5 . 8 8 9 3}$ & 0.265956 \\
(4) V-shaped & 5.57149 & 5.9151 & 0.254559 \\
(5) Cerra and Saxena & 5.5717 & 5.92523 & 0.255669
\end{tabular}

Note: Sample range is 1970-2005 and includes 68 of which 55 never experienced a currency crisis and used as the 'control group'. There are 46 episodes of currency crisis characterized by EVENT dummy. Models (1)-(5) are estimated using a panel two way fixed effect. The information criteria for each model are reported above. AIC and AIC correspond to Akaike and Schwarz criterion, respectively. The lower values of AIC and SIC represent the preferred model (highlighted in bold). 
Table 4.16- Shape of Growth Recovery for Middle Lower Income Group

\begin{tabular}{|c|c|c|c|}
\hline Model & AIC & SIC & Adjusted $\mathrm{R}^{\wedge} 2$ \\
\hline (1) L-Shaped & 5.751139 & 6.0723 & 0.302495 \\
\hline (2) U-Shaped & 5.696905 & 6.03116 & 0.317756 \\
\hline (3a) Long U-Shaped(2yrs) & 5.695255 & 6.03694 & 0.319456 \\
\hline (3b) Long U-Shaped(3yrs) & 5.695884 & 6.04551 & 0.320947 \\
\hline (4) V-shaped & 5.697742 & 6.03199 & 0.317184 \\
\hline (5) Cerra and Saxena & 5.696451 & 6.03848 & 0.318937 \\
\hline
\end{tabular}

Note: Sample range is 1970-2005 and includes 93 of which 55 never experienced a currency crisis and used as the 'control group'. There are 102 episodes of currency crisis characterized by EVENT dummy. Models (1)-(5) are estimated using a panel two way fixed effect. The information criteria for each model are reported above. AIC and AIC correspond to Akaike and Schwarz criteria, respectively. The lower values of AIC and SIC represent the preferred model (highlighted in bold).

Table 4.17- Shape of Growth Recovery for Lower Income Group

\begin{tabular}{lccc}
\hline Model & AIC & SIC & Adjusted R^2 \\
\hline (1) L-Shaped & 6.229273 & $\mathbf{6 . 5 4 5 9}$ & 0.152293 \\
(2) U-Shaped & 6.228856 & 6.5567 & 0.150339 \\
(3a) Long U-Shaped(2yrs) & 6.236784 & 6.5693 & 0.149402 \\
(3b) Long U-Shaped(3yrs) & 6.250386 & 6.5902 & 0.149696 \\
(4) V-shaped & 6.229048 & 6.5569 & 0.150175 \\
(5) Cerra and Saxena & $\mathbf{6 . 2 2 8 8 5 2}$ & 6.5637 & 0.151305
\end{tabular}

Note: Sample range is 1970-2005 and includes 105 of which 55 never experienced a currency crisis and used as the 'control group'. There are 132 episodes of currency crisis characterized by EVENT dummy. Models (1)-(5) are estimated using a panel two way fixed effect. The information criteria for each model are reported above. AIC and AIC correspond to Akaike and Schwarz criterion, respectively. The lower values of AIC and SIC represent the preferred model (highlighted in bold). 
Table 4.18- Determinants of Post-Crisis Recovery

\begin{tabular}{|c|c|c|c|c|c|c|}
\hline Model & $(1)$ & (2) & (3) & (4) & $(5)$ & $(6)$ \\
\hline \multirow[t]{2}{*}{$\Delta \mathrm{y}(\mathrm{t}-1)$} & $0.21 *$ & $0.16^{*}$ & $0.17 *$ & $0.20 *$ & $0.23 *$ & $0.16^{*}$ \\
\hline & $(20.94)$ & $(7.28)$ & $(8.69)$ & $(9.85)$ & (10.48) & (7.74) \\
\hline \multirow[t]{2}{*}{$\Delta \mathrm{y}(\mathrm{t}-2)$} & -0.008 & -0.02 & 0.01 & -0.016 & -0.03 & -0.01 \\
\hline & $(-0.4)$ & $(-0.89)$ & -0.74 & $(-0.82)$ & $(-1.62)$ & $(-0.64)$ \\
\hline \multirow[t]{2}{*}{$\Delta y(t-3)$} & 0.013 & $0.03 * *$ & $0.06^{*}$ & 0.022 & 0.01 & $0.06^{*}$ \\
\hline & $(0.62)$ & $(1.79)$ & $(3.11)$ & $(1.15)$ & $(0.4)$ & $(2.77)$ \\
\hline \multirow[t]{2}{*}{$\Delta \mathrm{y}(\mathrm{t}-4)$} & -0.02 & $-0.04 * *$ & -0.02 & $-0.04 * *$ & $-0.04 * * *$ & $-0.05^{*}$ \\
\hline & $(-1.05)$ & $(-2.14)$ & $(-1.06)$ & $(-2.34)$ & $(-1.87)$ & $(-2.81)$ \\
\hline \multirow[t]{2}{*}{ LV } & $-3.67 *$ & $-2.56^{*}$ & $-2.55^{*}$ & $-3.97^{*}$ & $-4.51^{*}$ & $-3.41 *$ \\
\hline & $(-8.13)$ & $(-5.44)$ & $(-5.88)$ & $(-9.98)$ & $(-11.68)$ & $(-8.24)$ \\
\hline \multirow[t]{2}{*}{$\mathrm{LV}(-1)$} & -0.96 & -0.89 & $-1.6 * * *$ & $-2.06 * * *$ & -2.73 & $-2.40 * *$ \\
\hline & $(-0.73)$ & $(-0.86)$ & $(-1.94)$ & $(-1.88)$ & $(-2.4)$ & $(-2.88)$ \\
\hline \multirow[t]{2}{*}{$L V(-1) \times$ investment rate } & -0.015 & & & 0.001 & 0.04 & \\
\hline & $(-0.27)$ & & & $(0.02)$ & $(0.72)$ & \\
\hline \multirow[t]{2}{*}{$L V(-1) \times$ exports/GDP $(-1)$} & $0.071 * *$ & $0.046 * *$ & 0.04 & $0.05 * *$ & $0.05 * *$ & $0.05 * *$ \\
\hline & $(2.79)$ & $(1.78)$ & $(1.59)$ & $(2.48)$ & 2.07 & -2.09 \\
\hline \multirow[t]{2}{*}{$L V(-1) \times$ short-term debt } & $-0.07 * *$ & $-0.07 * *$ & & & & \\
\hline & $(-2.06)$ & $(1.93)$ & & & & \\
\hline \multirow[t]{2}{*}{$\mathrm{LV}(-1) \times$ real credit growth } & & 0.015 & -0.015 & & & \\
\hline & & $(0.45)$ & $(-0.50)$ & & & \\
\hline \multirow[t]{2}{*}{$\mathrm{LV}(-1) \times$ reserves-to-M2 } & & & 0 & 0.001 & & \\
\hline & & & $(0.2)$ & -0.36 & & \\
\hline \multirow[t]{2}{*}{$\mathrm{LV}(-1) \times$ capital inflows } & & & & & -0.05 & -0.14 \\
\hline & & & & & $(-0.25)$ & $(-1.28)$ \\
\hline Sample Size & 1919 & 2143 & 2835 & 2451 & 2197 & 2768 \\
\hline Adjusted $\mathrm{R}^{2}$ & 0.27 & 0.23 & 0.28 & 0.3 & 0.35 & 0.27 \\
\hline
\end{tabular}

Note: The dependent variable is real GDP growth, $\Delta \mathrm{y}$. the $\mathrm{t}$-values are presented in the parenthesis. *, **, and *** represent significant at 1, 5, and 10 percent. The time pried is from 1970-2005. LV represents the currency crises dates obtained from Laeven and Valencia (2008). Short-term debt is the ratio of short-term debt to total external debt. The average of three years pre-crisis is used for investment rate, real credit growth, and reserves-to-M2. The estimation method is panel two way effects. 


\section{CHAPTER5. SUMMARY AND CONCLUSIONS}

This dissertation attempts to answer several questions regarding the impact of currency crises on an economy. In Chapter 2, I look at the long-run impact of currency crises on the level of output. From theoretical point of view, currency crises are nominal shocks and thus should not have a long-run impact on real output. However, the empirical literature on the issue presents some evidence of long-run decline in GDP after such events. In this chapter I argue that the observed long-run drop in GDP is because oftentimes currency crises were accompanied by a banking distress. Therefore, part of the observed loss in GDP is associated with the disruption in financial system rather than currency devaluation per se. Hence, I isolate twin crises episodes from currency crises dates and examine the long-run dynamics of real output and its components. The results indicate that in fact, output fully recovers four years after a large devaluation which is not associated with a banking crisis. Moreover, the full-recovery also depends on global conditions .The initial drop in output is a result of the decline in consumption and investment. Net export booms, however it is not enough to compensate for the drop in other components.

In chapter 3, I examine the labor market impact of currency crises. In particular, I look at real wage per person, labor productivity, and employment following a currency crisis in a panel of countries over 1990-2010. I find that most of the adjustment in labor market after a large devaluation is through cuts in real wages. The recovery in real wages is sluggish and usually takes at least three and at most eight years. Employment and productivity do decline; however these declines are far less than the decrease in real wages and the recovery is also swifter. The results are robust to different definitions of currency crisis and estimation methods. Furthermore, in a sub-sample of countries with available data on hours worked, I test to see if the estimated drop in real wage per person after currency crises is overstated by ignoring the cuts in hours worked. The sub-sample results provide some suggestive evidence that this is not case; the large 
drop in real wages is mainly attributed to the decline in nominal wages rather than changes in employment or hours worked.

In chapter 4, I explore two issues. First, the shape of output growth recovery following currency crises in a large panel of countries. Second, the factors determining the post-crisis recovery. In order to answer the first question, I consider currency crashes and reserve crises as the two forms of currency crises separately. I find that output growth recovery is U-shaped following currency crashes. Nevertheless, following reserve crises, output growth recovery resembles a long- $\mathrm{U}$. This is because there is positive and statistically significant bounce-back in growth rates after currency crashes where as in reserve crises such a bounce-back is not present. The robustness of the results is tested in different sub-samples. Moreover, I found that a large pre-crisis short term debt relative to total foreign debt and pre-crisis share of export sector in an economy are the best predictors of post-crisis recovery. 


\section{REFERENCES}

Agenor, R. P. (1991). Output, Devaluation, and the Real Exchange Rate in Developing Countries. $127,18-41$.

Aghion, P., Bacchetta, P., \& Banerjee, A. (2001). Currency crises and monetary policy in an economy with credit constraints. European Economic Review , 45, 1121-1150.

Angkinand, A., Li, J., \& Willett, T. (2006). Measures of Currency Crises: A Survey. Forthcoming in $\therefore$ International Interaction .

Arellano, M., \& Bond, S. (1991). Some Tests of Specification for Panel Data: Monte Carlo Evidence and an Application to Employment Equations. Review of Economic Studies , 58 (2), 277-97.

Aziz, J., Caramazza, F., \& Salgado, R. (2000). Currency Crises: In Search of Common Elements. IMF Working Paper WP/00/67.

Bauer, C., Erler, A., \& Herz, B. (February 2012). The dynamics of Currency Crises: Defendng the Exchage Rate is a Risky Decision.

Bazillier, R., \& Najman, B. Labour and Financial crises :Is labour paying the price of the crisis? unpublished.

Beaudry, P., \& Koop, G. (1993). Do Recessions Permanently Chnage output? Journal of Monetary Economics , 31, 149-163.

Bec, F., Bouabdallah, O., \& Ferrara, L. (March 2011). The possible shapes of recoveries in MarkovSwitching models. Banque De France Working Paper No. 321. Available at SSRN: http://ssrn.com/abstract=1783585 or http://dx.doi.org/10.2139/ssrn.1783585.

Bordo, M., Eichengreen, B., Klingebiel, D., \& Martinez-Peria, M. S. (2001). Is Crisis Problem Growing More severe? Economic Policy, 16, 53 - 82.

Bosworth, B., Perry, G. L., \& Shapir, M. D. Productivity and Real Wages: Is There a Puzzle? Brookings Papers on Economic Activity, 1994 (1), 317-344.

Burstein, A., Eichenbaum, M., \& Rebelo, S. (2005). Large Devaluations and the Real Exchange Rate. Journal of Political Economy, 113 (4), 742-784.

Bussiere, M., Saxena, S., \& Tavor, C. E. (2010). Chronicle of Currency Collapses:Re-Examining the Effects on Output. BIS Working Paper No.314.

Calvo, G. A. (1995). Varieties of Capital-Market Crises. Mimeo, University of Maryland.

Caprio, G., \& Klingebiel, D. (1996). Bank Insolvencies: Cross-Country Experience. Policy Research Working Paper. 
Caprio, G., \& Klingebiel, D. (1999). Episodes of Systemic and Borderline Financial Crises. World bank. Mimeo.

Cerra, V., \& Saxena, S. C. (2008). Growth Dynamics: The Myth of Economic Recovery. American Economic Review , 98 (1), 493-457.

Cerra, V., Panizza, U., \& Saxena, S. (2009). International Evidence on Recovery from Recessions. IMF working paper 09/183.

Chang, R., \& Velasco, A. (2001). A Model of Financial Crises in Emerging Markets. Quarterly Journal of Economics , 116, 489-517.

Choudhry, M. T., Marelli, E., \& Signorelli, M. (2010). Financial Crises and Female Work. XXV Convegno Nazionale di Economia del Lavoro:Università G. d'Annunzio - Chieti e Pescara.

Choudhry, M. T., Marelli, E., \& Signorelli, M. (2010). Financial Crises and Labour Market Performance. 69th International Atlantic Economic Conference. Prague, Czech Republic.

Choudhry, M. T., Marelli, E., \& Signorelli, M. (2010). Youth unemployment and the impact of Financial Crises. XXV Convegno Nazionale di Economia del Lavoro:Università $G$. d'Annunzio - Chieti e Pescara.

Cooper, R. N. (1971). Currency Devaluation in Developing Countries. (G. Ranis, Ed.) Government and Economic Development .

Diaz-Alejandro, C. (1985). Good-bye Financial Repression, Hello Financial Crash. Journal of Development Economics , 19, 1-24.

Diwan, I. (2001). Debt as Sweat: Labor, Financial Crises, and the Globalization of Capital. The world Bank.

Diwan, I. (November 1999). Labor shares and Financial Crises. The World Bank.

Dufour, M., \& Orhangazi, O. (2009). The 2000-2001 Financial Crisis in Turkey: A Crisis for Whom? Review of Political Economy, 21 (1), 101-122.

Edwards, S. Real Exchange Rates, Devaluation, and Adjustment. Cambridge, Massachusetts: MIT Press.

Eichengreen, B., Rose, A. K., \& Wyplosz, C. (1995, October). Exchange market mayhem:the antecedents and aftermath of speculative attacks. Economic Policy, 249-296.

Eichengreen, B., Rose, A., \& Wyplosz, C. (1997). Contagious Currency Crises. Scandinavian Journal of Economics , 98, 463-484.

Fallon, P., \& Lucas, R. E. (2002). Impact of Crises on Labor Markets, Household Incomes, and Poverty: A Review of Evidence. World Bank Research Observer, 17 (1), 21-45.

Feridhanusetyawan, T. (2002). The Social Impact of the Indonesian Economic. EAST ASIAN DEVELOPMENT NETWORK PROJECT. 
Frankel, J. A., \& Rose, A. K. (1997). Currency crashes in emerging markets: An empirical treatment. Journal of International Economics , 72 (2), 351-366.

Frankenberg, E., Smith, J. P., \& Thomas, D. (2003). Economic Shocks, Wealth and Welfare. Journal of Human Resources , 32 (2), 280-321.

Friedman, M. (1993). The "plucking model' of business fluctuations revisited. Economic Inquiry , 31 (2), 171-177.

Furceri, D., \& Mourougane, A. (2009b). How do Institutions Affect Structural Unemployment in Times of Crises? OECD Publishing.

Furceri, D., \& Mourougane, A. (2009). The Effect of Financial Crises on Potential Output: New Empirical Evidence from OECD Countries. OECD working paper 699.

Gamberoni, E., Von Uexkull, E., \& Weber, S. (2010). The Roles of Openess and Labor Market Institutions for Employment Dynamics During Economic Crises. The World Bank. Washington,DC: Unpublished Manuscript.

Gupta, P., Deepak, M., \& Ratna, S. (2007). Behavior of output during currency crises. Journal of International Economics , 72 (2), 428-450.

Hamilton, J. (1989). A new approach to the economic analysis of nonstationary time series and the business cycle. Econometrica, 57, 357-384.

Harrison, A. (2002). Has Globalization Eroded Labor's Share?Some Cross-Country Evidence. Berkeley:University of California at Berkeley and NBER: Mimeo.

Hong, K., \& Tornell, A. (2005). Recovery from a Currency Crisis: Some Stylized Facts. Journal of Developmnet Economics , 76 (1), 71-96.

Horton, S., \& Mazumdar, D. (2001). Vulnerable groups and the labor market: The aftermath of the Asian financial crisis. In G. Betcherman, \& I. Rizwanul, East Asian Labor Markets and the Economic Crisis:Impacts,Responses, and Lessons. Washington,DC: World Bank Publications.

Hutchison, M. M., \& Ilan, N. (2005). How Bad Are Twins? Output Costs of Currency and Banking Crises. Journal of Money, Credit and Banking , 37 (4), 725-752.

Hutchison, M. M., \& Noy, I. (2002). Output Costs of Currency Crisis and Balance of Payment Crises in Emerging Markets. Comparative Economic Studies , 44 (2), 27-44.

Hutchison, M. M., \& Reuven, G. (2001). Banking and Currency Crises : How common are Twins? Financial Crises in Emerging Markets. UCSC Department of Economics. Cambridge University Press.

Im, K. S., Pesaran, M. H., \& Shin, Y. (2003). Testing for Unit Roots in Heterogeneous. Journal of Econometrics , 115 (1), 53-74.

Joyce, J., \& Nabar, M. (2009). Sudden Stops, Banking Crises and Investment Expenditures in Emerging Markets. Journal Development Economics , 90, 314-322. 
Kamin, S. B., \& Rogers, J. H. (2000). Output and Real Exchange Rate in Developing Countries: An applicatio to Mexico. Journal of development Economics , 61, 85-109.

Kaminsky , G., \& Reinhart, C. (1999). The Twin Crises: the causes of banking and balance-ofpayments problems. American Economic Review , 89 (3), 473-500.

Kaminsky, G. (2008). Currency Crises. The New Palgrave Dictionary of Economics. (P. M. S. N. Durlauf and L. E. Blume, Ed.) Second Edition.

Kaminsky, G. L., \& Reinhart, C. M. (1999). The twin crises:the causes of banking and balance-ofpayments problems. American Economics Review , 89, 473-500.

Kaminsky, G., Lizondo, S., \& Reinhart, C. (1998). Leading Indicators of Currency Crises. IMF Staff Working Paper No.45.

Kihwan, K. (2006). The 1997-1998 Korean Financial Crisis: Causes, Policy Response, and Lessons. IMF Seminar on Crisis Prevention in Emerging Markets. Singapore.

Kilponen, J., Lodge, D., Strauch, R., \& Vanhala, J. (2010). Labor Markets During Recessions: Evidence on the Role of Wage Rigidity and Hysteresis. 8th EuroFrame Conference on the Economic Policy Issues in the European Union.

Kim, C.-J., Morley, J., \& Piger, J. (2005). Nonlinearity and the Permanent Effects of Recessions. Journal of Applies Econometrics , 20 (2), 291-309.

King, R., Plosser, C., Stock, J., \& Watson, M. (1991). Stochastic Trends and Economic Fluctuations. American Economic Review , 81 (4), 819-40.

Kiseok, H., \& Aaron, T. (2005). Recovery from a Currency Crisis : Some Stylized Facts. Journal of Development Economics , 76 (1), 71-96.

Krugman, P. (1979). A Model of Balance-of-Payments Crises. Journal of Money, Credit and Banking , $11(3), 311-325$.

Krugman, P. (1999). Balance Sheets, the Transfer Problem and Financial Crises. Unpublished working paper.

Krugman, P., \& Taylor, L. (1978). Contractionary Effects of Devaluation. Journal of International Economics , 8 (3), 445-456.

Laeven, L. A., \& Valencia, F. (2008). Systematic Banking Crises: A New Database. IMF Working Paper No. 08/224.

Laeven, L. A., \& Valencia, F. V. (2010). Resolution of Banking Crises: The Good, the Bad, and the Ugly. IMF Working Paper No.10/146.

Lee, J. W., \& Park, Y. C. (2002). Recovery and Sustainability in East Asia. World Economy, 25, 539-562.

Levin, A., Lin, C., \& Chu, C. (2002). Unit Root Tests in Panel Data: Asymptotic and Finite-sample Properties. Journal of Econometrics , 108 (1), 1-24. 
Lizondo, S., \& Montiel, P. (1989). Contractionary Devaluation in Developing Countries: An Analytical Overview. IMF Staff Papers , 36, 182-227.

Lokshin, M. M., \& Yemtsov, R. (2001). Household Strategies for coping with poverty and social exclusion in post-crisis Russia. The world Bank.

Luukkonen, R., \& Terasvirta, T. (1991). Testing Linearity of Economic Time Series Against Cyclical Asymmetry. Annales d'Economie et de Statistique , 20 (21), 125-142.

Maddala, G., \& Wu, S. (1999). A comparative study of unit root tests with panel data and new simple test. Oxford Bullertin of Economics and Statistics , 61 (0 (Special Issue Nov)), 631-652.

Maloney, W. F., Cunningham, W. V., \& Bosch, M. (2004). The Distribution of Income Shocks during Crises: An Application of Quantile Analysis to Mexico, 1992--95. World Bank Economi Review, Oxford University Press,.

McKenzie, D. (2004). Aggregate Shocks and Urban Labor Market Responses:Evidence from Argentina's Financial Crisis. Economic Development \& Cultural Change, 52 (4), 719-758.

McKenzie, D. J. (2003). How do Households Cope with Aggregate Shocks:Evidence from the Mexican Peso Crisis. World Development, 31 (7), 1179-1199.

Mckenzie, D. (2001). The Household Response to the Mexican Peso Crisis. Standford University, Department of Economics.

Mckinnon, R. I., \& Pill, H. (1997). Credible Economic Liberalization and Overborrowing. American Economic Review , 87 (2), 189-193.

Morley, J., \& Piger, J. (2010). The Asymetric Business Cycle. Washington Univeristy in St Louis: unpublished manuscript.

Morley, S. (1992). On the Effect of Devaluation During Stabilization Programs in LDCs. The Review of Economics and Statistics , 74, 21-27.

Neftci, S. N. (1984). Are Economics Time-Series Assymetric over the Business-cycles. Journal of Political Economy, 92 (21).

Nickell, S. (1981). Biases in Dynamic Models with Fixed Effects. Econometrica , 46 (6), 1417-26.

Noy, I., \& Hutchison, M. M. (2006). Sudden stops and the mexican wave: Currency crises, capital flow reversals and output loss in emerging markets. Journal of Development Economics , 79 (1), 225-248.

Obstfeld, M. (1994). The logic of CUrrency Crises. Working Paper (4640).

Piti, D. (2001). Currency Crises and The role of Real Economy: The role of Banks. IMF working Paper 01/49.

Queralto, A. (2011). Financial Frictions and Total Factor Productivity:Accounting for the Real Effects. working paper, New York University . 
Radelet, S., \& Sachs, J. (1998). The Onset of the East Asian Financial Crisis. National Bureau of Economic Research Working Paper No. 6680.

Ramesh, M. (2009). Economic Crisis and its Social Impacts : Lessons from the 1997 Asian Economic Crisis. Global Social Policy, 9.

Rodrik, D., \& Velasco, A. (1999). Short Term Capital Flows. Cambridge : NBER Working Paper No.7364.

Romer, C., \& Romer, D. (1989). Does monetary policy matter? A new test in the spirit of Friedman and Schwarz. NBER Macroeconomics Annual , 4, 121-184.

Sichel, D. E. (1994). Journal of Business \& Economic Statistics , 12 (3), 269-77.

Smith, J. P., Duncan, T., Frankenberg, E., Beegle, K., \& Teruel, G. (2002). Wages, employment and economic shocks: Evidence from Indonesia. Journal of Population Economics, 15, 161-93.

Tavor, C. E., Saxena, S. C., \& Bussiere, M. (2010). Chronicle of Currency Collapses: Re-Examining the Effects on Output. BIS Working Paper No.314.

Velasco, A. (1987). Financial and Balance of Payments Crisis. Journal of Development Economcs, 27, 263-83. 